\title{
A Membrane Process for Recycling Die Lube from Wastewater Solutions
}

Eric S. Peterson Jessica Trudeau Bill Cleary Michael Hackett William A. Greene

April 2003

Idaho National Engineering and Environmental Laboratory Bechtel BWXT Idaho, LLC 
INEEL/EXT-03-00307

\section{A Membrane Process for Recycling Die Lube from Wastewater Solutions}

\author{
Eric S. Peterson \\ Idaho National \\ Engineering and \\ Environmental Laboratory \\ P.O. Box 1625 \\ Idaho Falls, ID 83415-2208
}

Jessica Trudeau, Bill Cleary, and

Michael Hackett

Metaldyne, Inc. 8001 Bavaria Road

Twinsburg, OH 44087
William A. Greene

SpinTek Filtration, LLC

10851 Portal Drive

Los Alamitos, CA 90720

April 2003

\section{Idaho National Engineering and Environmental Laboratory \\ Chemistry Department \\ Idaho Falls, Idaho 83415}

Prepared for the

U.S. Department of Energy

Office of Energy Efficiency and Renewable Energy

Under DOE Idaho Operations Office

Contract DE-AC07-99ID13727 


\begin{abstract}
An active-surface membrane technology was used to separate a die lube manufacturing wastewater stream consisting of various oils, hydrocarbons, heavy metals, and silicones. The ultrafiltration membranes reduced organics from initial oil and grease contents by $20-25 \mathrm{X}$, carbon oxygen demand (COD) by 1.5 to $2 \mathrm{X}$, and total organic carbon (TOC) by 0.6 , while the biological oxygen demand (BOD) remained constant. The active-surface membranes were not fouled as badly as non-active-surface systems and the active-surface membrane flux levels were consistently higher and more stable than those of the non-active-surface membranes tested. Field testing demonstrated that the rotary microfilter can concentrate the die lube, i.e. remove the glycerin component, and produce a die lube suitable for recycling. The recycling system operated for six weeks with only seven cleaning cycles and no mechanical or electrical failures. Test data and quality records indicate that the die casting scrap was reduced from 8.4 to $7.8 \%$. There is no doubt that this test yielded tremendous results. This separation process presents significant opportunities that can be evaluated further.
\end{abstract}




\section{SUMMARY}

Metaldyne, Inc. generates a complex die lube wastewater stream in its manufacturing operation that cannot be directly discharged to the environment. The wastewater contains oils, hydrocarbons, heavy metals, and silicones. A team from Metaldyne, SpinTek, LLC, and the Idaho National Engineering and Environmental Laboratory tested an active-surface membrane technology for separating this waste stream; the ultimate goal is to recycle the major components, concentrate the contaminants for disposal, and dispose of the clean water permeates from the membranes into a municipal sewer.

Our laboratory and field studies show that Metaldyne's wastewater can be cleaned up using active-surface membrane technology. Active-surface ultrafiltration membranes reduced organics from initial oil and grease contents by 20-25X, carbon oxygen demand (COD) by $1.5-2 \mathrm{X}$, and total organic carbon (TOC) by 0.6 , while the biological organic carbon demand (BOD) remained constant. The metals content of the solutions can be reduced significantly using tight ultrafiltration active-surface membranes. The active-surface membranes were not fouled as badly as non-active-surface systems. The active-surface membrane flux levels are consistently higher and more stable than those of the non-active-surface membranes tested.

The field tests of the ST-II rotary filter system were very promising. The die lube concentration tests achieved the goal of 20X and the filtrate was clear and colorless, indicating nearly complete removal of the die lube. One test further concentrated the feed to 50X, but the membrane water flux decreased so much as the concentration went from $20 \mathrm{X}$ to $50 \mathrm{X}$ that this proved to be too low for commercial use.

The field results for glycerin removal and die lube recycling were also very favorable. The rotary microfilter concentrated the die lube components from the waste stream, and then the contaminating glycerin was washed out with water, producing a die lube suitable for recycling. The recycling system operated for six weeks with only seven cleaning cycles and no down time due to mechanical or electrical failure. There is no doubt that this full-scale production test yielded tremendous results - it proved that recycling of die lubricant is possible and reduced die casting scrap from 8.4 to $7.8 \%$. Further evaluation is needed to determine if it is cost effective. 


\section{ACKNOWLEDGMENTS}

Special thanks go to the people that made this project possible. The Metaldyne team included Eddie Bingham, Bill Cleary, Robert Stuhldreher, Jessica Trudeau, and Michael Hackett; the SpinTek team included Bill Greene and Jason Gilmore; and the U.S. Department of Energy, Office of Energy Efficiency and Renewable Energy's Office of Industrial Technologies team included Harvey Wong, Ehr-Ping Wang Fu and Denise Swink. 


\section{CONTENTS}

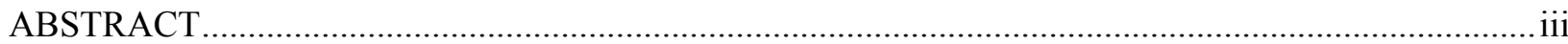

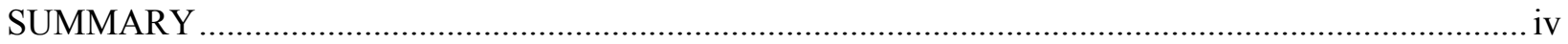

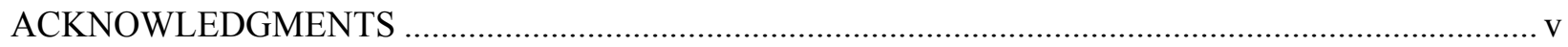

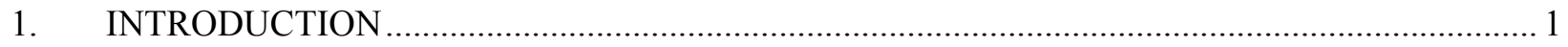

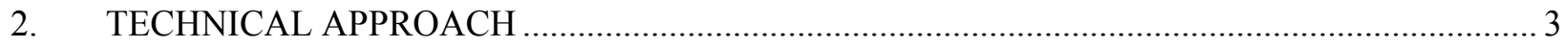

3. PHASE 1: LABORATORY MEMBRANE EVALUATION …............................................... 6

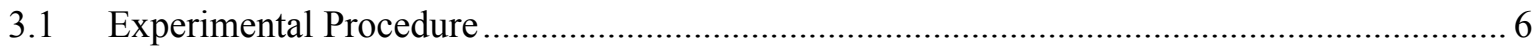

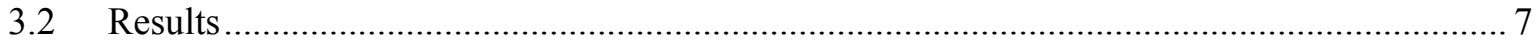

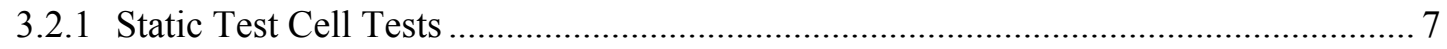

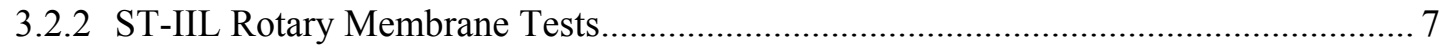

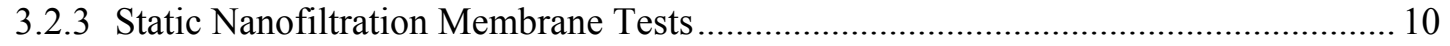

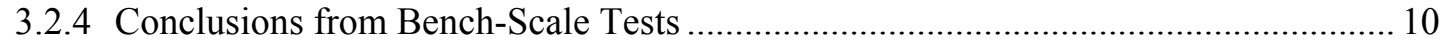

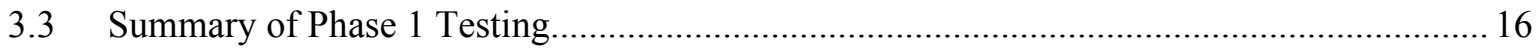

4. PHASE 2: FIELD DEMONSTRATION OF DIE LUBE CONCENTRATION.............................. 17

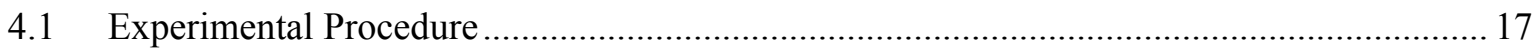

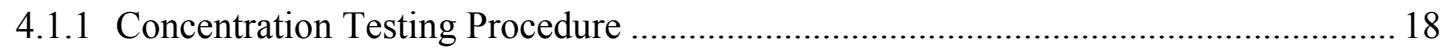

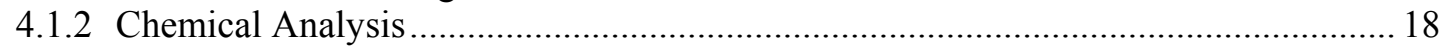

4.1.3 Solution Washing of Concentrated Feed Solution to Remove Glycerin ..................... 18

4.1.4 Membrane Cleaning Process Development ............................................................. 18

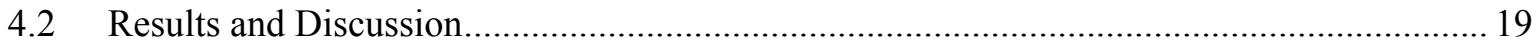

4.3 Summary of Phase 2 Concentration Tests ................................................................ 23

5. PHASE 3: FIELD DEMONSTRATION OF DIE LUBE RECYCLING ....................................... 24

5.1 Concentrating Die Lube and Removing Glycerin ..................................................... 24

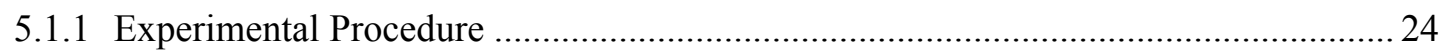

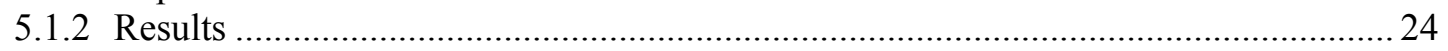

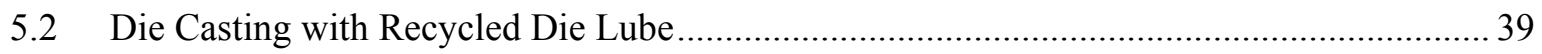

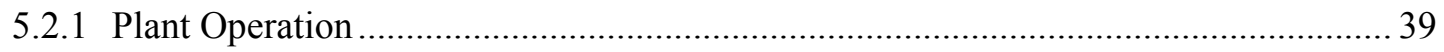

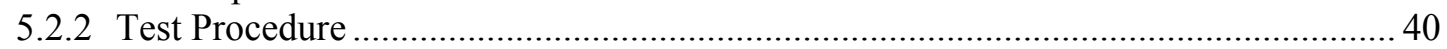

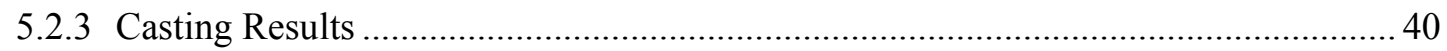

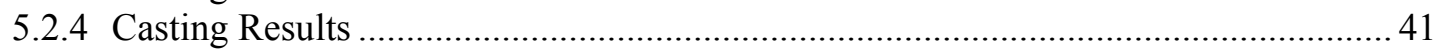




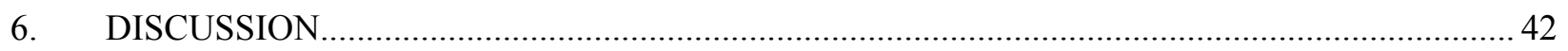

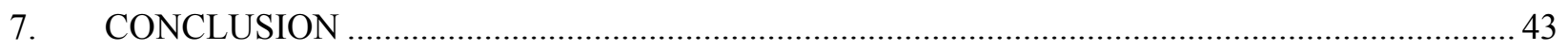

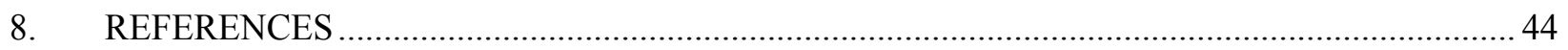

Appendix A-Raw and Run Data

\section{FIGURES}

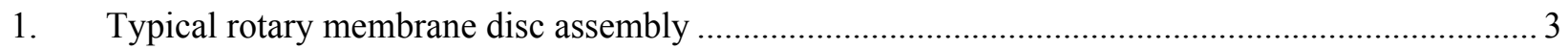

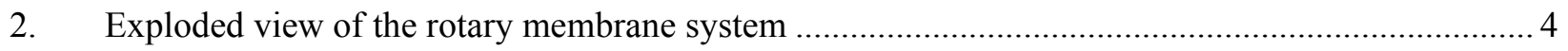

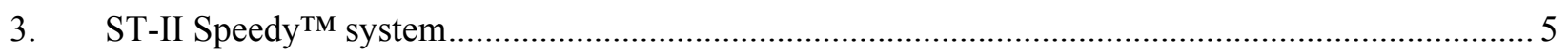

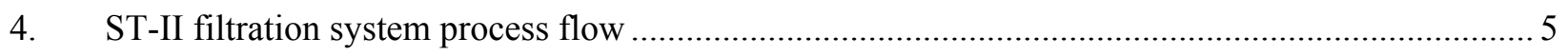

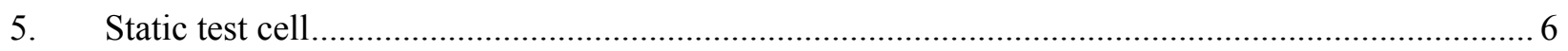

6. Process flow and instrument diagram for the static test cell ................................................. 7

7. Flux profile for STC with 0.15 micron ceramic membrane ….............................................. 8

8. Flux profile for STC with 0.007 micron ceramic membrane …................................................ 8

9. Flux profile for STC with 100,000 molecular weight cut-off polymeric membrane....................... 8

10. Flux profile for 100,000 NMWC cut-off polymeric membrane ................................................. 9

11. Concentration profile for 100,000 NMWC cut-off polymeric membrane..................................... 9

12. Flux profile for 10,000 NMWC cut-off polymeric membrane .................................................. 9

13. Concentration profile for 10,000 NMWC cut-off polymeric membrane ..................................... 10

14. Performance of ceramic ST-IIL nanofiltration membrane and improvement after cleaning ........... 12

15. Performance of Desal-5 spiral-wound, static polymeric nanofiltration membrane and

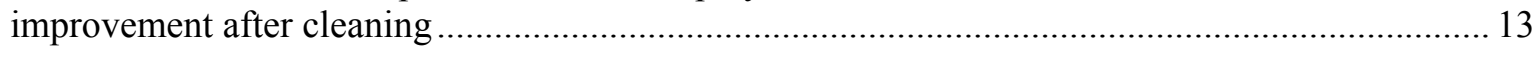

16. Process flow and instrument diagram for field demonstration system during stabilization............ 17

17. Performance plot for rotary filter of flux versus time during the dewatering of the die lube

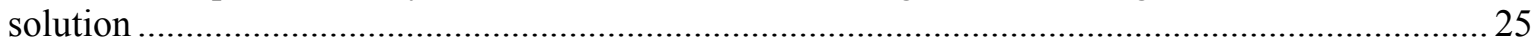

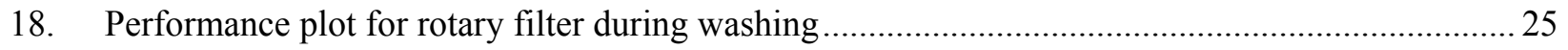

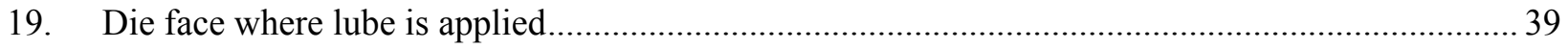


20. Spray manifold for applying die lube

21. Aluminum valve body cast with recycled die lube......

\section{TABLES}

1. Chemical analyses for laboratory tests with polymeric membranes …...................................... 11

2. Concentration factors for polymeric membranes in laboratory tests ............................................ 11

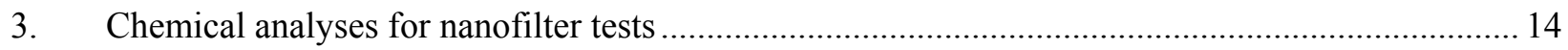

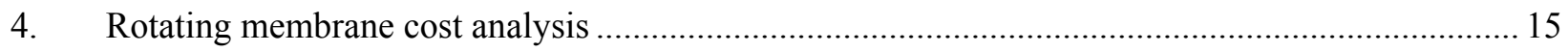

5. Membrane Cleaning Procedure Developed by INEEL for Trumem Membranes .......................... 19

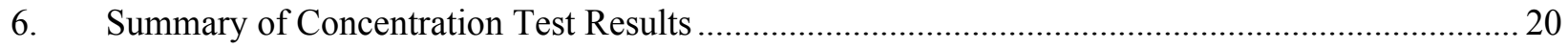

7. Phase III summary - die lube concentration and recycling runs ...............................................26

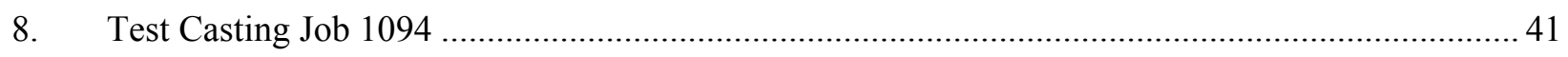




\section{A Membrane Process for Recycling Die Lube from Wastewater Solutions}

\section{INTRODUCTION}

Water treatment is a major separations challenge for all industrial water users. Environmental concerns and energy conservation have led both the industrial and governmental sectors to make significant efforts to develop energy-efficient separations processes. ${ }^{1,2}$ The Idaho National Engineering and Environmental Laboratory's Inorganic Membrane Technology Research Program is an ongoing Department of Energy effort to develop energy-efficient membrane separation processes in collaboration with industry. Membranes are energy efficient compared to traditional phase separation processes such as distillation. However, many membrane materials degrade in the harsh thermal and chemical environments frequently encountered in industrial settings. The Idaho National Engineering and Environmental Laboratory (INEEL) membrane program has traditionally focused on polymeric membrane separations. ${ }^{3-11}$ Recently, however, the program has begun working in the area of filtration and has teamed with Metaldyne, Inc. and SpinTek Filtration, LLC to develop a means of separating wastewater solutions generated by the die casting process. This report presents the results of that collaboration.

Metaldyne generates a complex wastewater stream that contains soaps, detergents, oils, hydrocarbons, heavy metals, and silicones. In 1999, Metaldyne's Twinsburg facility, in cooperation with The North American Die Casting Association, the Department of Energy's Office of Industrial Technology, and INEEL, launched an initiative to investigate the potential to separate solids from wastewater. The goal was to improve discharge quality, reduce loading on the plant's treatment system, and, potentially, recover these solids for reuse. Wastewater streams similar to Metaldyne's are common in the metal casting industry, and there are many other applications for a reliable, effective process for treating this type of wastewater.

Treating manufacturing wastewater requires a simple, rugged, and durable process. The system must be capable of handling a wide compositional range, and varied concentrations, of wastewater components and consistently providing purified water suitable for reuse. The system needs to remove large solids as well as very small organic molecules of detergents, other surfactants, and specific organic chemicals. In addition to purifying the wastewater, the system must be able to concentrate the feed water contaminants to a thick slurry, both for potential recycling and for minimizing the waste for storage and subsequent disposal.

To address this challenging problem, a three-phased project was defined. Each phase was independent and, at its completion, the feasibility of continuing the project was evaluated. The phases were:

- $\quad$ Phase 1-Problem Identification, Evaluation, and Bench-Scale Process Studies

We identified the real bottlenecks in current separations processes, the specific families of materials that are causing fouling, and possible methods for eliminating the fouling problems. We established the scope of the bench-scale experimental studies. These studies examined membrane fouling by the feed streams, fouling prevention methods, membrane replacement costs, and lifetime evaluations. 
- $\quad$ Phase 2-Recommendations for Alternative Processes Studies

The Phase 2 recommendations were based upon the studies performed in Phase 1 and the suggested field studies for Phase 3. After performing Phase 1, we decided that Phase 2 would focus on demonstrating the capability to concentrate die lube by separating it from Metaldyne's wastewater.

- $\quad$ Phase 3-Initiation of Field Studies Based upon the Results of Phases 1 and 2

One technology was to be selected for field studies and the separations of concern were to be fully evaluated at the mini- or full pilot-scale. Based on the results from Phases 1 and 2, we determined that Phase 3 would be to concentrate the die lube as in Phase 2, then wash the glycerin component from the concentrated die lube/glycerin mixture and reuse the die lube in casting operations on a single full-scale, full-production die casting machine.

The following sections describe our research and results. 


\section{TECHNICAL APPROACH}

During Phase 1, we identified three commercial technical approaches to separating complex wastewater streams such as Metaldyne's. These separation systems all use an active porous membrane surface as the primary contactor with the medium to be filtered. The companies selling these systems are MonTec Associates of Butte, Montana; New Logic, Inc. of Emeryville, California (now owned by Pall Corporation); and SpinTek Filtration Systems, Inc., from Huntington Beach, California. Other competitive technologies may exist; however, they were not identified during the careful literature and Internet research in Phase 1.

SpinTek was selected as the partner for this research for several reasons, including the ruggedness of their design, the novelty of their technology, their history of installed commercial systems, and the overall cost. However, during Phase 1 we continued to search for, and evaluate, other potential partners that might be able to contribute to these studies. No other potential partners were identified, resulting in selection of SpinTek as the partner for Phases 2 and 3. Thus, the active-surface membranes manufactured by SpinTek were finally chosen as the systems of choice for this application. As a consequence of selecting SpinTek as a partner, the goal of this project became demonstrating their microfiltration rotary membrane technology for die casting wastewater applications.

SpinTek's ST-II/Speedy ${ }^{\mathrm{TM}}$ rotary membrane system has one to twenty-five spinning membrane disks with $1.0 \mathrm{ft}^{2}$ of membrane per disk (Figures 1 and 2). These units may be placed in series or parallel, as needed, to obtain the desired membrane surface area. The membrane disk consists of a central Ryton ${ }^{\mathrm{TM}}$ core that is overlaid with a permeate carrier mesh. The disc-carrier system is then overlaid with a selective filtration membrane and the entire assembly glued with appropriate adhesives. The rotation rate on the discs we used was fixed at $1200 \mathrm{rpm}$. The ST-II/Speedy ${ }^{\mathrm{TM}}$ can be fully automated, including feed flow, pressure, temperature instrumentation, permeate flow rate, and all the necessary safety instrumentation. The systems we used have automated data logging of the above instrumentation.

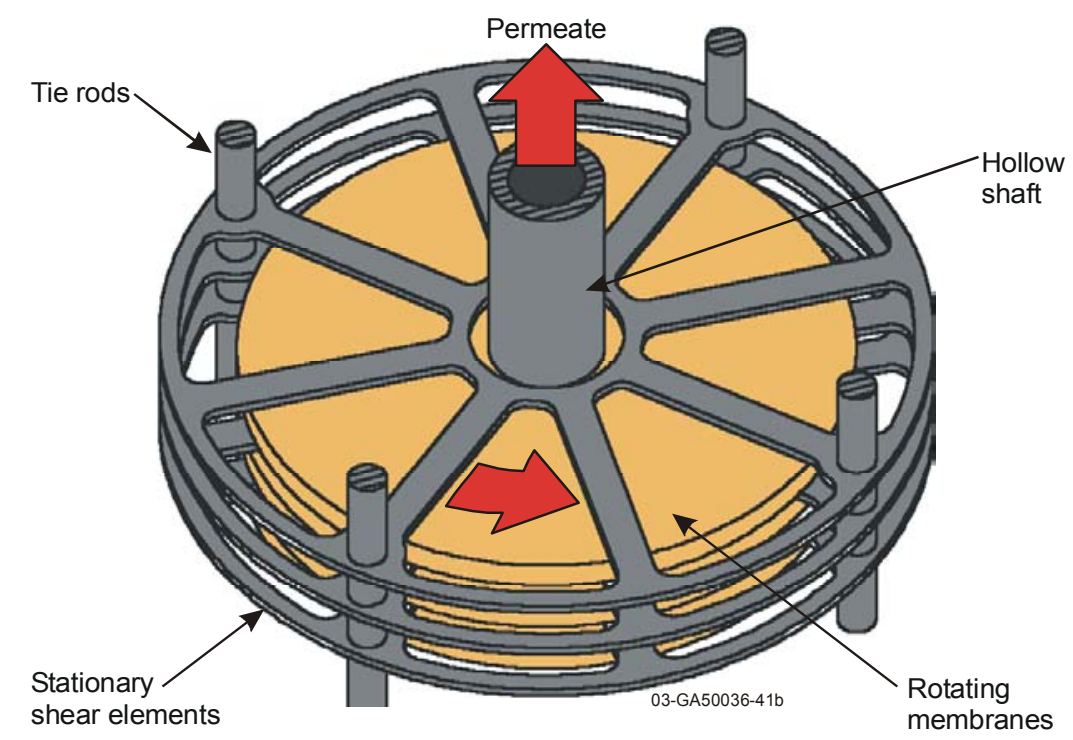

Figure 1. Typical rotary membrane disc assembly, shown with three discs and stationary "wagon wheel"elements. 


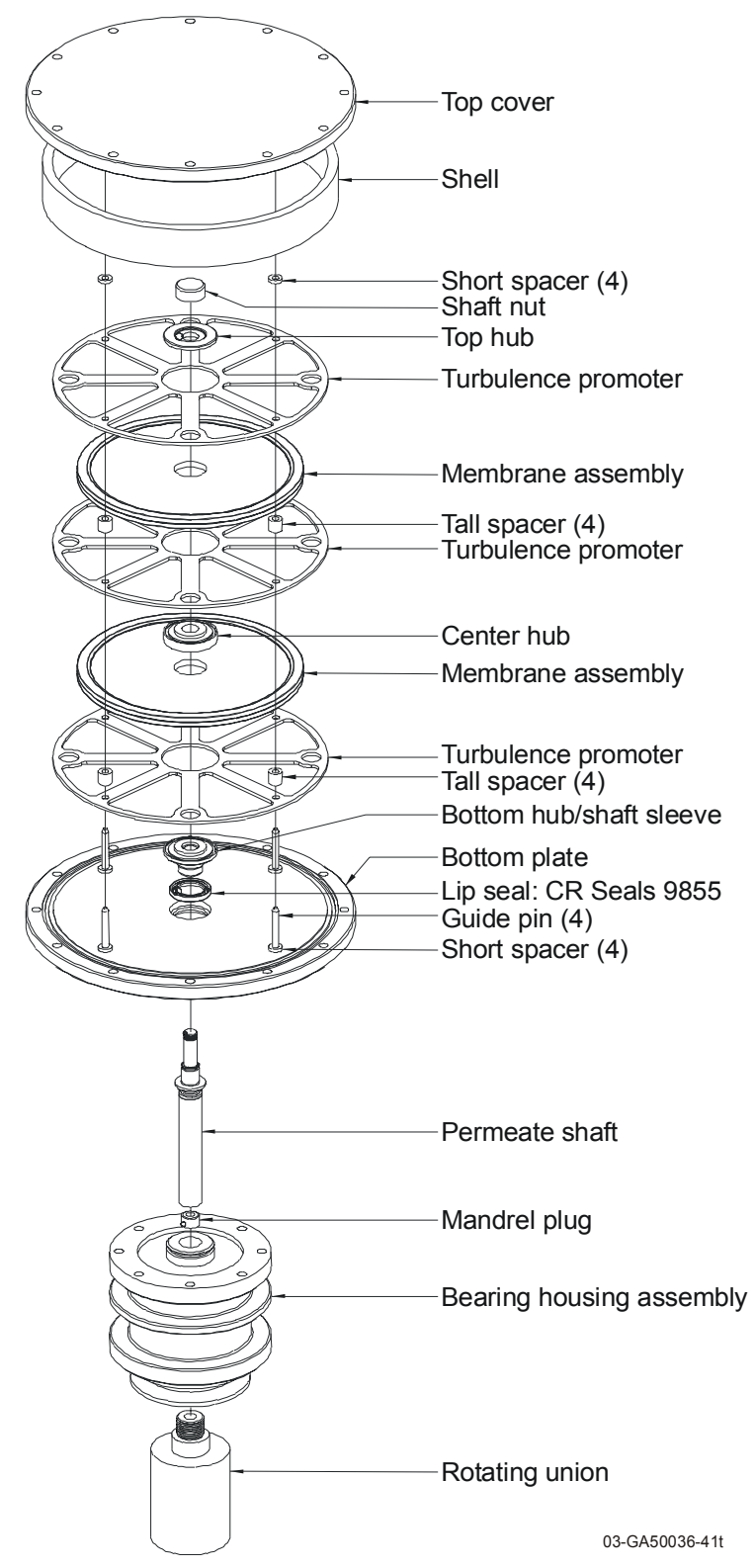

Figure 2. Exploded view of the rotary membrane system.

We planned to use SpinTek's ST-II rotary microfiltration system (Figure 3) with 0.1 micron ceramic-stainless steel or polymeric composite membranes to remove all of the suspended solids and many of the organic contaminants. If necessary, the filtrate from the ST-II could be polished by a nanofiltration system to remove smaller organic chemicals from the wastewater. This approach, shown schematically in Figure 4, was followed. In Phase 1, samples of the wastewater solution were tested in the laboratory on a small, flat-sheet test system and a single disk rotary filter. In Phase 2, two five-disk ST$\mathrm{II} /$ Speedy ${ }^{\mathrm{TM}}$ rotary microfilters were used to demonstrate that the system could concentrate die lube by separating it from wastewater. In Phase 3, the two five-disk ST-II rotary microfilters were used to separate die lube for recycling. First, the die lube, combined with wastewater, was dewatered. Then the retentate/die lube was flushed of glycerin using the ST-II rotary membrane filter to separate the die lube from the water/glycerin mixture. Finally, the die lube was reused on a single full-scale die casting machine at full production. 


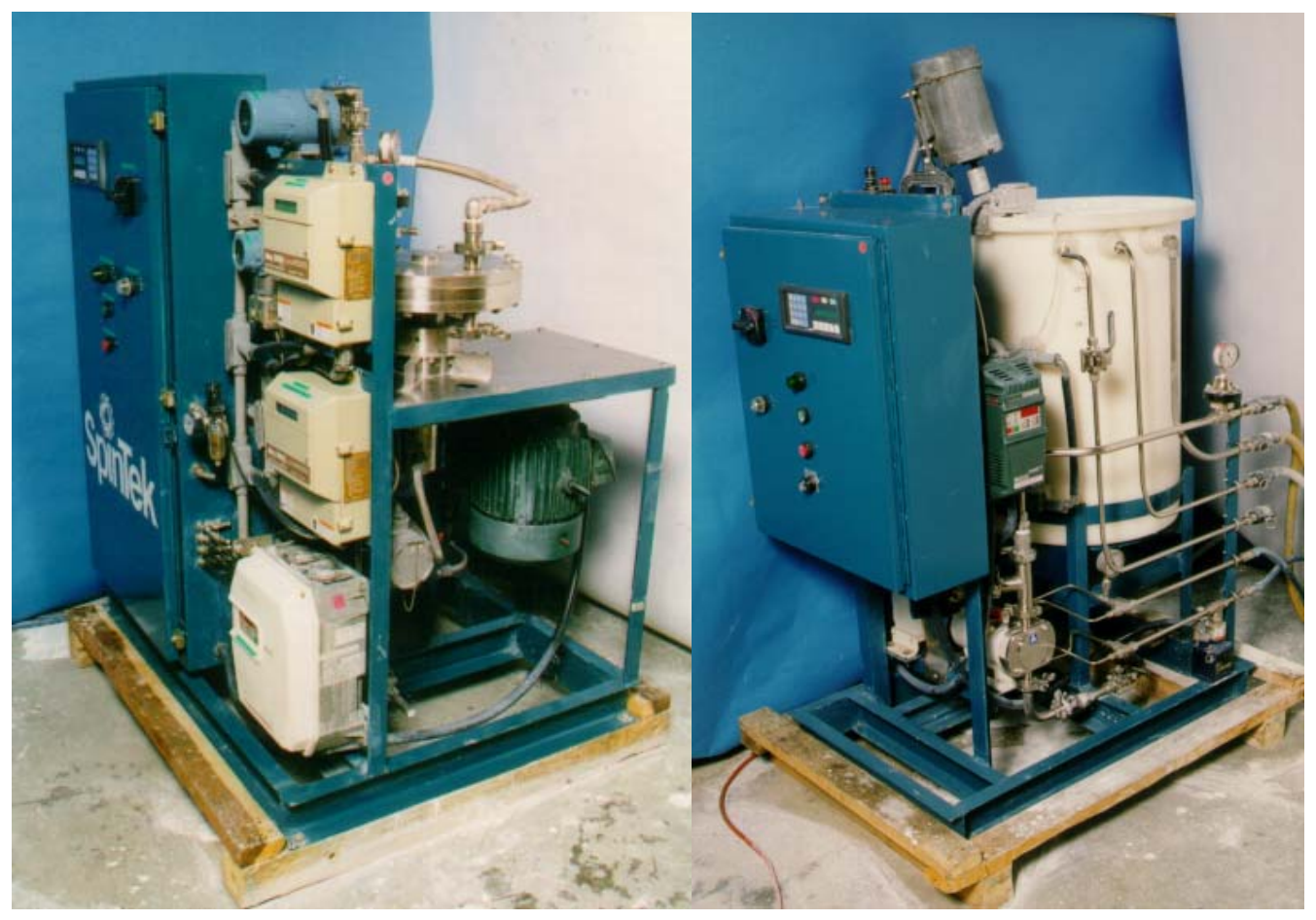

Figure 3. ST-II Speedy ${ }^{\mathrm{TM}}$ system.

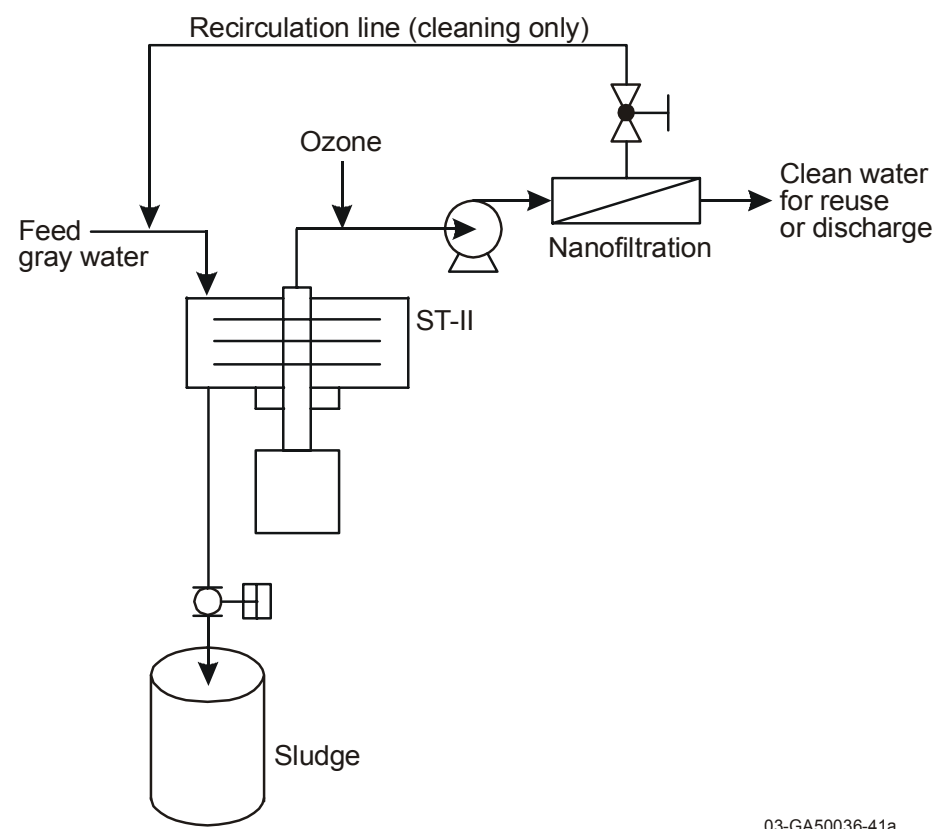

Figure 4. ST-II filtration system process flow. 


\section{PHASE 1: LABORATORY MEMBRANE EVALUATION}

\subsection{Experimental Procedure}

SpinTek assembled two test platforms consisting of a membrane filtration system and a pumped skid. The static test cell (STC), shown in Figure 5, contained one flat-sheet membrane test sample, while the ST-IIL had a single disk rotary with the membrane filter. The major difference between the two systems is the shear generated at the surface of the membrane. The STC has a static membrane, while the ST-IIL uses a membrane disk rotating at high velocities to generate shear (the membrane rotates at $1200 \mathrm{rpm}$, with an average radial Reynolds Number, $\operatorname{Re}_{\mathrm{r}(\mathrm{avg})}$, of $2.0 \times 10^{5}$ to $\left.1.2 \times 10^{6}\right){ }^{12}$ The membranes used in these bench-scale systems are also used in the full-scale ST-II rotary membrane system.

Membranes were tested in the bench-scale systems with wastewater provided by Metaldyne. The static system allowed initial membrane screening while the single disc spinning membrane system offered initial data on specific membranes that passed the initial static testing. This was a rapid method of membrane selection for this application.

The general layout of the bench-scale STC testing equipment is shown in Figure 6. The process solutions were pumped from the feed tank to the STC membrane system. A throttling valve on the feed pump controlled the flow to the system. A back-pressure control valve maintained a constant pressure on the membrane system. The feed solution, supplied by Metaldyne, was pumped from 55-gallon drums into a 2-liter feed tank equipped with an agitating stirrer. The stirrer assured good mixing of the feed solution prior to its circulation in the membrane testing system. The feed tank was held at constant temperature. During testing, data were recorded every $15 \mathrm{~min}$, or as needed. Membrane fluxes are defined as:

Flux $=\frac{\text { Filtrate Flow Rate }}{\text { Area of Membrane }}$, which is measured in units of $\frac{\text { gallons per day }}{\text { square feet }}$ or gfd.

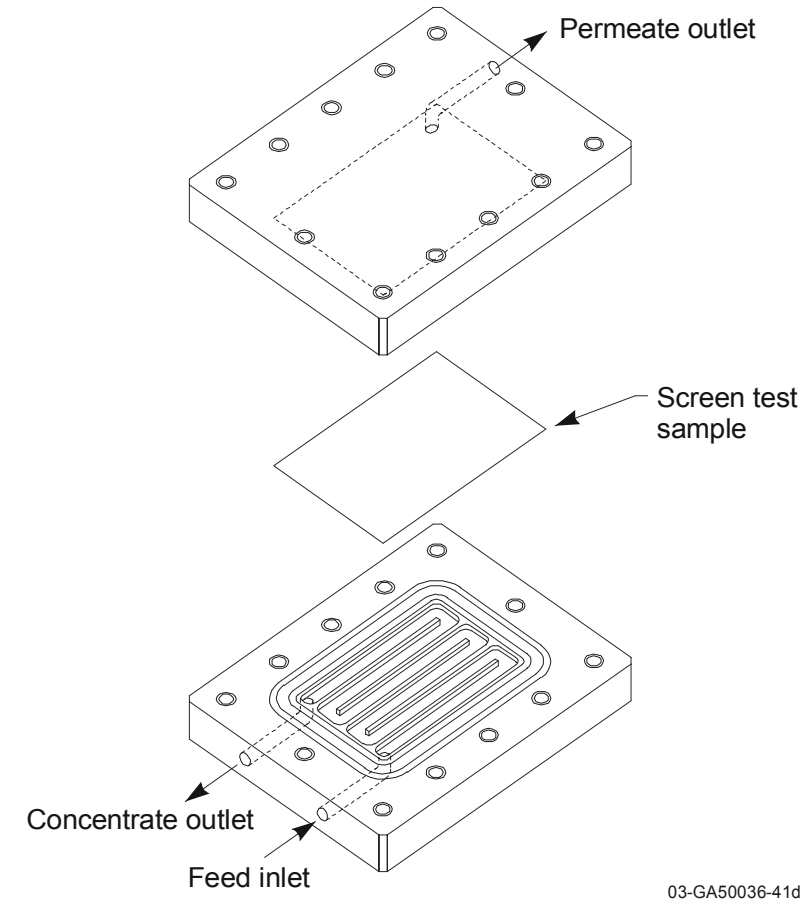

Figure 5. Static test cell. 


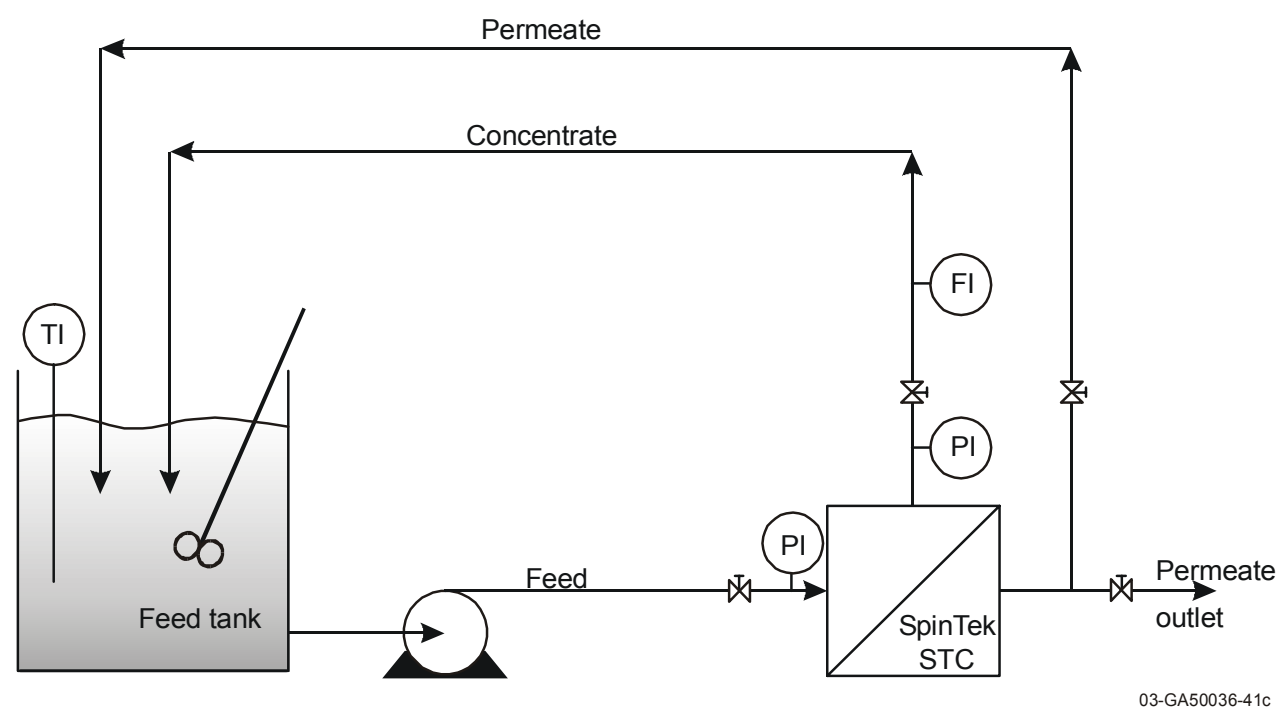

Figure 6. Process flow and instrument diagram for the static test cell.

A nanofiltration polishing step was also evaluated to remove the remaining metal ions from the solution. The assumption was that, under the conditions at Metaldyne's plant (temperature, $\mathrm{pH}$, etc.), the metal ions would be clustered and contained within the larger organic phase globules, as is typically observed with solvent extraction systems. Therefore, one could assume that a nanofilter would remove the metal ions from the stream.

\subsection{Results}

\subsubsection{Static Test Cell Tests}

Unexpected fouling and flux decline problems encountered using the ceramic-stainless steel composite membranes, Figures 7 and 8, suggested that we not pursue these membranes any further. The results of our experiments with the polymeric membranes, shown in Figure 9, suggested that we pursue these membranes and their relatives for the Metaldyne water treatment process. Thus, the polymeric membranes were slated for further evaluation on the ST-IIL rotary membrane. (Later in the study we did pursue the stainless-steel ceramic composite membranes due to the low durability of the polymeric membranes in Metaldyne's particular feed stream, a problem that only became evident in the early stages of our pilot studies. Data from the STC tests are included in the appendix.)

\subsubsection{ST-IIL Rotary Membrane Tests}

Two different polyvinylidene fluoride-based membranes were tested, an ultrafiltration membrane with a 100,000 molecular weight cut-off ( 0.05 micron, 400 angstrom mean pore diameter), and a "tighter" ultra/nanofiltration membrane with a 10,000 molecular weight cut-off ( 0.005 microns, 40 angstrom mean pore diameter). These membranes were made by different manufacturers, and the pore sizes probably are not exactly what they are specified in relationship to one another, which likely explains why they had similar fluxes even though their pore sizes differed by a factor of ten. Flux and concentration profiles from these tests are shown in Figures 10 through 13. At the completion of each of these experiments, the permeate solutions were allowed to stand overnight before being delivered to the analytical labs. During this time, significant hydro-gel-like precipitates formed in the permeate solutions. The gels, speculatively, are hydrated aluminum, zinc, and iron oxy-/hydroxy-species. ${ }^{13}$ The gels are very $\mathrm{pH}$ sensitive, and 


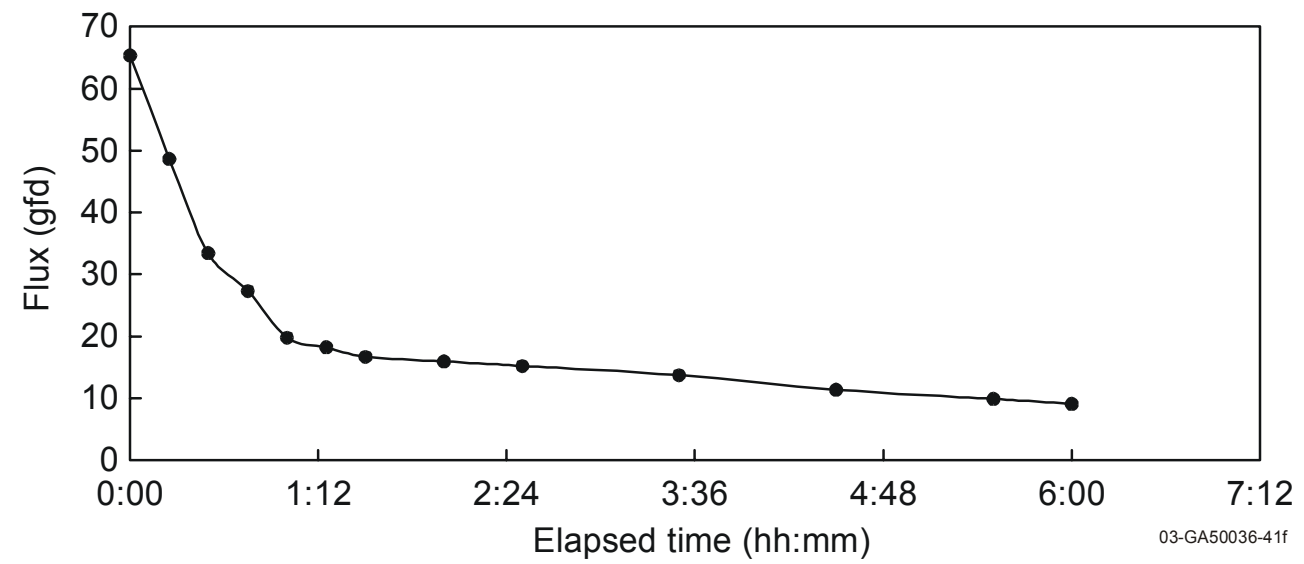

Figure 7. Flux profile for STC with 0.15 micron ceramic membrane. The test was stopped due to low flux.

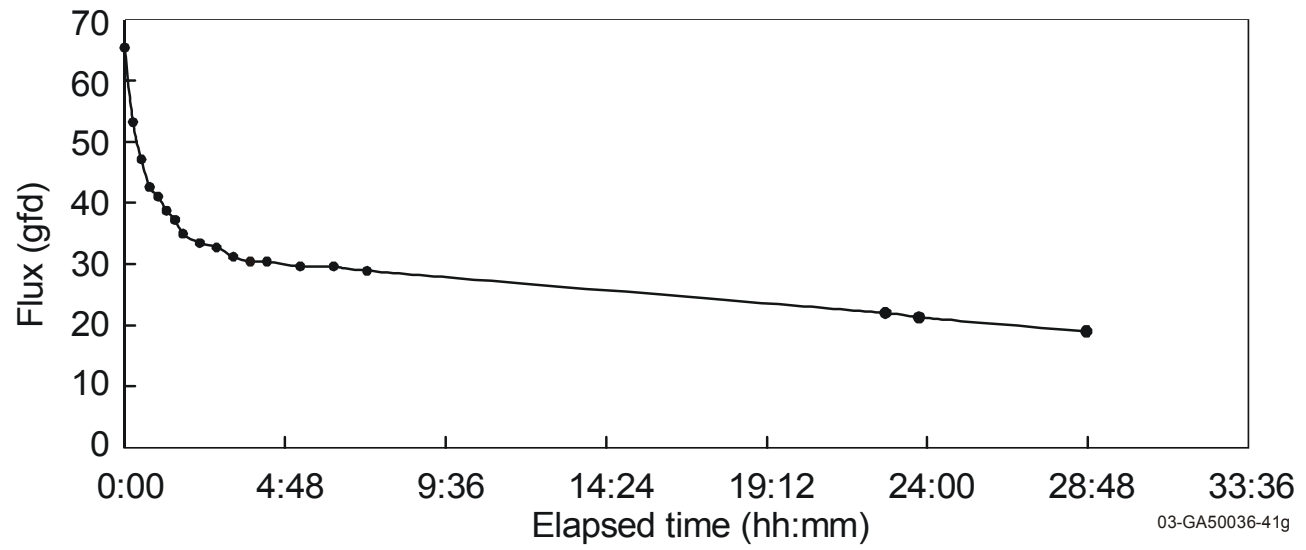

Figure 8. Flux profile for STC with 0.007 micron ceramic membrane.

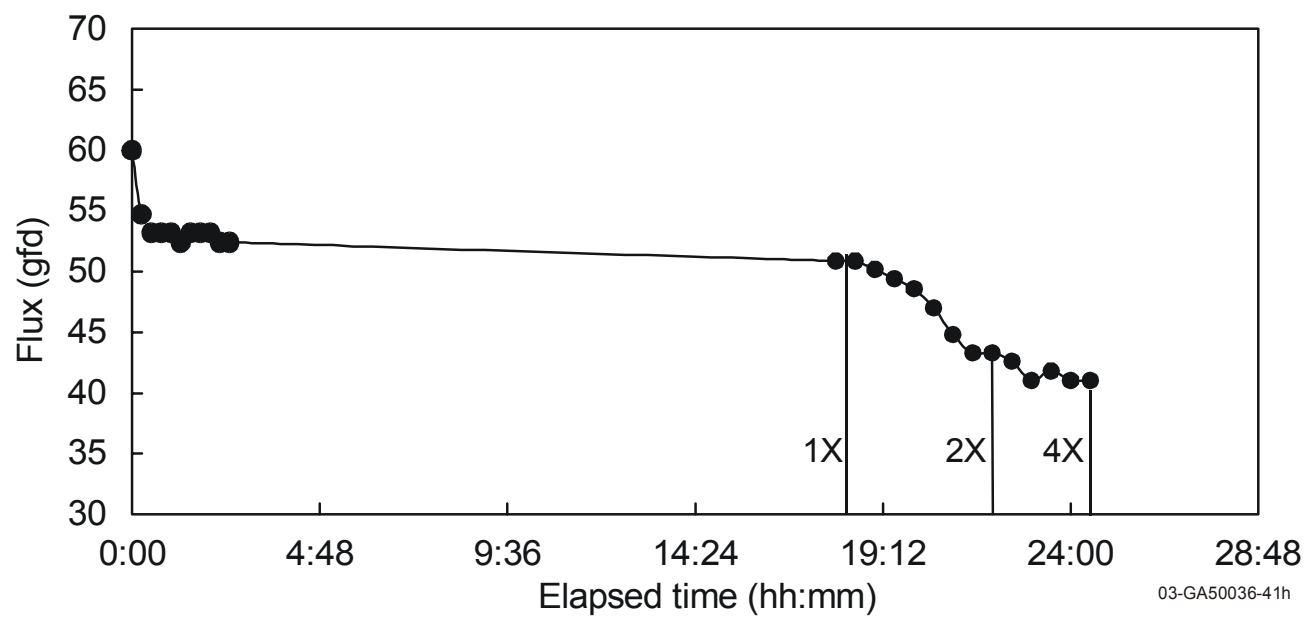

Figure 9. Flux profile for STC with 100,000 molecular weight cut-off ( 0.05 microns) polymeric membrane. 


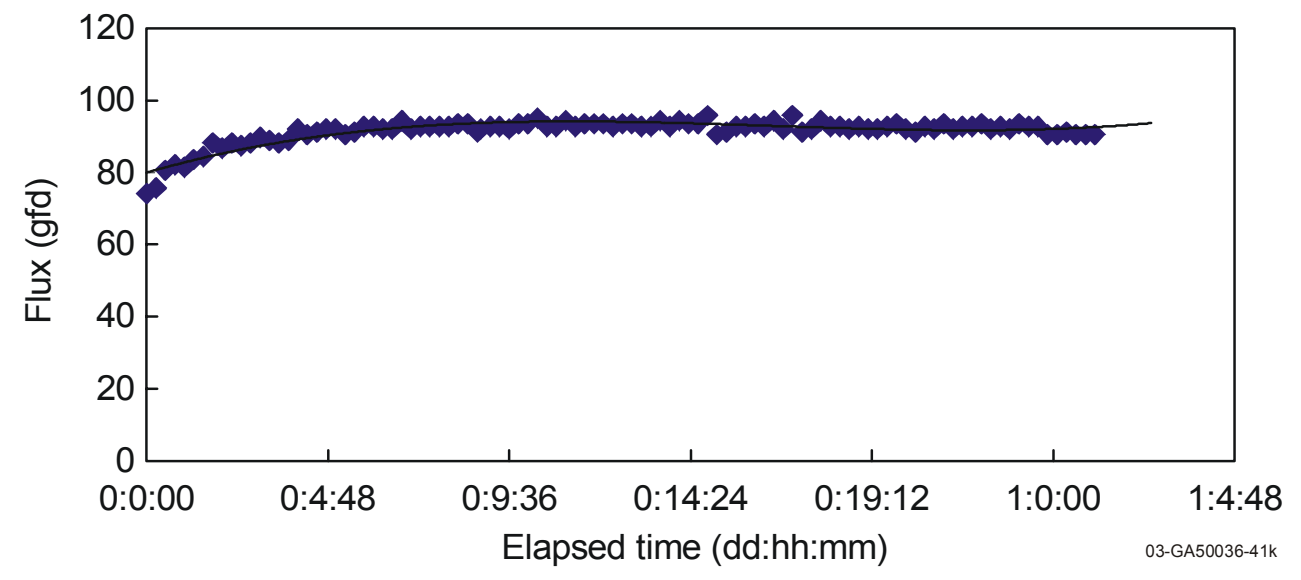

Figure 10. Flux profile for 100,000 NMWC cut-off polymeric membrane (ST-II-1 Test 2).

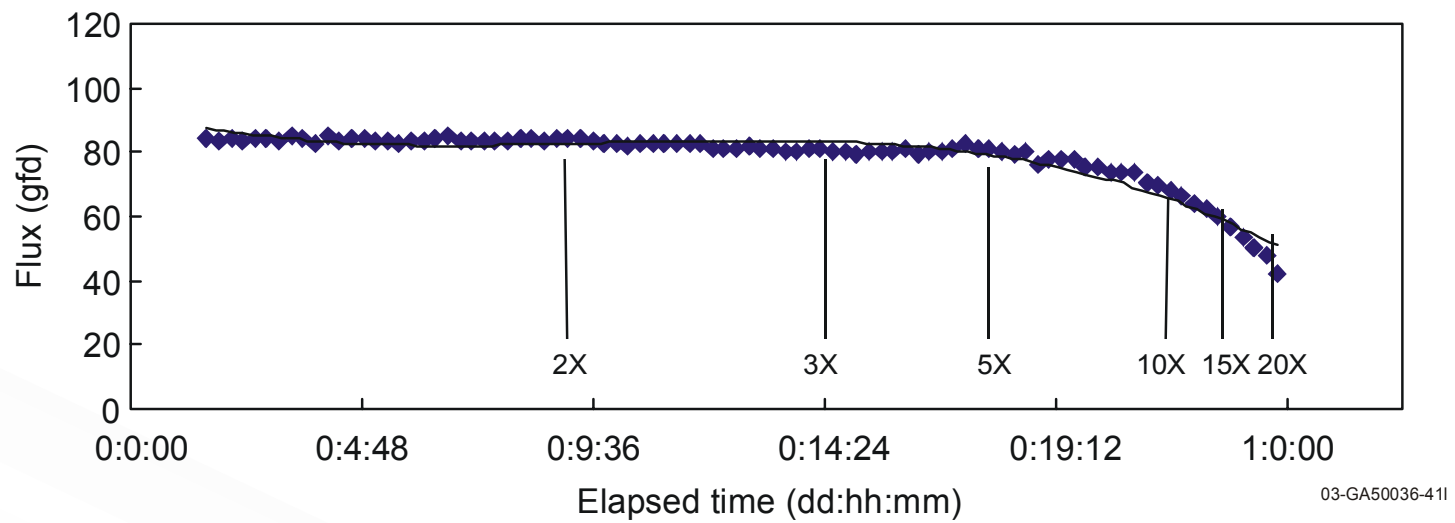

Figure 11. Concentration profile for 100,000 NMWC cut-off polymeric membrane (ST-II-1 Test 2).

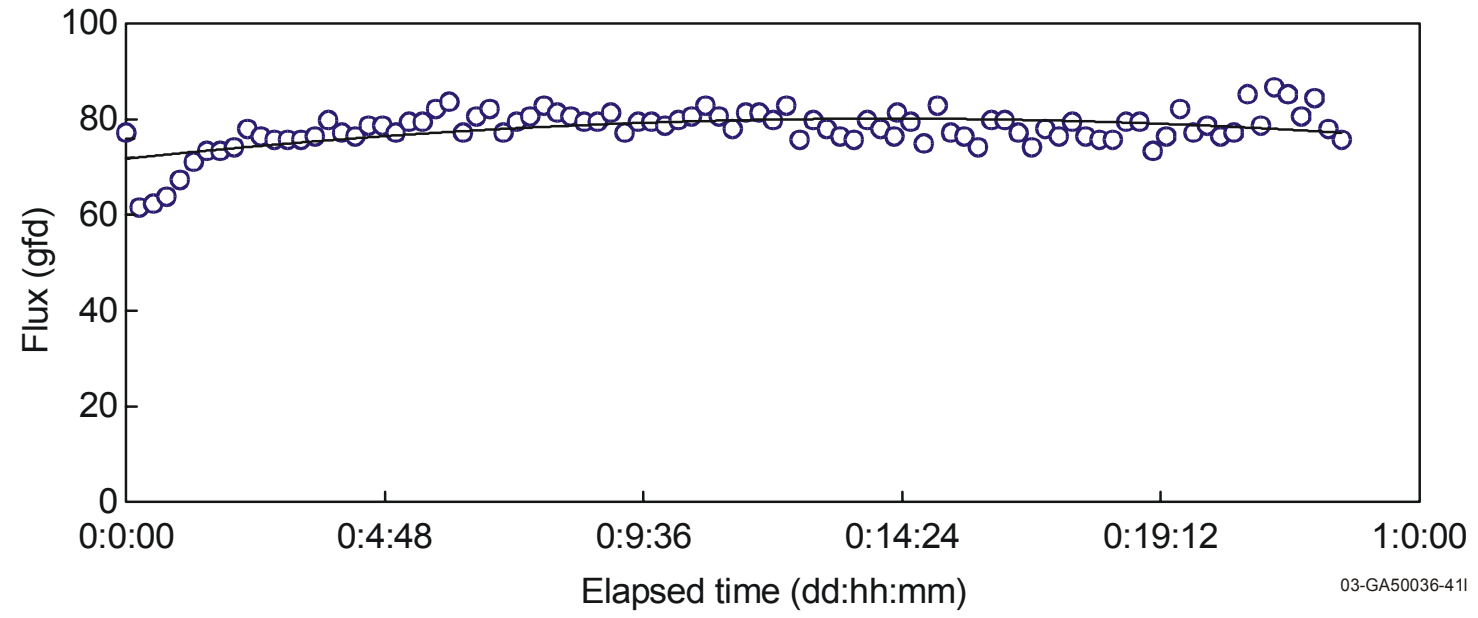

Figure 12. Flux profile for 10,000 NMWC cut-off polymeric membrane (ST-II-1 Tests). 


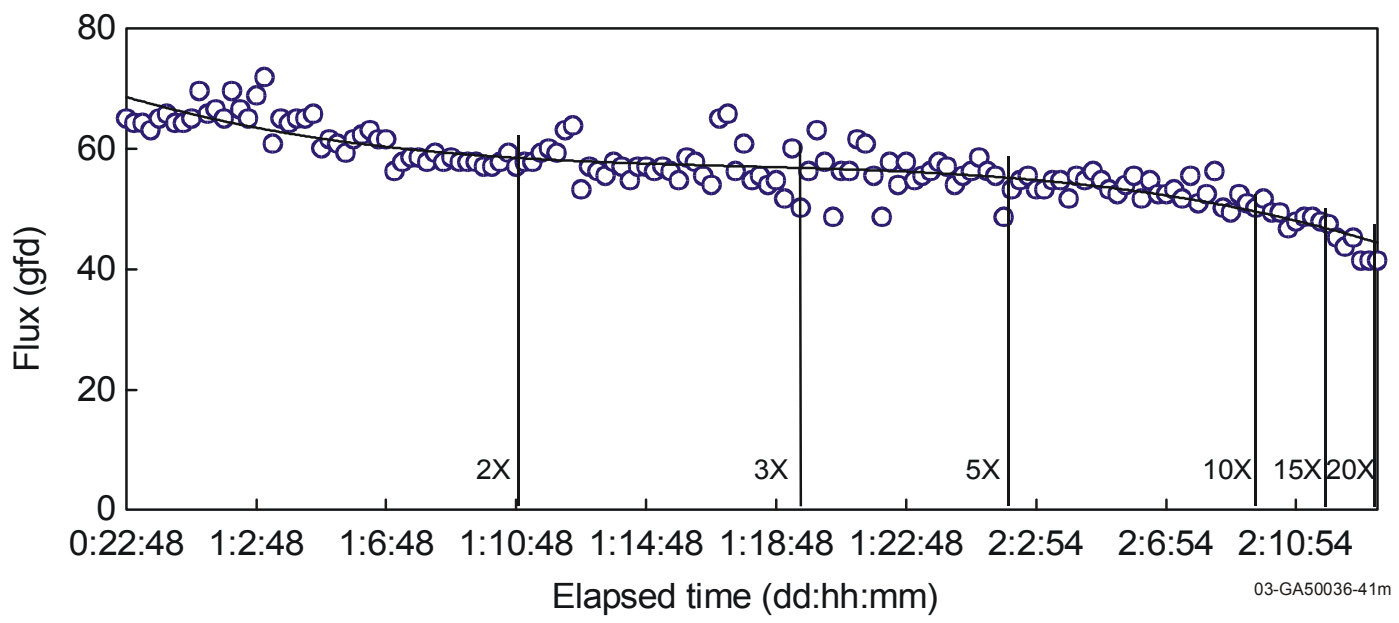

Figure 13. Concentration profile for 10,000 NMWC cut-off polymeric membrane (ST-II-1 Test 3).

dissolve immediately with drop-wise additions of acid in 1-L samples. Due to the complex nature of the solutions that have been evaluated (i.e. high aluminum and zinc contents), the chemical analyses required greater time to accomplish than originally anticipated. Prior to analysis, all samples were acidified with drop-wise additions of hydrochloric acid to assure that all metal ions were dissolved in the solutions.

Truesdail Laboratories, Inc., Tustin, CA, a commercial laboratory certified by the U.S. Environmental Protection Agency (EPA), performed the chemical analyses. The data are summarized in Table 1; the concentration factors for each component are summarized in Table 2. The large number and volume of samples taken at high concentrations for laboratory analysis after tests with the ultrafiltration membrane resulted in the remaining raw feed having slightly lowered concentrations for the ultra/nanofiltration membrane tests. This resulted in reduced metals and organics in the concentrates, but should have had no effect on the overall permeate analysis because the concentrations were not significantly different.

\subsubsection{Static Nanofiltration Membrane Tests}

The results, presented in Figures 14 and 15, show, to our surprise, that a nanofilter is not adequate to remove the metal ions from the stream. Therefore, a membrane cleaning procedure was developed in Phase 2. Truesdail Laboratories also performed chemical analyses on the samples resulting from these tests; the data are summarized in Table 3.

\subsubsection{Conclusions from Bench-Scale Tests}

Based upon our experimental results, we asserted that the active-surface ultrafiltration membranes can substantially reduce organics found in the die-casting solutions. The initial oil and grease are reduced by $20-25 \mathrm{X}$, carbon oxygen demand (COD) by $1.5-2 \mathrm{X}$, total organic carbon (TOC) by 0.6 , while biological oxygen demand (BOD) remained the same. As the organic concentrations of die lube increased in the retentate, the permeate concentrations of the organics remained remarkably similar to their original concentrations. This speaks for an equilibrium being reached and the membrane pore size being very stable. 
Table 1. Chemical analyses for laboratory tests with polymeric membranes.

\begin{tabular}{|c|c|c|c|c|c|c|c|c|}
\hline Sample ID & $\begin{array}{l}\mathrm{TOC} \\
\mathrm{mg} / \mathrm{L}\end{array}$ & $\begin{array}{l}\text { BOD } \\
\mathrm{mg} / \mathrm{L}\end{array}$ & $\begin{array}{l}\mathrm{COD} \\
\mathrm{mg} / \mathrm{L}\end{array}$ & $\begin{array}{c}\text { Oil \& Grease } \\
\mathrm{mg} / \mathrm{L}\end{array}$ & $\begin{array}{c}\mathrm{Pb} \\
\mathrm{mg} / \mathrm{L}\end{array}$ & $\begin{array}{c}\mathrm{Cu} \\
\mathrm{mg} / \mathrm{L}\end{array}$ & $\begin{array}{c}\mathrm{Ni} \\
\mathrm{mg} / \mathrm{L}\end{array}$ & $\begin{array}{c}\mathrm{Zn} \\
\mathrm{mg} / \mathrm{L}\end{array}$ \\
\hline \multicolumn{9}{|c|}{$100,000 \mathrm{MW}$ cut-off polymeric membrane } \\
\hline 1) Initial Perm. & 2108 & 2262 & 6296 & 11.2 & ND & ND & 0.08 & 0.47 \\
\hline 2) Raw Feed & 3463 & 2714 & 12567 & 225 & ND & 0.12 & 0.08 & 0.55 \\
\hline 3) 1X Final & 2143 & 2456 & 6174 & 12.7 & ND & ND & ND & 0.46 \\
\hline 4) $4 \mathrm{X}$ Conc. & 9287 & 6030 & 48230 & 490 & ND & 0.70 & 0.10 & 0.74 \\
\hline 5) 4X Perm. & 2272 & 2445 & 6456 & 12.0 & ND & ND & 0.09 & 0.47 \\
\hline 6) 8 X Conc. & 19637 & 8072 & 87928 & 634 & 0.36 & 1.44 & 0.15 & 1.00 \\
\hline 7) 8x Perm. & 2683 & 2277 & 6915 & 10.5 & ND & ND & 0.09 & 0.52 \\
\hline 8) 12 X Conc. & 22518 & 3438 & 117498 & 1078 & 0.51 & 2.01 & 0.19 & 1.22 \\
\hline 9) 12 x Perm. & 2488 & 2295 & 7344 & 11.6 & ND & ND & 0.11 & 0.51 \\
\hline 10) $16 \mathrm{X}$ Conc. & 29404 & 11789 & 163077 & 1538 & 0.70 & 2.80 & 0.22 & 1.38 \\
\hline 11) $16 \mathrm{X}$ Perm. & 2839 & 1558 & 8593 & 6.5 & ND & ND & 0.10 & 0.54 \\
\hline 12) $20 X$ Conc. & 43339 & 12250 & 206172 & & 1.04 & 4.00 & 0.29 & 1.72 \\
\hline 13) $20 \mathrm{X}$ Perm. & 2680 & 4014 & 8725 & 12.4 & ND & ND & 0.09 & 0.51 \\
\hline \multicolumn{9}{|c|}{$10,000 \mathrm{MW}$ cut-off polymeric membrane } \\
\hline 14) Initial Perm. & 2406 & 2219 & 7393 & 11.3 & ND & ND & 0.08 & 0.52 \\
\hline 15) Raw Feed & 3210 & 2416 & 11590 & 274 & ND & 0.11 & 0.10 & 0.54 \\
\hline 16) Final Perm. & 2211 & 1443 & 6758 & 13.8 & ND & ND & 0.08 & 0.51 \\
\hline 17) 4X Perm. & 2206 & 2049 & 7115 & 5.6 & ND & ND & 0.08 & 0.51 \\
\hline 18) $4 \mathrm{X}$ Conc. & 6504 & 3388 & 26060 & 294 & ND & 0.36 & 0.09 & 0.63 \\
\hline 19) $8 X$ Perm. & 2388 & 2152 & 7012 & 18.4 & ND & ND & 0.09 & 0.55 \\
\hline 20) 8x Conc. & 10380 & 3880 & 47890 & 634 & ND & 0.72 & 0.13 & 0.83 \\
\hline 21) 12 X Perm. & 2606 & 2611 & 7408 & 9.4 & ND & ND & 0.09 & 0.57 \\
\hline 22) $12 \times$ Conc. & 10572 & 4699 & 72370 & 713 & 0.33 & 1.12 & 0.16 & 1.04 \\
\hline 23) $16 \mathrm{X}$ Perm. & 2764 & 2205 & 8047 & 7.9 & ND & ND & 0.09 & 0.56 \\
\hline 24) 16X Conc. & 14340 & 5176 & 79200 & 944 & 0.35 & 1.31 & 0.15 & 1.01 \\
\hline 25) $20 \mathrm{X}$ Perm. & 2756 & 1979 & 8315 & 11.7 & ND & ND & 0.09 & 0.58 \\
\hline 26) $20 \mathrm{X}$ Conc. & 18614 & 6117 & 104687 & 1202 & 0.40 & 1.68 & 0.17 & 1.11 \\
\hline
\end{tabular}

Table 2. Concentration factors for polymeric membranes in laboratory tests.

\begin{tabular}{|c|c|c|c|c|c|c|c|c|}
\hline Sample ID & $\begin{array}{l}\mathrm{TOC} \\
\mathrm{mg} / \mathrm{L}\end{array}$ & $\begin{array}{l}\text { BOD } \\
\mathrm{mg} / \mathrm{L}\end{array}$ & $\begin{array}{l}\mathrm{COD} \\
\mathrm{mg} / \mathrm{L}\end{array}$ & $\begin{array}{c}\text { Oil \& Grease } \\
\mathrm{mg} / \mathrm{L}\end{array}$ & $\begin{array}{c}\mathrm{Pb} \\
\mathrm{mg} / \mathrm{L}\end{array}$ & $\begin{array}{c}\mathrm{Cu} \\
\mathrm{mg} / \mathrm{L}\end{array}$ & $\begin{array}{c}\mathrm{Ni} \\
\mathrm{mg} / \mathrm{L}\end{array}$ & $\begin{array}{c}\mathrm{Zn} \\
\mathrm{mg} / \mathrm{L}\end{array}$ \\
\hline \multicolumn{9}{|c|}{$100,000 \mathrm{MW}$} \\
\hline $1,3 / 2$ & $1 \mathrm{X}$ & $1 \mathrm{X}$ & $2 \mathrm{X}$ & $18 \mathrm{X}$ & ND & $\mathrm{R}$ & $1 \mathrm{X}$ & $1 \mathrm{X}$ \\
\hline $4 / 5$ & $4 \mathrm{X}$ & $2 \mathrm{X}$ & $7 \mathrm{X}$ & $41 X$ & ND & $\mathrm{R}$ & $1 \mathrm{X}$ & $1 \mathrm{X}$ \\
\hline $6 / 7$ & $7 \mathrm{X}$ & $3 \mathrm{X}$ & $13 \mathrm{X}$ & $60 \mathrm{X}$ & $\mathrm{R}$ & $\mathrm{R}$ & $1 \mathrm{X}$ & $1 \mathrm{X}$ \\
\hline $8 / 9$ & $9 \mathrm{X}$ & $1.5 \mathrm{X}$ & $15 \mathrm{X}$ & $98 \mathrm{X}$ & $\mathrm{R}$ & $\mathrm{R}$ & $1 \mathrm{X}$ & $1 \mathrm{X}$ \\
\hline $10 / 11$ & $10 \mathrm{X}$ & $8 \mathrm{X}$ & $19 \mathrm{X}$ & $220 \mathrm{X}$ & $\mathrm{R}$ & $\mathrm{R}$ & $2 \mathrm{X}$ & $2 \mathrm{X}$ \\
\hline $12 / 13$ & $16 \mathrm{X}$ & $3 \mathrm{X}$ & $24 \mathrm{X}$ & $120 \mathrm{X}$ & $\mathrm{R}$ & $\mathrm{R}$ & $3 \mathrm{X}$ & $3 \mathrm{X}$ \\
\hline \multicolumn{9}{|c|}{$10,000 \mathrm{MW}$} \\
\hline $15 / 14,16$ & $1 \mathrm{X}$ & $1 \mathrm{X}$ & $2 \mathrm{X}$ & $25 \mathrm{X}$ & ND & $\mathrm{R}$ & $1 \mathrm{X}$ & $1 \mathrm{X}$ \\
\hline $18 / 17$ & $3 \mathrm{X}$ & $1 \mathrm{X}$ & $3 X$ & $50 \mathrm{X}$ & ND & $\mathrm{R}$ & $1 \mathrm{X}$ & $1 \mathrm{X}$ \\
\hline $20 / 19$ & $4 \mathrm{X}$ & $1 \mathrm{X}$ & $2 \mathrm{X}$ & $34 \mathrm{X}$ & $\mathrm{R}$ & $1 \mathrm{X}$ & $1 \mathrm{X}$ & $1 \mathrm{X}$ \\
\hline $22 / 21$ & $4 \mathrm{X}$ & $2 \mathrm{X}$ & $9 \mathrm{X}$ & $75 \mathrm{X}$ & $\mathrm{R}$ & $\mathrm{R}$ & $2 \mathrm{X}$ & $2 \mathrm{X}$ \\
\hline $24 / 23$ & $5 \mathrm{X}$ & $2 X$ & $10 \mathrm{X}$ & $120 \mathrm{X}$ & $\mathrm{R}$ & $\mathrm{R}$ & $2 \mathrm{X}$ & $2 \mathrm{X}$ \\
\hline $26 / 25$ & $6 \mathrm{X}$ & $3 \mathrm{X}$ & $13 \mathrm{X}$ & $100 \mathrm{X}$ & $\mathrm{R}$ & $\mathrm{R}$ & $2 \mathrm{X}$ & $2 X$ \\
\hline
\end{tabular}



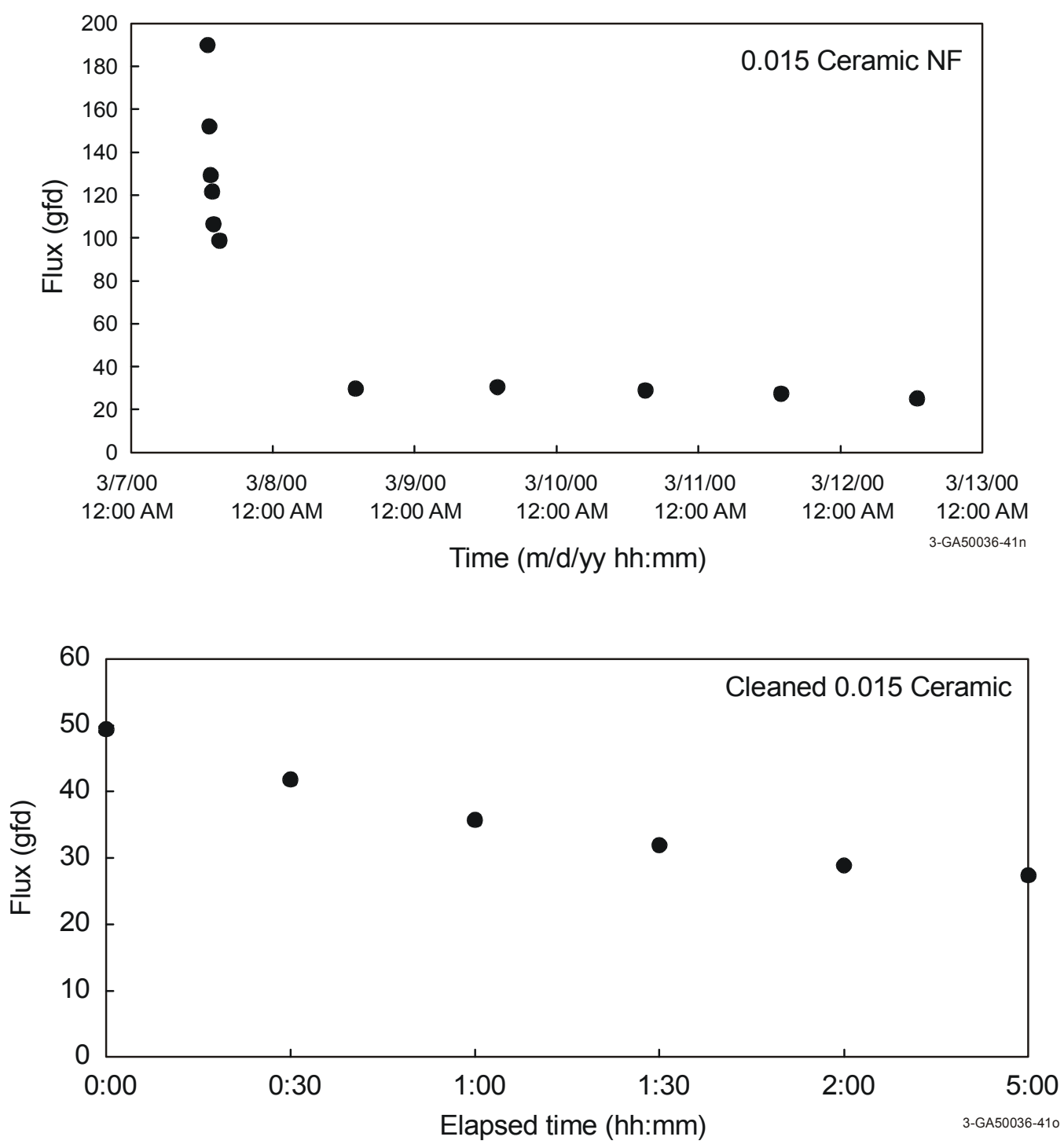

Figure 14. Performance of ceramic ST-IIL nanofiltration membrane (nominal 0.015 micron mean pore diameter) shows flux decline (top), probably due to fouling, and improvement after cleaning (bottom). 

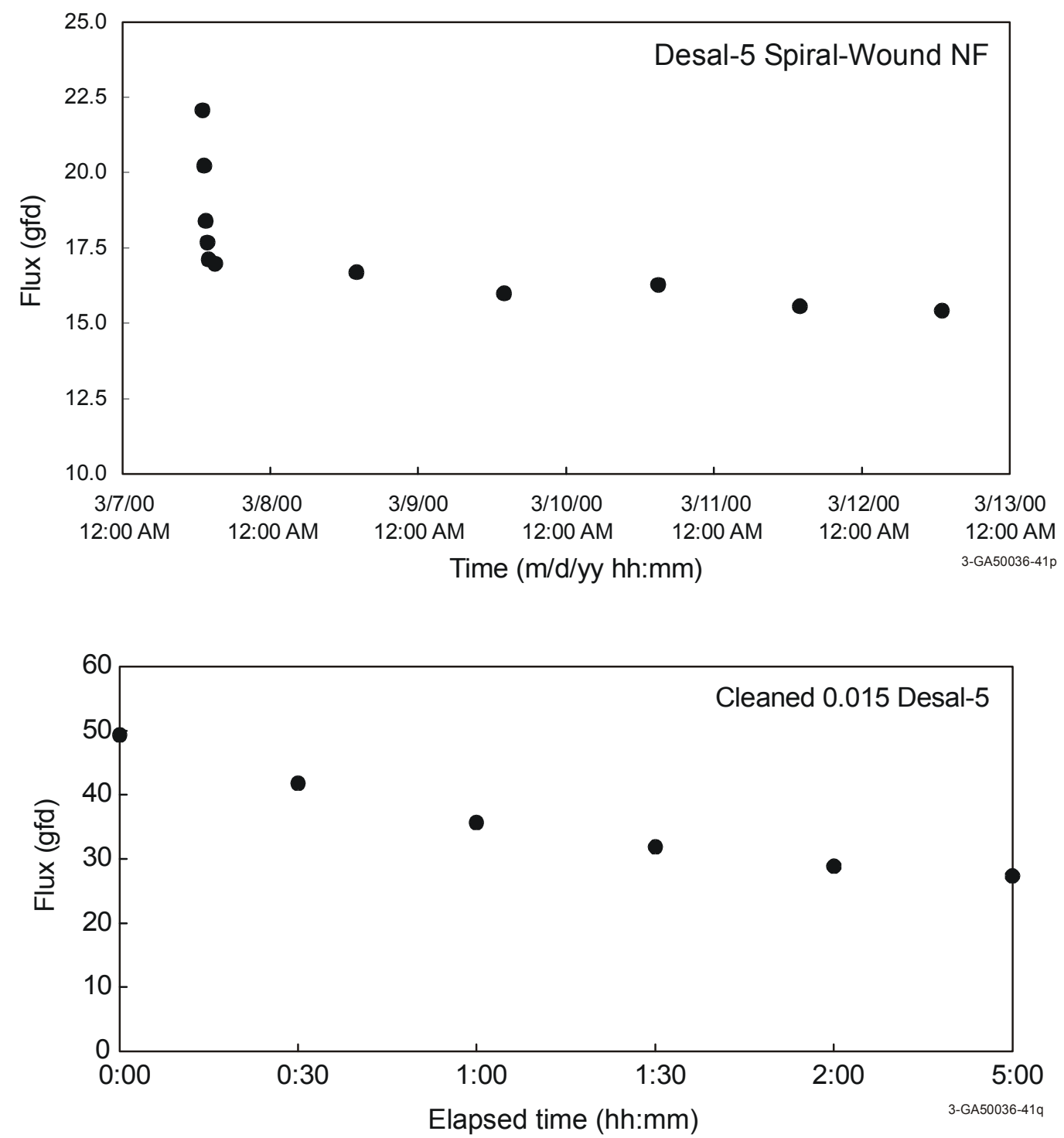

Figure 15. Performance of Desal-5 spiral-wound, static polymeric nanofiltration membrane shows flux decline (top), probably due to fouling, and improvement after cleaning (bottom). 
Table 3. Chemical analyses for nanofilter tests.

\begin{tabular}{lcccccccc}
\hline \multicolumn{1}{c}{ Sample ID } & $\begin{array}{c}\text { TOC } \\
\mathrm{mg} / \mathrm{L}\end{array}$ & $\begin{array}{c}\text { BOD } \\
\mathrm{mg} / \mathrm{L}\end{array}$ & $\begin{array}{c}\mathrm{COD} \\
\mathrm{mg} / \mathrm{L}\end{array}$ & $\begin{array}{c}\text { Oil \& Grease } \\
\mathrm{mg} / \mathrm{L}\end{array}$ & $\begin{array}{c}\mathrm{Pb} \\
\mathrm{mg} / \mathrm{L}\end{array}$ & $\begin{array}{c}\mathrm{Cu} \\
\mathrm{mg} / \mathrm{L}\end{array}$ & $\begin{array}{c}\mathrm{Ni} \\
\mathrm{mg} / \mathrm{L}\end{array}$ & $\begin{array}{c}\mathrm{Zn} \\
\mathrm{mg} / \mathrm{L}\end{array}$ \\
Pesal-5 spiral & \multicolumn{8}{c}{ wound cartridge } \\
Raw Feed & 1510 & 1160 & 3931 & $\mathrm{ND}$ & $\mathrm{ND}$ & 0.09 & 0.24 & 0.63 \\
& 3463 & 2714 & 12567 & 225 & $\mathrm{ND}$ & 0.12 & 0.08 & 0.55 \\
Permeate & 1894 & 2418 & 4885 & $\mathrm{ND}$ & $\mathrm{ND}$ & 0.05 & 0.23 & 0.42 \\
Raw Feed & 3463 & 2714 & 12567 & 225 & $\mathrm{ND}$ & 0.12 & 0.08 & 0.55 \\
\hline
\end{tabular}

These studies showed that active-surface ultrafiltration membranes can reduce total metals in the aqueous phase of a die casting waste solution that is having the water removed from it. The metals concentrations in the permeate (water) are reduced significantly; however, after a period of time, several metals (notably lead and copper) are detectable in the retentate as the organic concentration of the feed solutions increases. This result suggests that the metals probably preferred to stay with the organic components of the die casting solutions. The active-surface membranes were observed to exhibit less fouling than the non-active-surface systems. The fluxes of the active-surface membranes were consistently higher and more stable than those of the non-active-surface membranes tested.

We observed that using polymer materials for the active-surface membranes provided surprisingly high fluxes and high quality separations. (However durability of the polymers became an issue for these systems when we entered the pilot phase, which led to substitution of the inorganic membranes.)

Metaldyne's previous studies with ultrafiltration followed by reverse osmosis had significant problems with membrane fouling by oils, greases, and a material that adheres to all processing equipment and membrane surfaces as well as forms a "scum," with the consistency of lipstick, on the top of the holding tanks. Metaldyne has installed a gravimetric skimmer and a prefilter for removal of particulates and oils and greases from the solutions prior to further water treatment; however, they have not successfully been able to remove all of these components. Some of the "lipstick" components are carried through the system into the membrane systems. The SpinTek active-surface membrane systems showed no significant build up of the "lipstick" as had been previously observed by Metaldyne in their reverse osmosis and ultrafiltration systems (Zenon Environmental). A cleaning procedure for the ultrafiltration membranes using detergents was developed in these experiments, and implemented. The process worked well and is described later in this report.

The preliminary studies with static nanofiltration membranes/modules as a polishing step provided very slight concentration of metal ions. A true reverse osmosis membrane, such as those already installed at Metaldyne's plant, would be most appropriate for a polishing step should it be needed. The operational cost analysis for a rotary membrane system in Metaldyne's application is summarized in Table 4. 
Table 4. Rotating membrane cost analysis.

\section{Costs}

\section{Capital}

Rotating Membrane System $\$ \$ 750,000$

Commissioning

$\$ 20,000$

Shipping/Handling

$\$ 4,000$

\section{Total capital cost $\quad \$ \mathbf{\$ 7 4 , 0 0 0}$}

Operating

$\begin{array}{lc}\text { Power cost } & \$ 0.06 / \mathrm{KW}-\mathrm{hr} \\ \text { Cost per cleaning } & \$ 25.00 \\ \text { Membrane replacement } & \$ 96,000 \\ \text { Cost per Kgal } & \\ \quad \text { Membrane replacement } & \$ 13.00 \\ \text { Membrane cleaning } & \$ 0.26 \\ \text { Power } & \$ 9.05 \\ \text { Misc. operating cost } & \$ 0.56\end{array}$
Total operating cost per Kgal $\quad \$ \mathbf{2 2 . 8 7}$
Total daily operating cost $\quad \$ \mathbf{\$ 4 5 7 . 4 0}$

\section{Assumptions}

System

Feed water volume

System output

Percentage recovery $\quad 95 \%$

Membrane

$\begin{array}{ll}\text { Type } & 0.1 \mathrm{micron} \\ \text { Performance } & 60 \mathrm{gfd} \\ \text { Diameter } & 11 \mathrm{in} . / \text { disc pack } \\ \text { Surface area } & 1 \mathrm{sq} . \mathrm{ft} / \text { disc pack } \\ \begin{array}{l}\text { Disc } \\ \text { packs/system }\end{array} & 320\end{array}$

Operation

\begin{tabular}{|c|c|}
\hline Operating days/month & 30 days \\
\hline Operating pressure & 40 psig \\
\hline Recycle flow/disc pack & 1 gal \\
\hline Total recycle flow & 320 gpm \\
\hline Recycle pressure drop & 30 psig \\
\hline Pump efficiency & $80 \%$ \\
\hline Motor efficiency & $94 \%$ \\
\hline Brake HP - Recycle pump & 5.0 BHP \\
\hline Brake HP - Rotors & $200 \mathrm{BHP}$ \\
\hline Brake HP - Total required & 160.0 BHP \\
\hline $\begin{array}{l}\text { Total system power } \\
\text { consumption }\end{array}$ & $119.4 \mathrm{KW}-\mathrm{hr}$ \\
\hline \multicolumn{2}{|l|}{ Membrane } \\
\hline Cleaning interval & 5 days \\
\hline Lifetime (conservatively) & $1 \mathrm{yr}$ \\
\hline
\end{tabular}




\subsection{Summary of Phase 1 Testing}

Laboratory testing, using small, flat, sheet membranes and a bench-scale rotary filter, demonstrated that active-surface membrane technology was a good candidate for field testing at Metaldyne's plant. The metals content of the feed solutions was reduced significantly using tight ultrafiltration active-surface membranes. However, significant hydro-gel-like precipitates formed in the permeate solutions upon standing. The gels may be hydrated aluminum and iron oxy-/hydroxy-species. ${ }^{13}$ These gels are very $\mathrm{pH}$ sensitive and dissolved immediately with drop-wise additions of acid to 1-L samples. Nanofiltration to polish the effluent concentrated the metal ions slightly. The results of the experiments were encouraging because permeates from the nanofiltration system are clear, colorless, and show only slight discoloration and no significant gel precipitation upon standing. These results provided the basis for proceeding to Phase 2 testing and evaluation. 


\section{PHASE 2: FIELD DEMONSTRATION OF DIE LUBE CONCENTRATION}

\subsection{Experimental Procedure}

After the successful completion of Phase 1, SpinTek fabricated a system consisting of two five-disk ST-II rotary microfilter units (Speedy ${ }^{\mathrm{TM}}$ systems), a feed pump, storage tank, associated piping and valves, and a fully automatic control panel. The system was designed to provide continuous operation of the ST-II filter on wastewater and allow high concentrations of the feed samples. The general layout of the pilot testing process equipment is shown in Figure 16. The process solutions were pumped from the feed tank to a bypass line and the ST-II membrane system. Throttling valves on the bypass line and the membrane feed line were used to control flow through the respective process piping. A valve on the concentrate line of the ST-II was used to maintain a constant pressure on the membrane system. The temperature was controlled using heaters located in the feed tank, along with a heat exchanger on the feed bypass line.

The die lube separated from the feed solution must be concentrated to a $20 \mathrm{X}$ level $\left(90^{+} \%\right.$ water removal) for recycling into the die casting machines. To allow testing up to 50X concentration (i.e., 100 gallons reduced to 2 gallons, $98^{+} \%$ ), a 500 -gallon polyethylene feed tank was installed at the Metaldyne plant. The system's dead or "hold-up" volume was approximately 5 gallons, so at the end of the 50X experiment just enough concentrated feed solution remained to operate the ST-II feed pump and rotors. During normal operations at the $20 \mathrm{X}$ level, about 25 gallons typically remained and the membrane rotors and pumps were not threatened with going dry.

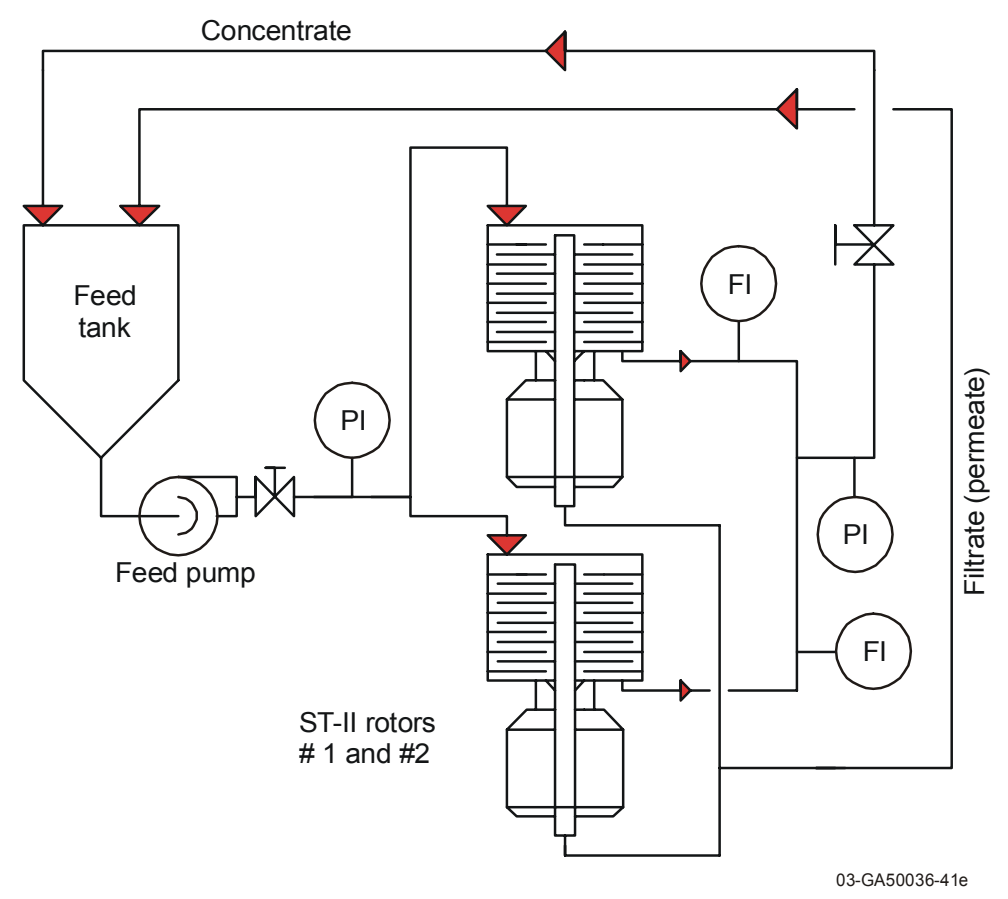

Figure 16. Process flow and instrument diagram for field demonstration system during stabilization. After the membrane fluxes are stable, the filtrate (permeate) line is removed from the feed tank to allow concentration. 
The two five-disk rotary filter systems were equipped with ceramic stainless steel composite microfiltration membranes with a pore size of 0.1 microns, supplied by Trumem (Moscow, Russia; available through SpinTek, LLC). The ceramic composite membrane structures were assembled by SpinTek using permeate spacers and Ryton ${ }^{\mathrm{TM}}$ disks as previously described.

\subsubsection{Concentration Testing Procedure}

The feed tank was filled with 500 gallons of fresh die lube wastewater, then the pumps and rotary membrane system were activated. The permeate and concentrate were recycled back to the feed tank until system performance, gauged by membrane fluxes, was stabilized. The permeate line was then withdrawn from the feed tank and placed in the industrial water drain at the plant while the feed solution was concentrated to the target concentration, typically $20 \mathrm{X}$. The concentration was determined volumetrically (i.e., $20 \mathrm{X}$ is achieved when 100 gallons is reduced to 5 gallons).

Membrane cleaning needs were determined at the end of each experiment. Membrane cleaning procedures were implemented when the permeation rate fell to approximately $30 \mathrm{gpm}$.

\subsubsection{Chemical Analysis}

Chemical analysis for Phase 2 was performed by Nalco Diversified Technologies (NDT, P.O. Box 200 Chagrin Falls, Ohio. NDT has Ohio EPA Certificate \#1291 for inorganics and Ohio permit \#849 for total coliform). All analyses were performed according to EPA standard methods, typically within 5 days of sampling at Metaldyne. The samples were refrigerated during storage prior to analysis at both Metaldyne and NDT to inhibit biological growth.

\subsubsection{Solution Washing of Concentrated Feed Solution to Remove Glycerin}

A method of removing glycerin was developed during Phase 2 for possible use in Phase 3 . After the die lube solution was concentrated to $20 \mathrm{X}$, the concentrated solution was removed, the ST-II system was flushed with fresh water to establish that the membranes were not fouled, the concentrated the feed solution was returned to the feed tank, and the balance of the volume made up with softened water. The system was then restarted with the concentrate and permeate lines recycled back into the feed tank until a stable flux was achieved. Upon achieving a stable flux, the permeate line was moved to the industrial drain. After $3 \mathrm{~h}$ of concentration, the COD level in the permeate stream was $6700 \mathrm{mg} / \mathrm{L}$; after $5.5 \mathrm{~h}$ it was $4400 \mathrm{mg} / \mathrm{L}$. This $30 \%$ reduction in COD suggests that the glycerin could be washed from the solution prior to recycling the die lube in the plant, which is desirable from the perspective of closed plant recycling.

\subsubsection{Membrane Cleaning Process Development}

During the early stages of Phase 2, INEEL was requested to develop a cleaning process that removes foulants (the "lipstick" and its associated greases and oils) from the Trumem membranes, supports, and rotary disc shrouds. Suggested cleaners included 2-butoxy-ethanol at elevated temperatures, hot water, and detergent (specifically, Proctor and Gamble's Dawn" ${ }^{\mathrm{TM}}$, and "MC-4" a specialized alkaline membrane cleaner supplied by Zenon Environmental, Inc.). We chose to clean the membranes with hot water and Alkanox ${ }^{\mathrm{TM}}$ laboratory cleanser as a model for Zenon's MC-4 membrane cleanser. The results of those efforts are summarized in Table 5. 
Table 5. Membrane Cleaning Procedure Developed by INEEL for Trumem Membranes.

Feed: clean water at

\begin{tabular}{llcccc}
\multicolumn{1}{c}{$\begin{array}{c}\text { Membrane } \\
\text { Description }\end{array}$} & \multicolumn{1}{c}{$\begin{array}{c}\text { Membrane } \\
\text { Condition }\end{array}$} & $\begin{array}{c}\text { Temperature } \\
\left({ }^{\circ} \mathrm{C}\right)\end{array}$ & $\begin{array}{c}\text { Pressure } \\
(\mathrm{psi})\end{array}$ & $\begin{array}{c}\text { Flux } \\
(\mathrm{gfd})\end{array}$ & $\begin{array}{c}\text { Flux } \\
\left(\mathrm{L} / \mathrm{m}^{2} \text {-hr }\right)\end{array}$ \\
\hline $\begin{array}{l}\text { Baseline: Virgin } \\
\text { Membrane }\end{array}$ & Virgin & 35 & 45 & 624 & 1,062 \\
$\begin{array}{l}\text { Used, Supplied by } \\
\text { Metaldyne }\end{array}$ & Fouled & 43 & 45 & 10.4 & 17.5 \\
& Fouled & 90 & 45 & 20 & 34 \\
& $\begin{array}{l}\text { Fouled, soaked in } \\
\text { Alcanox } \\
\text { Overnight }\end{array}$ & 90 & 45 & 155 & 264.7 \\
& $\begin{array}{l}\text { Fouled, treated } \\
\text { w/ Alcanox }\end{array}$ & 40 & 40 & 173.5 & 294 \\
$\begin{array}{l}\text { Used, Supplied by } \\
\text { Metaldyne }\end{array}$ & $\begin{array}{l}\text { Fouled, treated } \\
\text { w/ Alcanox }\end{array}$ & 50 & 40 & 212.4 & 360 \\
& $\begin{array}{l}\text { Fouled, treated } \\
\text { w/ Alcanox }\end{array}$ & 70 & 40 & 277.7 & 459.8 \\
& $\begin{array}{l}\text { Fouled, treated } \\
\text { w/ Alcanox }\end{array}$ & 85 & 40 & 281.1 & 475.5 \\
& $\begin{array}{l}\text { Fouled, treated } \\
\text { w/ Alcanox }\end{array}$ & 40 & 40 & 210.5 & 358 \\
\hline
\end{tabular}

Based upon these results, the membranes were cleaned as follows. The commercial caustic MC-4 cleaner (from Zenon Environmental, Inc. Oakville, ON, Canada) was combined with $5 \mathrm{wt} \%$ Dawn ${ }^{\mathrm{TM}}$ detergent and 5\% Cellusolve (ethyleneglycol monobutyl ether, Aldrich Chemicals, Inc.) in clean water in the feed tank. The system was run with the membranes spinning $(1100 \mathrm{rpm})$ at $155-160^{\circ} \mathrm{F}$ without pressure for 30 to $100 \mathrm{~min}$ to wash the surfaces of the membranes. Then pressure was applied ( $25 \mathrm{psig})$ and the water flux was observed. If the water flux approached the original water flux (plus or minus $20 \%$ ), then the membranes were considered clean. The membranes were then rinsed with water. A $5 \%$ citric acid rinse to neutralize the surfaces of the membranes was then applied for $30 \mathrm{~min}$, followed by a plain softened water (Culligan, Inc.) rinse for 20 to $40 \mathrm{~min}$. When Metaldyne implemented this cleaning protocol in Phase 3, the oils and greases were removed from the Trumem membranes, and the fluxes approached the manufacturer's original clean water specifications.

\subsection{Results and Discussion}

The membranes that SpinTek first mounted on the Speedy ${ }^{\mathrm{TM}}$ systems were commercial polymer ultrafiltration membranes. These membranes worked well for the initial operational run. However, upon standing in clean or dirty water - for as little as a few minutes - the membranes tended to pucker on the discs. Then, when the membranes started to rotate, they rubbed on the spacers, marking or tearing the surface of the membranes and causing them to become non-selective. Attempts to move the spacers to eliminate rubbing failed. Therefore, we decided to use the stainless steel/ceramic composite membrane materials available from Trumem with 0.1 micron pores. The performance of the Trumem membranes in 
the pilot concentration studies exceeded our expectations. Fouling was a problem, so we developed cleaning protocols to remove oils, greases, and other foulants from the membranes.

The test data are summarized in Table 6. The following descriptions of each concentration test run present our work verbally and express both the advantages and challenges that were encountered during routine operation of the SpinTek pilot system at Metaldyne's plant.

\section{Concentration Run \#1}

The initial feed flux with feed solution on the membrane (feed-based flux) for Concentration Run \#1 was 34 gfd with a final flux of 38 gfd at the end of the experiment. The feed volume of 655 gallons was reduced $51 \%$ to 334 gallons over $9 \mathrm{~h}$ of operation. An addition of 50 gallons of city water was made to the feed tank. The flux increased to $45 \mathrm{gfd}$ after $6.5 \mathrm{~h}$. After flushing the membrane system with warm city water, the flux increased to $55 \mathrm{gfd}$. The system was allowed to stand overnight without water on the membranes.

Following return to service, the flux increased to $101 \mathrm{gfd}$ after $15 \mathrm{~min}$ and was then flushed with city water, yielding a flux of 118 gfd. The system was washed for $4 \mathrm{~h}$ and the flux started at $44 \mathrm{gfd}$ but was reduced to $41 \mathrm{gfd}$ at the end of the wash. A fresh water flush slightly reduced the flux to $39 \mathrm{gfd}$. A subsequent wash with plain water for $9 \mathrm{~h}$ did not increase the flux nor did a 5 min rinse with soft water. The system was then cleaned with Cellusolve for $30 \mathrm{~min}$. The starting flux was $41 \mathrm{gfd}$ and flux at the completion of the cleaning at $85 \mathrm{gfd}$. The flux remained at $85 \mathrm{gfd}$ after a $5 \mathrm{~min}$ flush with softened water. System pressure remained constant during the test at 50-56 psig inlet pressure and 47 psig on the concentrate.

Table 6. Summary of Concentration Test Results

\begin{tabular}{|c|c|c|c|c|}
\hline Test No. & Cleaning $^{\mathrm{a}}$ & Flux at Start ${ }^{\mathrm{b}}$ & Flux at End ${ }^{\mathrm{b}}$ & $\begin{array}{c}\text { Final } \\
\text { Concentration } \\
\end{array}$ \\
\hline 1 & Cellusolve & 34 & 38 & $2 \mathrm{X}$ \\
\hline 2 & Cellusolve, MC-4 & 164 & & Water \\
\hline 3 & Cellusolve, MC-4 & 49 & 46 & $1.1 \mathrm{X}$ \\
\hline 4 & $\begin{array}{l}\text { Soaked, MC-4, alcohol } \\
\text { and glycerin mixture }\end{array}$ & 75 & 63 & $20 X$ \\
\hline 5 & None & 73 & 54 & $20 X$ \\
\hline 6 & None & 61 & 29 & $50 X$ \\
\hline 7 & None & 50 & 48 & $20 X$ \\
\hline 8 & Cellusolve & 91 & 51 & $20 X$ \\
\hline 9 & None & 112 & 58 & $20 X$ \\
\hline 10 & None & 65 & 62 & $20 X$ \\
\hline 11 & None & 48 & 25 & $20 X$ \\
\hline
\end{tabular}


Several factors were considered when these wild variations in flux were observed. First, membrane performance seemed to vary with each operation and, secondly, the need to cleanse the membranes was determined to be rather frequent. Additional research performed at INEEL suggests that a component of the Russian manufactured membranes could be slowly washing out of the membranes, causing the observed variation in flux.

\section{Concentration Run \#2}

The membranes were cleaned at the end of Run \#1. The initial feed-based flux was low, at $25 \mathrm{gfd}$, and remained there during a short run of $1 \mathrm{~h}$. Pressure during this service run was 54/49 psig (feed/concentrate). The system was flushed and then cleaned with MC-4 (caustic 5\%) and Cellusolve (3\%) to $32 / 26 \mathrm{psig}$. The cleaning lasted $2.25 \mathrm{~h}$ and flux increased to $132 \mathrm{gfd}$. Pressure of the cleaning solution was increased to 52/41 psig and flux increased to $246 \mathrm{gfd}$. The membranes were then soaked in softened water and the flux remained at 246 gfd. The system was flushed with water at 52/42 psig and the flux decreased to $230 \mathrm{gfd}$. The system and feed tank were flushed and refilled with water. Hydrochloric acid (5\%) was added to the water. At a low pressure of 32/25 psig, the flux started at $164 \mathrm{gfd}$ and ended at 246 gfd after $2 \mathrm{~h}$. Pressure was increased to $42 / 32$ psig and the permeate flow was too high to measure by the flow meters. After 5 min the pressure was increased to 52/39 psig and the flux dropped to 396 gfd. The test was ended when a case bolt on one of the ST-II systems began to leak.

\section{Concentration Run \#3}

The membranes were flushed with water for $25 \mathrm{~min}$ at 58/37 psig with a starting flux of $58 \mathrm{gfd}$. Fresh feed (500 gallons) was introduced into the feed tank. The feed was introduced at 59/38 psig and the system ran for $2.5 \mathrm{~h}$ with an average flux of $55 \mathrm{gfd}$. The system was flushed with softened water and allowed to stand overnight. The initial 500 gallons of feed had been reduced to 450 gallons in the initial $2.5 \mathrm{~h}$ of operation. The system was restarted in the morning and operated for $6.25 \mathrm{~h}$ at $48 / 31 \mathrm{psig}$ and flux was stable at $49 \mathrm{gfd}$. The system was flushed with water and allowed to stand over night with water on the membranes. The system was restarted $8-10 \mathrm{~h}$ later (in the morning) and operated for $7 \mathrm{~h}$ at 48/31 psig; flux was stable at 46 gfd. Further tests were performed with apparently low fluxes but this was due to one of the rotors not operating due to a blown fuse, which the operators did not know until completion of the test. Test \#3 ended with an unremarkable die lube solution concentration of $1.4 \mathrm{X}$.

\section{Concentration Run \#4}

Prior to Concentration Run \#4, the membrane disks were removed from the system and hand washed with a Safety-Kleen solvent, MC-4 (alkaline cleaner), and an alcohol/glycerin solution. The membranes were reinstalled, followed by system flushing with water for $10 \mathrm{~min}$. The resulting flux was 163 gfd at $76 / 52$ psig.

The feed tank was filled with 500 gallons of fresh feed and concentrated to 25 gallons (20X) over $26 \mathrm{~h}$ of continuous operation. The pressure was $50 / 34 \mathrm{psig}$ with an initial flux of $75 \mathrm{gfd}$. The final flux was $63 \mathrm{gfd}$. The system was flushed with water; the flux returned to $135 \mathrm{gfd}$ after $2 \mathrm{~min}$.

\section{Concentration Run \#5}

The membranes were only flushed with water, not cleaned, after the previous experiment. A 500 gallon feed solution was reduced to 25 gallons with pressure at 50/35 psig. The initial flux was 73 gfd and final flux was $54 \mathrm{gfd}$. The system was flushed with water with the flux returning to $97 \mathrm{gfd}$ at a pressure of $42 / 28 \mathrm{psig}$. When the pressure was increased to $50 / 35 \mathrm{psig}$, the flux increased to $135 \mathrm{gfd}$, thereby showing that the membranes were clean. 


\section{Concentration Run \#6 (50X Concentration Experiment)}

Concentration Run \#6 began without cleaning the membranes as they were demonstrated to be clean at the end of Test Run \#5. The run started with 500 gallons of fresh feed, which was reduced to 10 gallons (50X) during the run. Pressure was 50/35 psig though most of the test. The flux started at 61 gfd and continually rose to 81 gfd until $6 \mathrm{X}$ concentration of the feed was accomplished. The flux then continuously decreased to $52 \mathrm{gfd}$ at $20 \mathrm{X}$ and finally to $29 \mathrm{gfd}$ at $50 \mathrm{X}$. The entire concentration run lasted $32 \mathrm{~h}$. The system was flushed with water for $5 \mathrm{~min}$ and the flux was $31 \mathrm{gfd}$, indicating significant fouling of the membranes. The membranes were flushed with Safety-Kleen solvent followed by water, with the flux returning to $128 \mathrm{gfd}$ at 50/35 psig. The membranes were allowed to stand in softened water awaiting the next experiment.

\section{Concentration Run \#7}

For Concentration Run \#7, 500 gallon of fresh feed solution was added to the feed tank and concentrated to 25 gallons (20X). The flux started at $50 \mathrm{gfd}$ and ended the run at $48 \mathrm{gfd}$. Pressure started at 50/33 psig and decreased to $42 / 29$ psig at $1.2 \mathrm{X}$ for unknown reasons. The entire concentration test lasted $36 \mathrm{~h}$. The membranes were flushed with water and flux increased to 105 at 50/35 psig. The membranes were then soaked in butyl cellosolve for $10 \mathrm{~min}$, followed by water rinsing with the flux increasing to 237 at 50/33 psig, indicating very clean membranes. The membranes were allowed to stand in softened water awaiting the next experiment.

\section{Concentration Run \#8}

For Concentration Run \#8, a fresh 500 gallon feed sample was concentrated to 25 gallons (20X). The flux was initially $91 \mathrm{gfd}$ and ended the run at $51 \mathrm{gfd}$ at a pressure of 50/21 psig. It was later determined that the low concentrate pressure of 21 was an incorrect reading by a faulty pressure gauge. The entire concentration run lasted $35 \mathrm{~h}$. The membranes were flushed with water and flux increased to 109 gfd at 50/21 psig, indicating reasonably clean membranes. The membranes were allowed to stand in softened water awaiting the next experiment.

\section{Concentration Run \#9}

Concentration Run \#9 was initiated with a fresh 500 gallon sample of feed that was reduced to 25 gallons (20X). The initial flux was $112 \mathrm{gfd}$ and final flux was $58 \mathrm{gfd}$ at a pressure of 50/35 psig. The entire concentration run lasted $22 \mathrm{~h}$. The membranes were flushed with water and flux increased to $83 \mathrm{gfd}$ at 50/35 psig. The membranes were allowed to stand in softened water awaiting the next experiment.

\section{Concentration Run \# 10}

Concentration Run \#10 started with 500 gallons of fresh feed, which was reduced to 25 gallons (20X). Pressure was 50/35 psig throughout the test run. The entire concentration run lasted $29 \mathrm{~h}$. Initial flux was $65 \mathrm{gfd}$ and final flux was $62 \mathrm{gfd}$ at a concentration of 20X. After completion of Test Run \#10, the system was flushed with water for $5 \mathrm{~min}$ and the flux was $31 \mathrm{gfd}$, indicating membrane fouling. The membranes were allowed to stand in softened water awaiting the next experiment.

\section{Concentration Run \#11}

Concentration Run \#11 was started without cleaning the membranes from Test Run \#10. As previously, the run started with 500 gallons of fresh feed and was reduced to 25 gallons (20X). The entire concentration run lasted $47 \mathrm{~h}$. Pressure was 50/35 psig though the Test Run \#11. Initial flux was 48 gfd 
and final flux was $25 \mathrm{gfd}$ at a concentration of 20X. The system was flushed with water for 5 min and the flux was $39 \mathrm{gfd}$, indicating membrane fouling.

At this point a vigorous cleaning regimen was implemented on the membranes. The system was first flushed with water at 50/35 psig, the flux was 32 gfd. The membranes were then cleaned with MC-4, and the flux dropped to 6 gfd at 50/35 psig. The system was flushed with water at 50/35 psig and the flux increased to $25 \mathrm{gfd}$. The system was then cleaned with Ultrasil ${ }^{\mathrm{TM}}$ solvent (4 butoxy ethanol, Ultrasil, Corp.) for $16 \mathrm{~min}$ and the flux increased to $151 \mathrm{gfd}$. After the Ultrasil ${ }^{\mathrm{TM}}$ cleaning, the system was flushed with water to remove the Ultrasil, and the clean water flux was $177 \mathrm{gfd}$ at 50/36 psig, indicating clean membranes. The balance of Test \#11 was then completed. At the completion of Test \#11 the membranes were rinsed with clean water and the clean water flux decreased very slightly to $174 \mathrm{gfd}$.

\subsection{Summary of Phase 2 Concentration Tests}

In tests at Metaldyne's plant, we successfully concentrated the die lube solution to the expected 20X concentration and even as high as 50X. However, at 50X process reliability was difficult to maintain, membrane life was limited, and permeate quality was poor. We concluded that $50 \mathrm{X}$ is impractical for commercial implementation. At 20X, the equipment was reliable, the quality of permeate was acceptable, and solids removal was accomplished to support reuse. 


\section{PHASE 3: FIELD DEMONSTRATION OF DIE LUBE RECYCLING}

During the casting operation, the die lube becomes contaminated with glycerin from the hydraulic systems of the casting machinery. When the machines are washed, die lube enters the wastewater stream. The die lube must be removed from the wastewater and, if the lube is to be recycled, the glycerin must be removed from the die lube. Because glycerin is water soluble, we expected it to pass through the membrane of the rotary microfilter and be flushed away from the water-insoluble (oily) components of die lube. The purpose of Phase 3 was to determine if the die lube could be recycled from the wastewater and be directly reinjected into the die casting machinery.

\subsection{Concentrating Die Lube and Removing Glycerin}

\subsubsection{Experimental Procedure}

The first step in recycling die lube is to collect the mixture of die lube applied to the die as well as the wash-down waters used to clean the die and other plant equipment. Experimentally, we determined that concentrating this feed solution by $70 \%$ (100 gallons become 30 gallons, or 3.3X) is optimal for subsequent washing of the glycerin from the die lube solution. After the $70 \%$ concentration was achieved, the rotary filter continued to operate and fresh soft water was added to the feed tank to selectively wash out (diafiltration) the glycerin. When the glycerin was washed out, the concentrated die lube was transferred to another tank for remixing and reintroduction into the die casting machine.

To begin each batch, 500 gallons of fresh die lube wastewater was added to the feed tank of the Speedy ${ }^{\mathrm{TM}}$ rotary microfilter system used in Phase 2 . Concentration began, with the filtrate being sent to the drain and the concentrate back to the feed tank. More fresh wastewater was added to the feed tank to replace the filtrate sent to the drain until the feed tank concentration reached $70 \%$. At that point, softened water was added to the feed tank. The amount of water required to "wash" out the glycerin varied depending on the amount of glycerin in the concentrated feed solution. Once the concentrated die lube was free of glycerin, it was directly transferred to another tank for remixing and reuse in the die casting machine. For Phase 3, the rotary microfilter operated continuously for six weeks, producing recycled, washed die lube for reuse in the die casting operations.

\subsubsection{Results}

Biosolutions, LLC (10180 Queensway \#6, Chagrin Falls, OH 44023) performed the chemical analyses for Phase 3. The COD of the wastewater solution, after concentration by $70 \%$, varied between 12,000 and $15,000 \mathrm{mg} / \mathrm{L}$. After washing with soft water, the COD was reduced to 1,500 to 2,000 mg/L. This reduction was attributed to removal of small, soluble, organic chemicals, primarily glycerin.

The results of Phase 3 recycling runs are summarized in Figures 17 and 18 and Table 7, presented in more detail in the appendix, and discussed below.

\section{Recycling Run \#1}

The flux for the die lube wastewater feed solution was initially $124 \mathrm{gfd}$ and declined to $94 \mathrm{gfd}$ at completion of the concentration operation, when the die lube feed was concentrated by $69 \%$ or about 3.3X. The die lube feed was then washed with a volume of soft water equal to $70 \%$ of the total concentrated feed volume. During washing, the membrane flux increased from 94 to $98 \mathrm{gfd}$. The COD of the die lube wastewater feed, initially $12,300 \mathrm{mg} / \mathrm{L}$, was reduced to 7,240 $\mathrm{mg} / \mathrm{L}$. Upon completion of solution washing, the membranes were flushed with water; the flux returned to $147 \mathrm{gfd}$. 


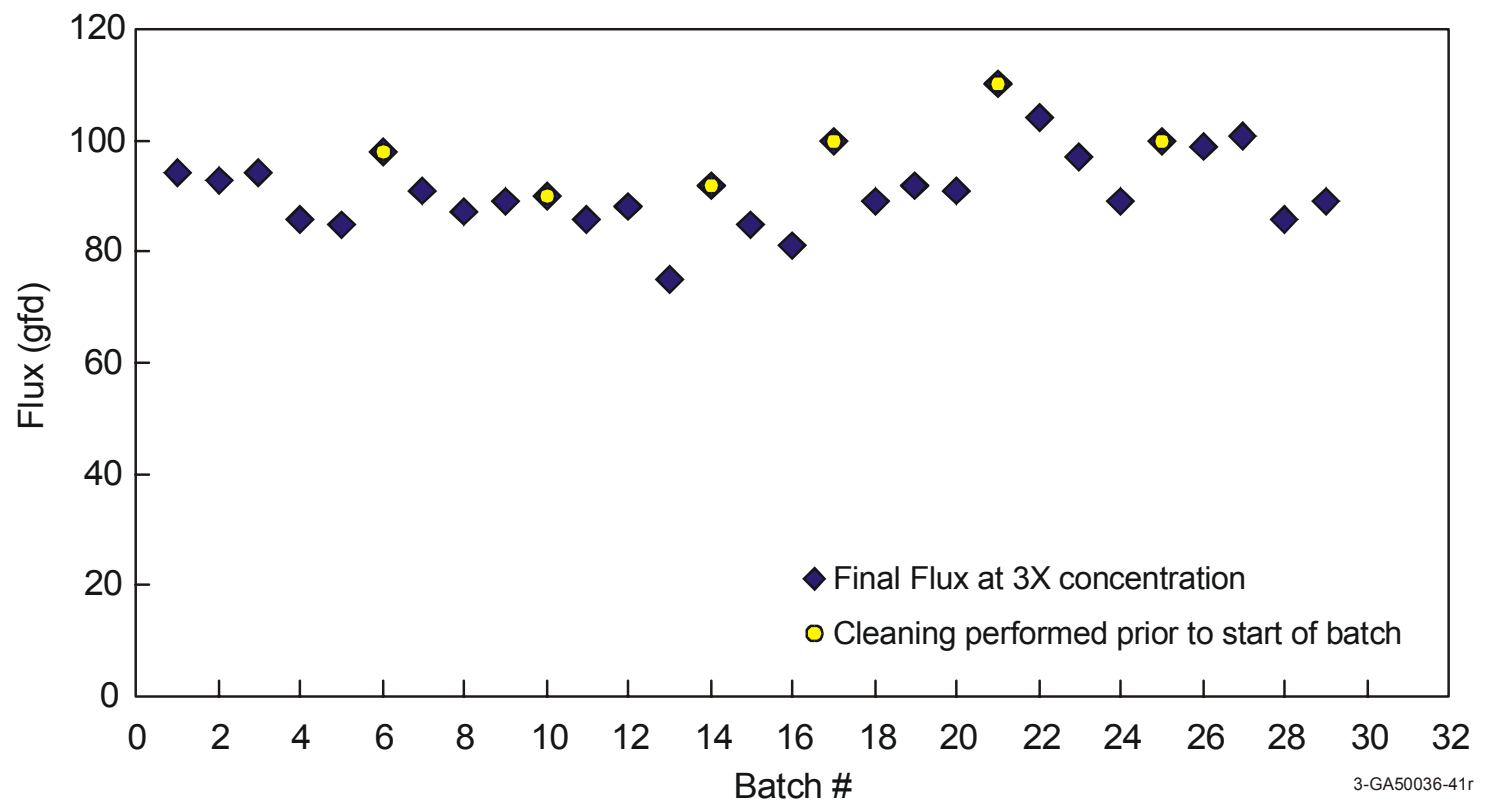

Figure 17. Performance plot for rotary filter of flux versus time during the dewatering of the die lube solution.

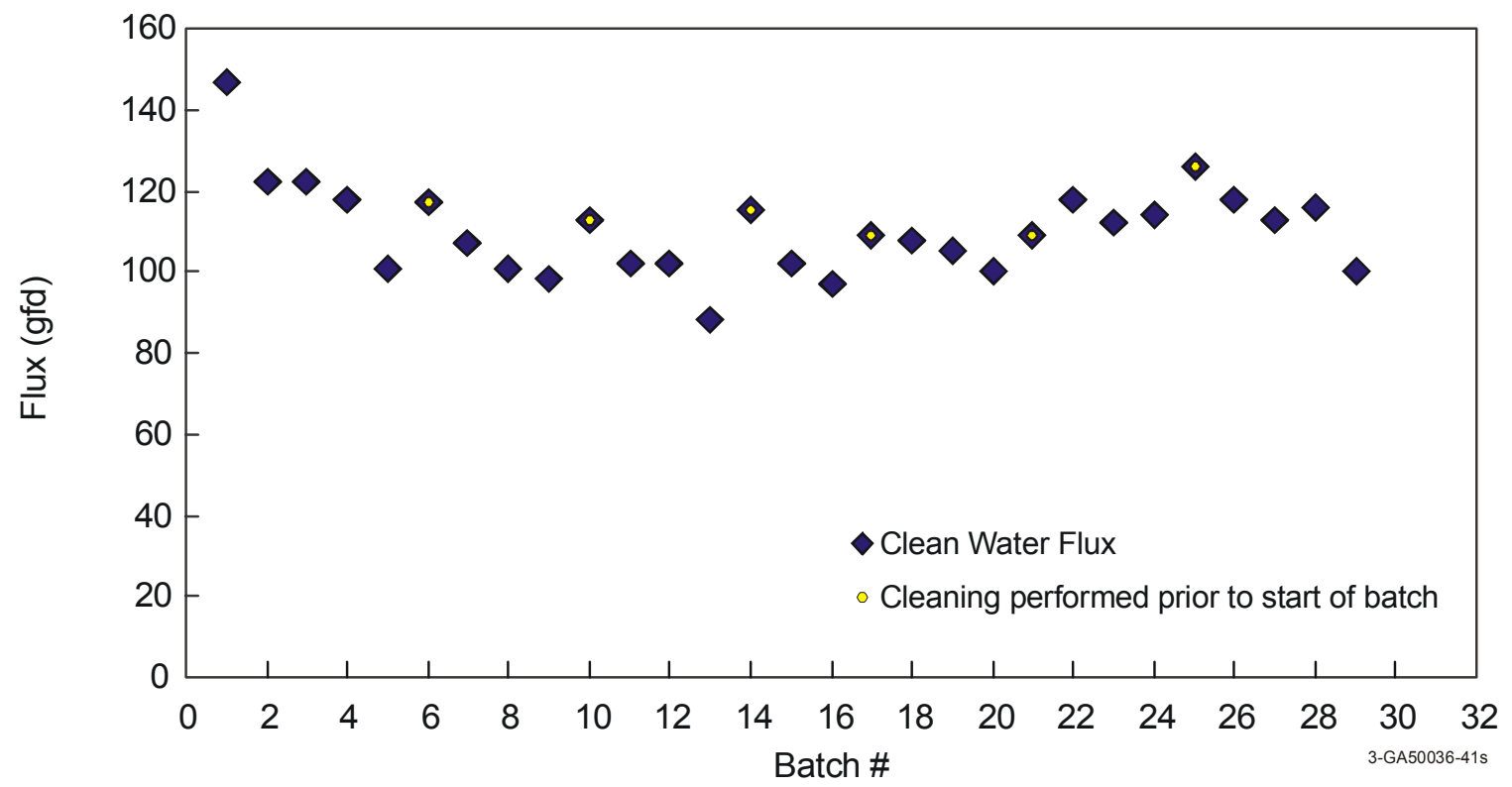

Figure 18. Performance plot for rotary filter during washing (diafiltration). 


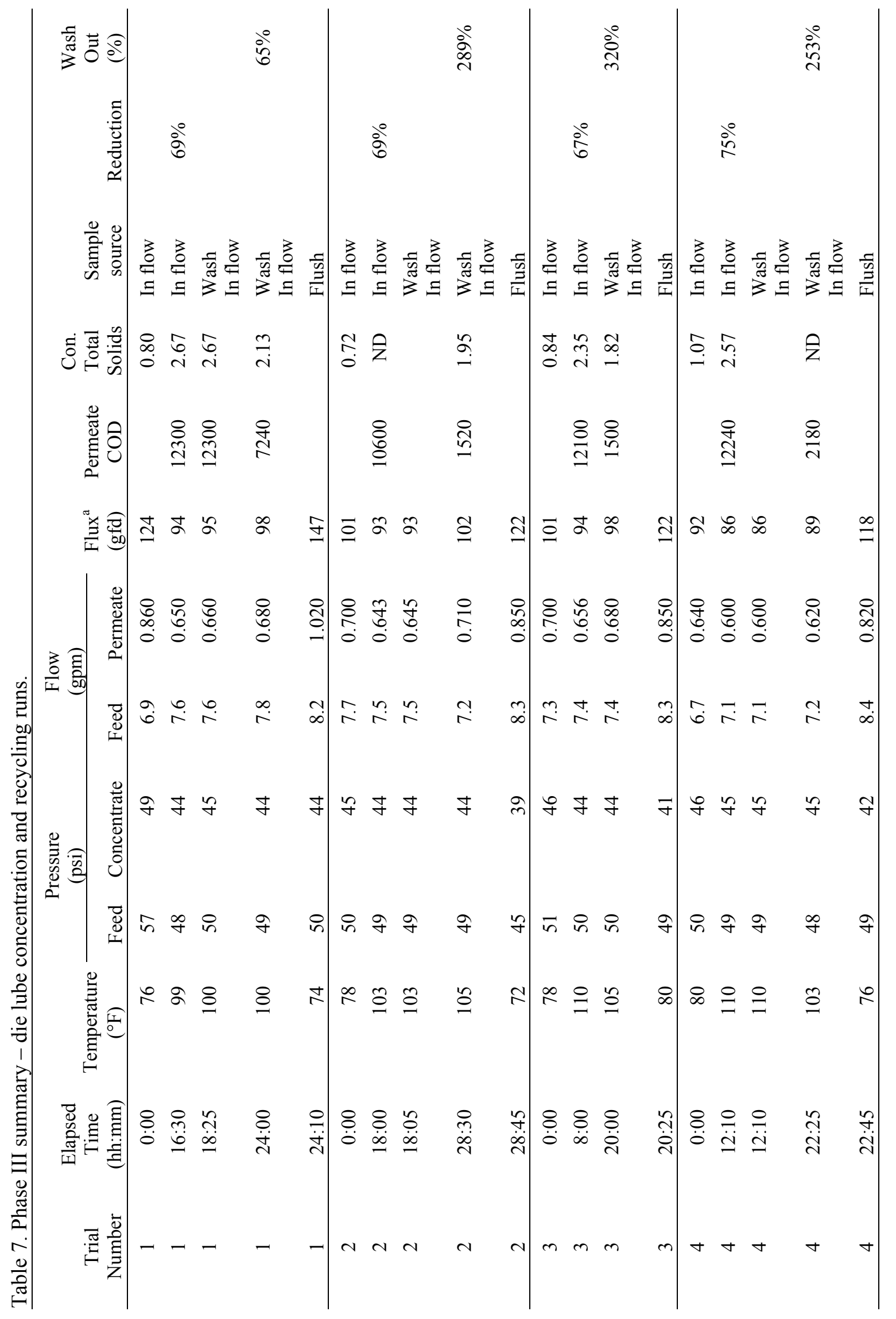




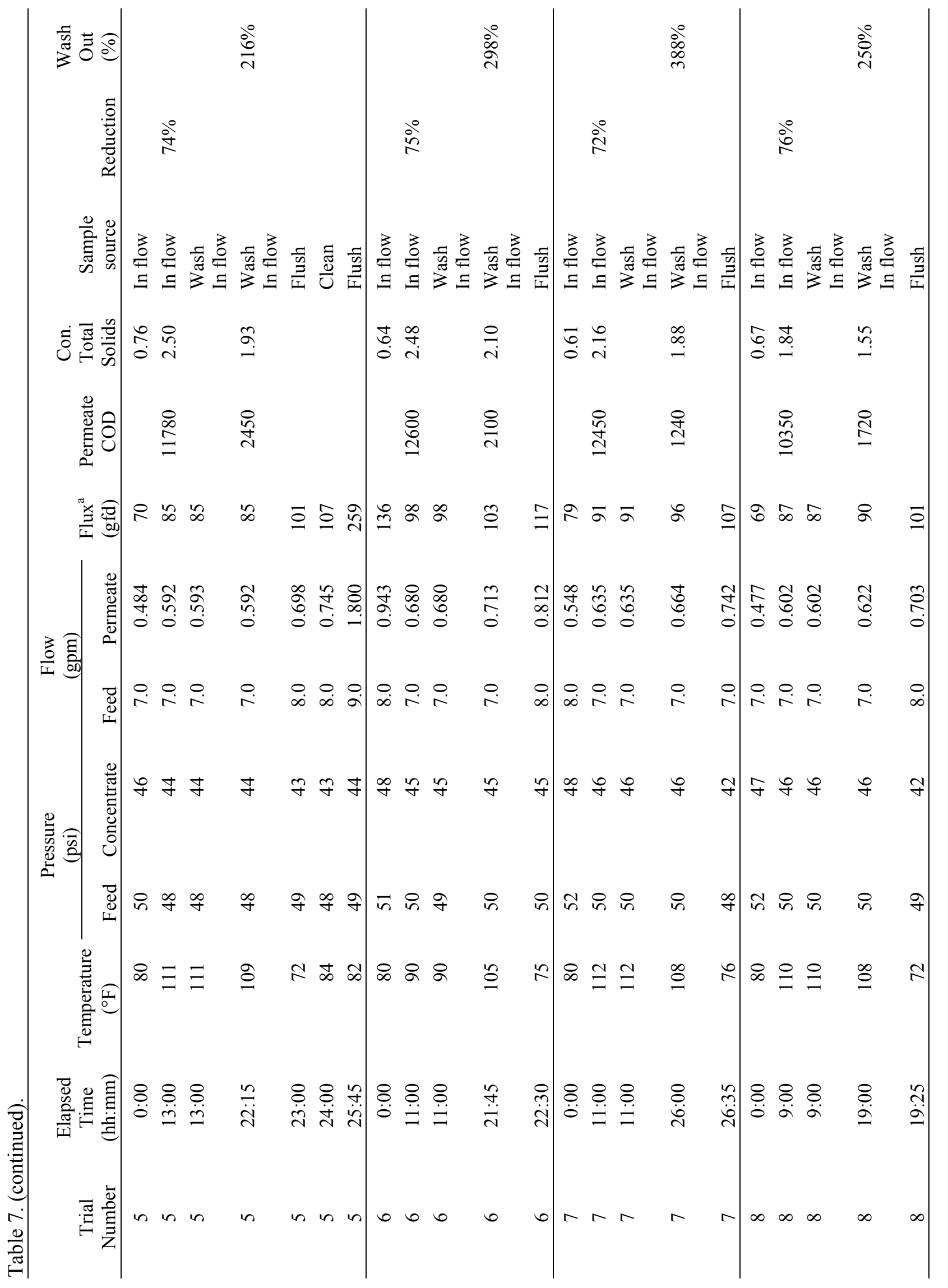




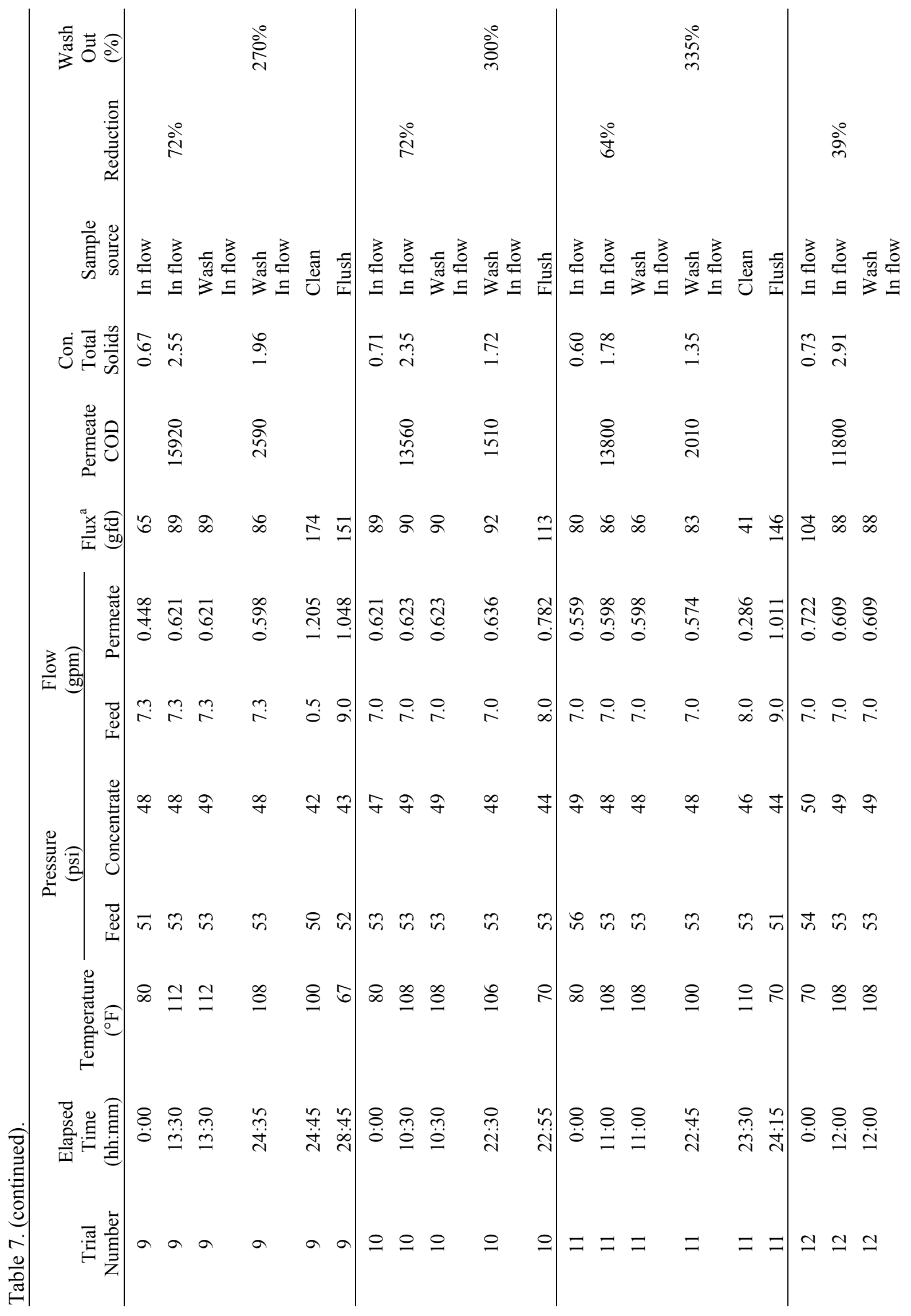




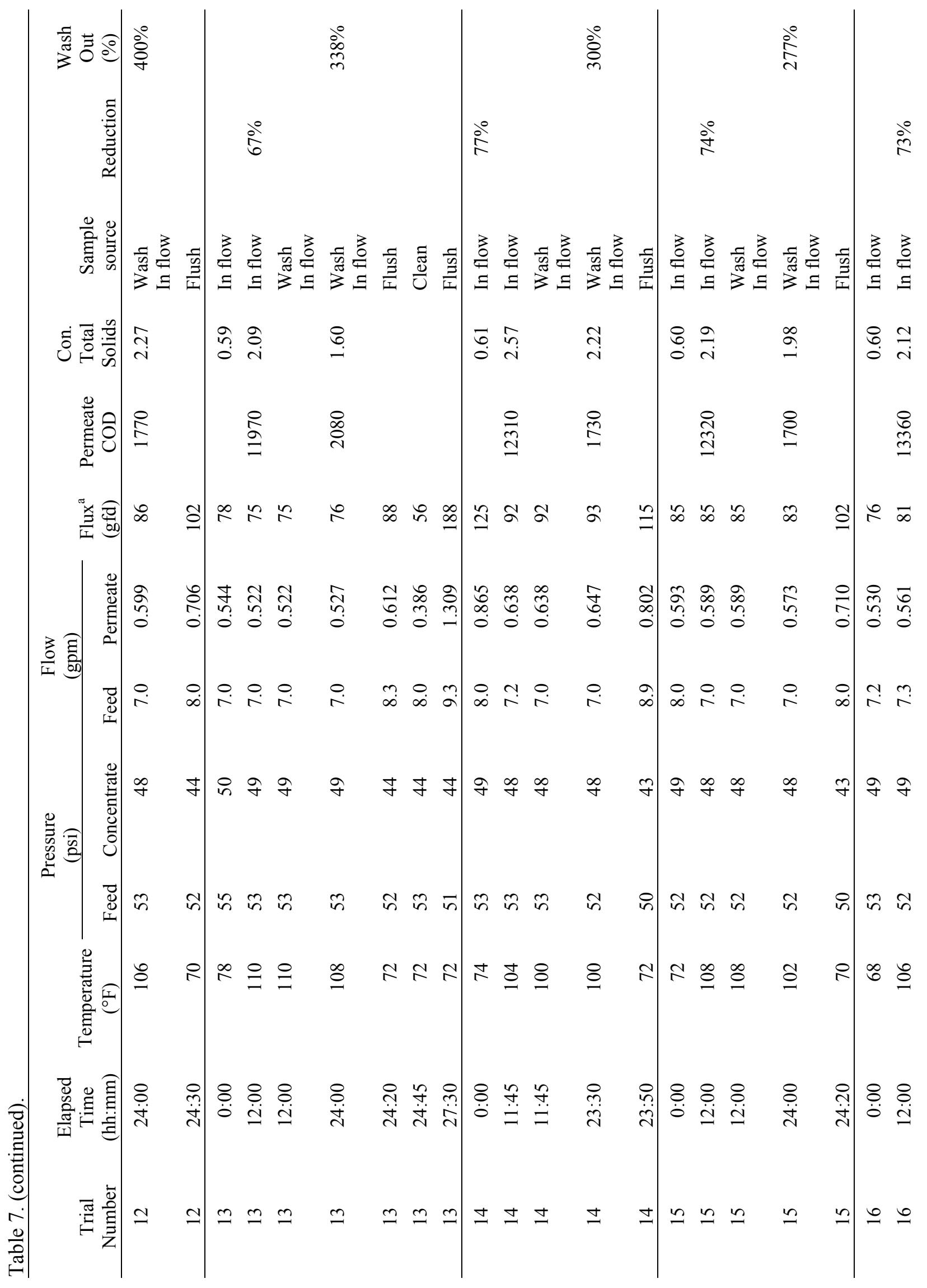




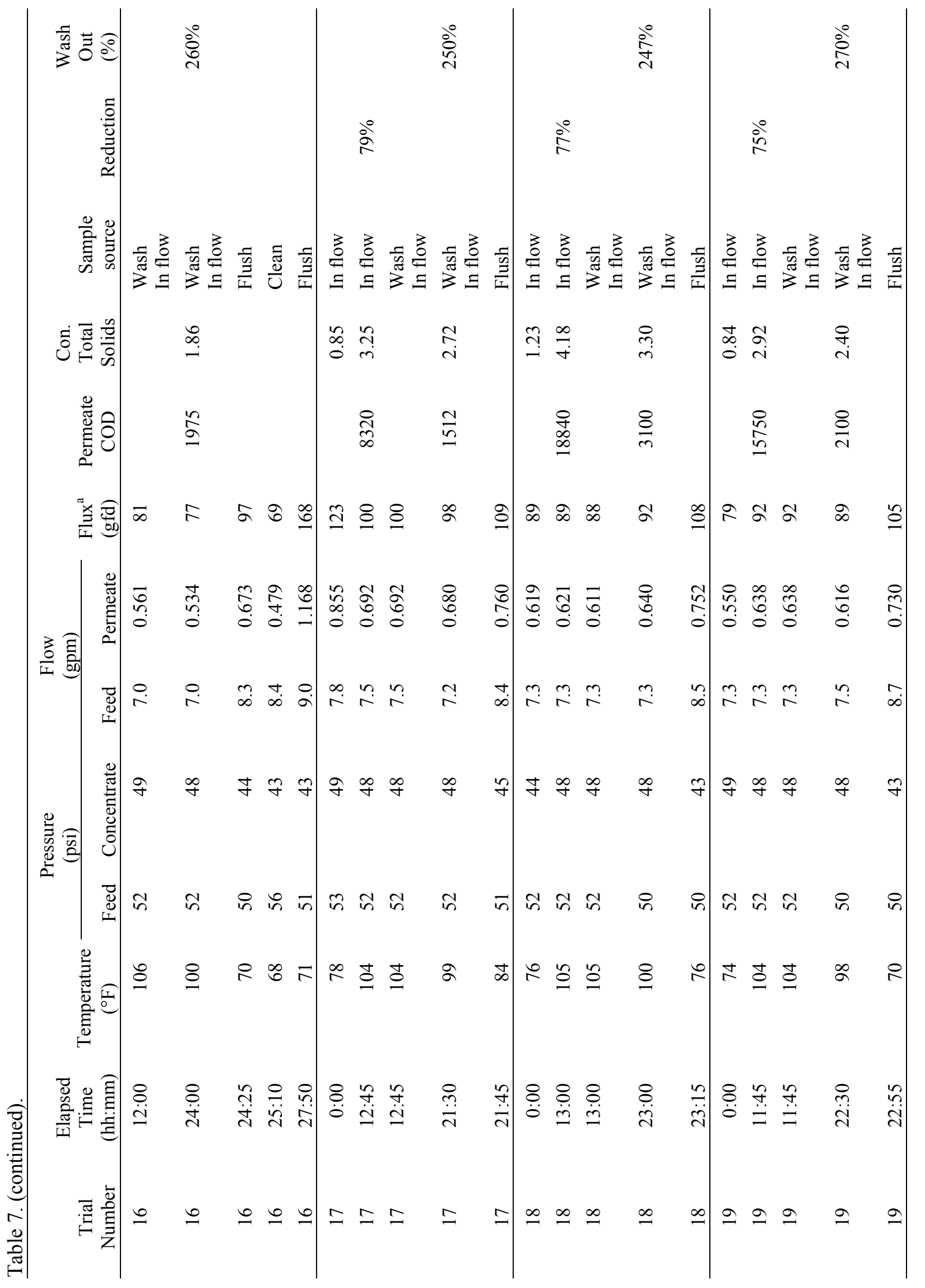




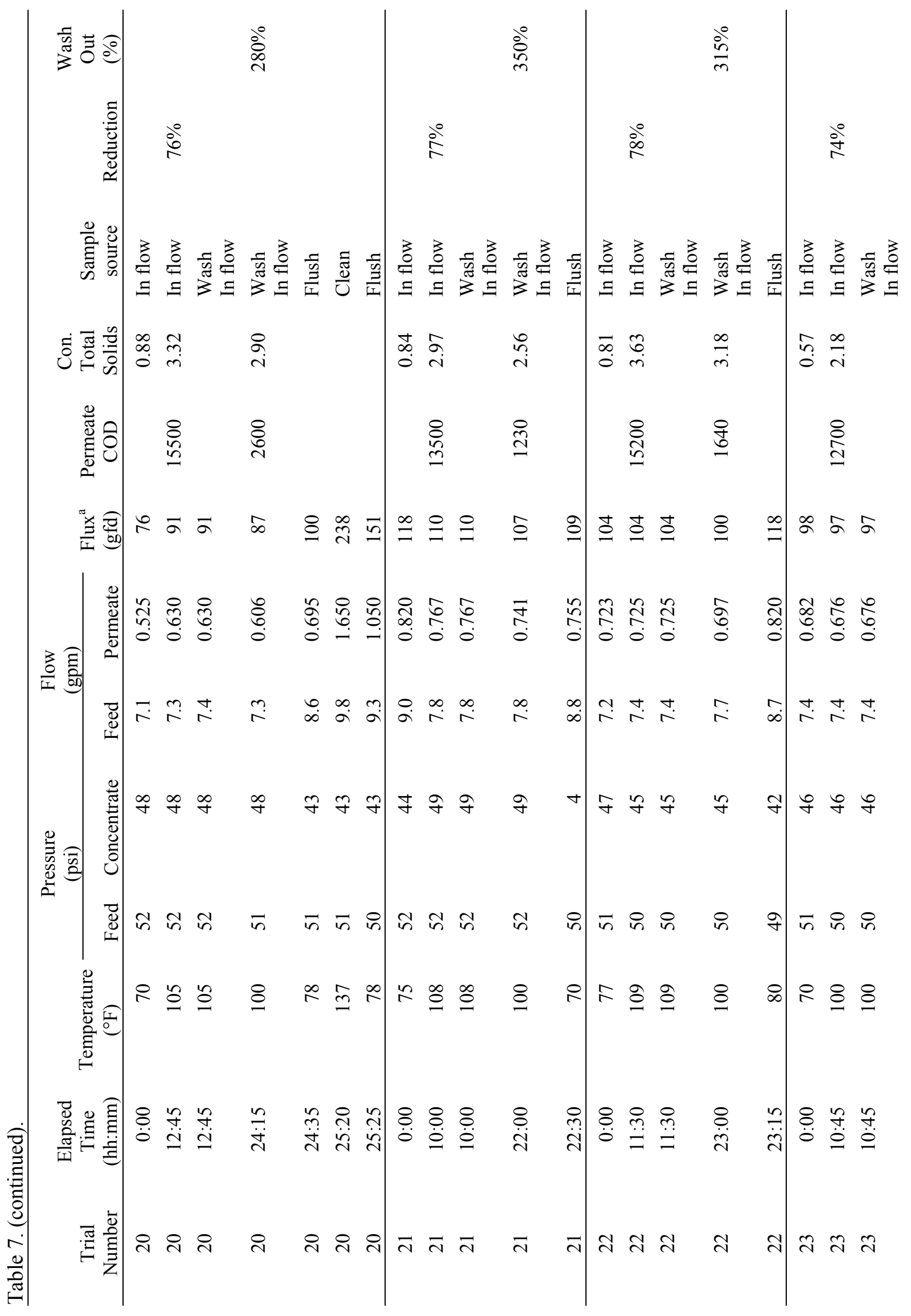




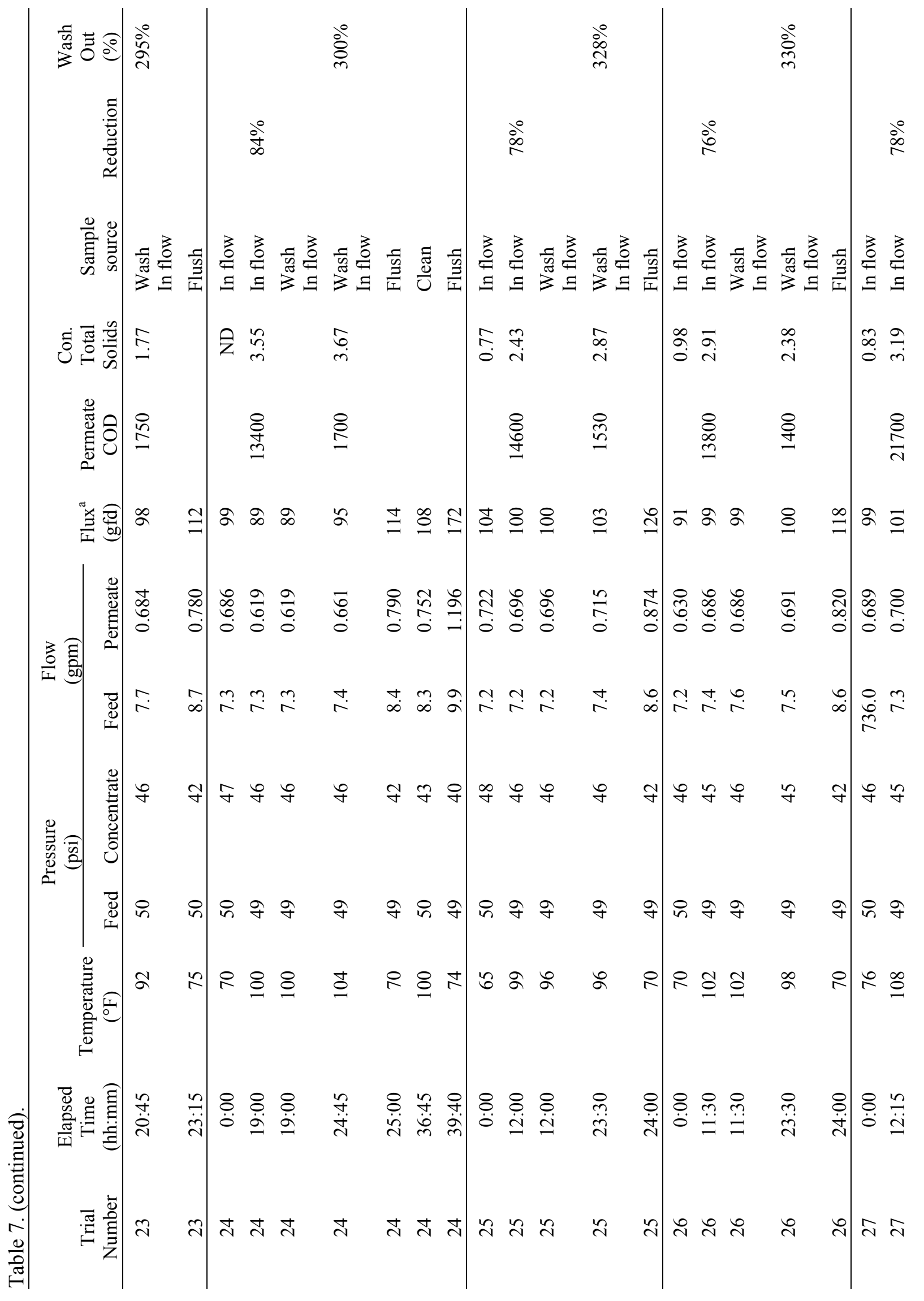




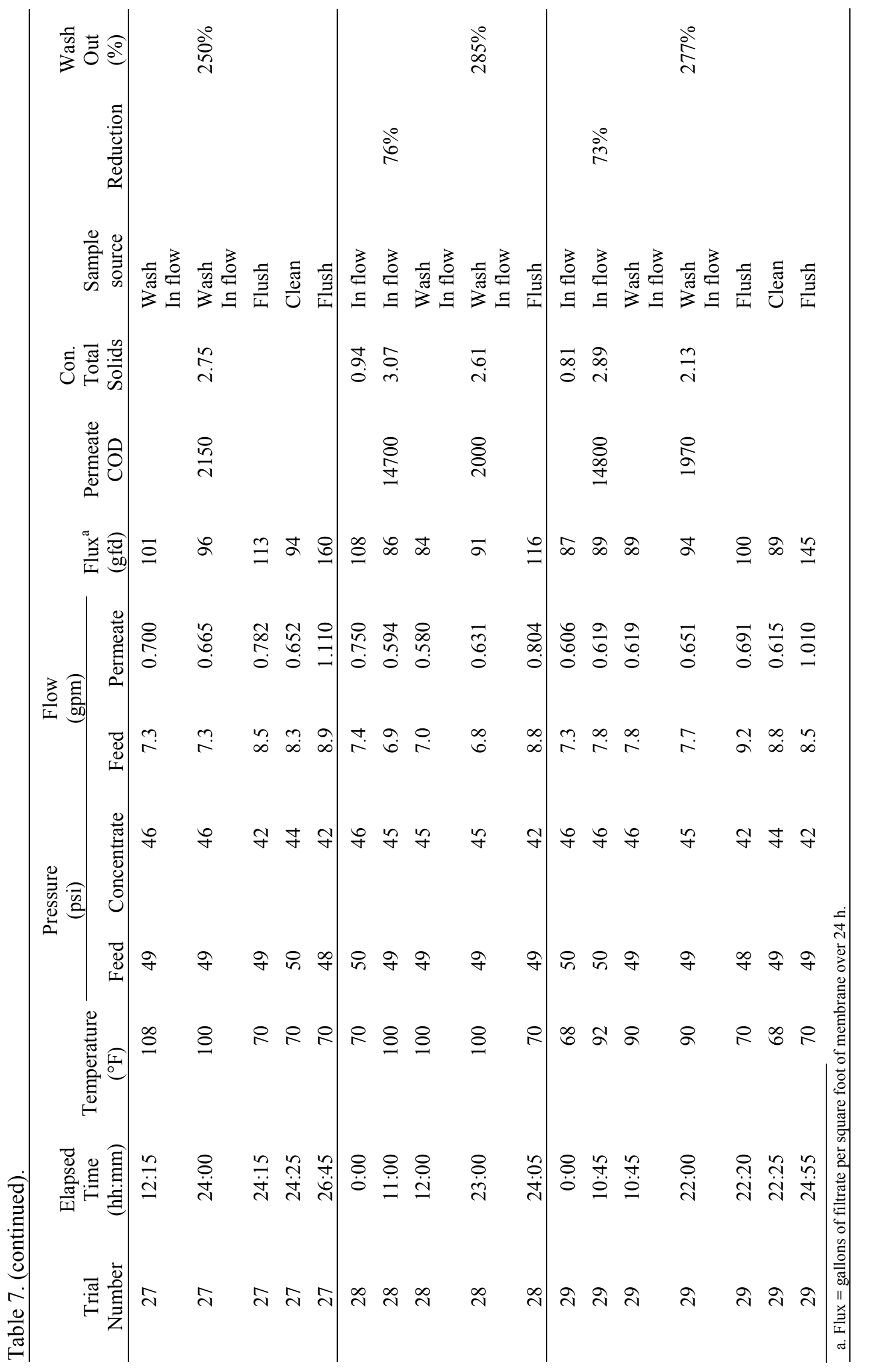




\section{Recycling Run \#2}

The flux for the die lube wastewater feed solution was initially $101 \mathrm{gfd}$ and declined to $93 \mathrm{gfd}$ at the completion of the concentration operation, when the die lube feed was concentrated by $69 \%$. The die lube feed was then washed with a volume of soft water equal to $107 \%$ of the total concentrated feed volume. During washing, the membrane flux was stable at $93 \mathrm{gfd}$. The COD of the die lube wastewater feed, initially $10,600 \mathrm{mg} / \mathrm{L}$, was reduced to $3,900 \mathrm{mg} / \mathrm{L}$. The die lube wastewater feed was washed with water by an additional $189 \%$ and the flux increased from 93 to $102 \mathrm{gfd}$. The COD of the rewashed die lube wastewater feed was further reduced from 3,900 mg/L to $1,520 \mathrm{mg} / \mathrm{L}$. Upon completion of the experiment, the membranes were flushed with water; the flux was $122 \mathrm{gfd}$.

\section{Recycling Run \#3}

The flux for the die lube wastewater feed solution was initially $101 \mathrm{gfd}$ and declined to $94 \mathrm{gfd}$ at the completion of the concentration operation, when the die lube feed was concentrated by $67 \%$. The die lube wastewater feed was then washed with a volume of soft water equal to $320 \%$ of the total concentrated feed volume. During washing, the membrane flux increased from 94 to $98 \mathrm{gfd}$. The COD of the die lube wastewater feed, initially $12,100 \mathrm{mg} / \mathrm{L}$, was reduced to $1,500 \mathrm{mg} / \mathrm{L}$. Upon completion of the experiment, the membranes were flushed with water; the flux returned to $122 \mathrm{gfd}$.

\section{Recycling Run \#4}

The flux for the die lube wastewater feed solution was initially 92 gfd and declined to 86 gfd at completion of the concentration operation, when the die lube feed was concentrated by $75 \%$. The die lube wastewater feed was then washed with a volume of soft water equal to $253 \%$ of the total concentrated feed volume. During washing, the membrane flux increased from 86 to $89 \mathrm{gfd}$. The COD of the die lube wastewater feed, initially $12,240 \mathrm{mg} / \mathrm{L}$, was reduced to $2,180 \mathrm{mg} / \mathrm{L}$. Upon completion of the experiment, the membranes were flushed with water; the flux was $118 \mathrm{gfd}$.

\section{Recycling Run \#5}

The flux for the die lube wastewater feed solution was initially 70 gfd and increased to 85 gfd at completion of the concentration operation, when the die lube feed was concentrated by $74 \%$. The die lube wastewater feed was then washed with a volume of soft water equal to $216 \%$ of the total concentrated feed volume. During washing, the membrane flux increased from 85 to $88 \mathrm{gfd}$. The COD of the die lube wastewater feed, initially $11,780 \mathrm{mg} / \mathrm{L}$, was reduced to $2,450 \mathrm{mg} / \mathrm{L}$. Upon completion of the experiment, the membranes were flushed with water; the flux was $101 \mathrm{gfd}$. The system was then cleaned with MC-4 at a $\mathrm{pH}$ of $11,150^{\circ} \mathrm{F}$, dissolved in water. After cleaning, the flux of clean water increased to $259 \mathrm{gfd}$.

\section{Recycling Run \#6}

The flux for the die lube wastewater feed solution was initially $136 \mathrm{gfd}$ and decreased to $98 \mathrm{gfd}$ at completion of the concentration operation, when the die lube feed was concentrated by $75 \%$. The die lube wastewater feed was then washed with a volume of soft water equal to $298 \%$ of the total concentrated feed volume. During washing, the membrane flux increased from 98 to $103 \mathrm{gfd}$. The COD of the die lube wastewater feed, initially $12,600 \mathrm{mg} / \mathrm{L}$, was reduced to $2,100 \mathrm{mg} / \mathrm{L}$. Upon completion of the experiment, the membranes were flushed with water; the flux was $117 \mathrm{gfd}$. 


\section{Recycling Run \#7}

The flux for the die lube wastewater feed solution was initially 79 gfd and increased to 91 gfd at completion of the concentration operation, when the die lube feed was concentrated by $73 \%$. The die lube wastewater feed was then washed with a volume of soft water equal to $388 \%$ of the total concentrated feed volume. During washing, the membrane flux increased from 91 to 96 gfd. The COD of the die lube wastewater feed, initially $12,450 \mathrm{mg} / \mathrm{L}$, was reduced to $1,240 \mathrm{mg} / \mathrm{L}$. Upon completion of the experiment, the membranes were flushed with water; the flux was $107 \mathrm{gfd}$.

\section{Recycling Run \#8}

The flux for the die lube wastewater feed solution was initially 69 gfd and increased to 87 gfd at completion of the concentration operation, when the die lube feed was concentrated by $76 \%$. The die lube wastewater feed was then washed with a volume of soft water equal to $250 \%$ of the total concentrated feed volume. During washing, the membrane flux increased from 87 to $90 \mathrm{gfd}$. The COD of the die lube wastewater feed, initially $10,350 \mathrm{mg} / \mathrm{L}$, was reduced to $1,720 \mathrm{mg} / \mathrm{L}$. Upon completion of the experiment, the membranes were flushed with water; the flux was $101 \mathrm{gfd}$.

\section{Recycling Run \#9}

The flux for the die lube wastewater feed solution was initially 65 gfd and increased to 89 gfd at completion of the concentration operation, when the die lube feed was concentrated by $72 \%$. The die lube wastewater feed was then washed with a volume of soft water equal to $270 \%$ of the total concentrated feed volume. During washing, the membrane flux decreased from 89 to $86 \mathrm{gfd}$. The COD of the die lube wastewater feed, initially $15,920 \mathrm{mg} / \mathrm{L}$, was reduced to $2,590 \mathrm{mg} / \mathrm{L}$. The membranes were cleaned with MC-4 at a $\mathrm{pH}$ of $11,150^{\circ} \mathrm{F}$, dissolved in water. After cleaning, the flux of clean water increased to 151 gfd.

\section{Recycling Run \#10}

The flux for the die lube wastewater feed solution was initially 89 gfd and increased to 90 gfd at completion of the concentration operation, when the die lube feed was concentrated by $72 \%$. The die lube wastewater feed was then washed with a volume of soft water equal to $300 \%$ of the total concentrated feed volume. During washing, the membrane flux increased from 90 to $92 \mathrm{gfd}$. The COD of the die lube wastewater feed, initially $13,560 \mathrm{mg} / \mathrm{L}$, was reduced to $1,510 \mathrm{mg} / \mathrm{L}$. Upon completion of the experiment, the membranes were flushed with water; the flux was $113 \mathrm{gfd}$.

\section{Recycling Run \#11}

The flux for the die lube wastewater feed solution was initially 80 gfd and increased to 86 gfd at completion of the concentration operation, when the die lube feed was concentrated by $64 \%$. The die lube wastewater feed was then washed with a volume of soft water equal to $335 \%$ of the total concentrated feed volume. During washing, the membrane flux decreased from 86 to $83 \mathrm{gfd}$. The COD of the die lube wastewater feed, initially $13,800 \mathrm{mg} / \mathrm{L}$, was reduced to $2,010 \mathrm{mg} / \mathrm{L}$. The membranes were cleaned with MC-4 at a $\mathrm{pH}$ of $11,150^{\circ} \mathrm{F}$, dissolved in water. After cleaning, the flux of clean water increased to 146 gfd.

\section{Recycling Run \#12}

The flux for the die lube wastewater feed solution was initially 104 gfd and decreased to 88 gfd at completion of the concentration operation, when the die lube feed was concentrated by $67 \%$. The die lube 
wastewater feed was then washed with a volume of soft water equal to $400 \%$ of the total concentrated feed volume. During washing, the membrane flux decreased from 88 to $86 \mathrm{gfd}$. The COD of the die lube wastewater feed, initially $11,800 \mathrm{mg} / \mathrm{L}$, was reduced to $1,770 \mathrm{mg} / \mathrm{L}$. After washing was complete, the membranes were flushed with water; the flux was $102 \mathrm{gfd}$.

\section{Recycling Run \#13}

The flux for the die lube wastewater feed solution was initially $78 \mathrm{gfd}$ and decreased to $75 \mathrm{gfd}$ at completion of the concentration operation, when the die lube feed was concentrated by $67 \%$. The die lube wastewater feed was then washed with a volume of soft water equal to $338 \%$ of the total concentrated feed volume. During washing, the membrane flux increased from 75 to $76 \mathrm{gfd}$. The COD of the die lube wastewater feed, initially $11,970 \mathrm{mg} / \mathrm{L}$, was reduced to $2,080 \mathrm{mg} / \mathrm{L}$. The system was then cleaned with MC-4 at a $\mathrm{pH}$ of $11,150^{\circ} \mathrm{F}$, dissolved in water. After cleaning, the flux of clean water increased to $188 \mathrm{gfd}$.

\section{Recycling Run \#14}

The flux for the die lube wastewater feed solution was initially 125 gfd and decreased to 92 gfd at completion of the concentration operation, when the die lube feed was concentrated by $77 \%$. The die lube wastewater feed was then washed with a volume of soft water equal to $300 \%$ of the total concentrated feed volume. During washing, the membrane flux increased from 92 to $93 \mathrm{gfd}$. The COD of the die lube wastewater feed, initially $12,310 \mathrm{mg} / \mathrm{L}$, was reduced to $1,730 \mathrm{mg} / \mathrm{L}$. Upon completion of the experiment, the membranes were flushed with water; the flux was $115 \mathrm{gfd}$.

\section{Recycling Run \#15}

The flux for the die lube wastewater feed solution was $85 \mathrm{gfd}$ at the start and completion of the concentration operation, when the die lube feed was concentrated by $74 \%$. The die lube wastewater feed was then washed with a volume of soft water equal to $277 \%$ of the total concentrated feed volume. During washing, the membrane flux decreased from 85 to $83 \mathrm{gfd}$. The COD of the die lube wastewater feed, initially $12,320 \mathrm{mg} / \mathrm{L}$, was reduced to $1,700 \mathrm{mg} / \mathrm{L}$. Upon completion of the experiment, the membranes were flushed with water; the flux was $102 \mathrm{gfd}$.

\section{Recycling Run \#16}

The flux for the die lube wastewater feed solution was initially 76 gfd and increased to 81 gfd at completion of the concentration operation, when the die lube feed was concentrated by $73 \%$. The die lube wastewater feed was then washed with a volume of soft water equal to $260 \%$ of the total concentrated feed volume. During washing, the membrane flux decreased from 81 to $77 \mathrm{gfd}$. The COD of the die lube wastewater feed, initially $13,360 \mathrm{mg} / \mathrm{L}$, was reduced to $1,975 \mathrm{mg} / \mathrm{L}$. The system was then cleaned with MC-4 at a $\mathrm{pH}$ of $11,150^{\circ} \mathrm{F}$, dissolved in water. After cleaning, the flux of clean water increased to 168 gfd.

\section{Recycling Run \#17}

The flux for the die lube wastewater feed solution was initially $123 \mathrm{gfd}$ and decreased to $100 \mathrm{gfd}$ at completion of the concentration operation, when the die lube feed was concentrated by $79 \%$. The die lube wastewater feed was then washed with a volume of soft water equal to $250 \%$ of the total concentrated feed volume. During washing, the membrane flux increased from 82 to $83 \mathrm{gfd}$. The COD of the die lube wastewater feed, initially $8320 \mathrm{mg} / \mathrm{L}$, was reduced to $1,512 \mathrm{mg} / \mathrm{L}$. Upon completion of the experiment, the membranes were flushed with water; the flux was $109 \mathrm{gfd}$. 


\section{Recycling Run \#18}

The flux for the die lube wastewater feed solution was $89 \mathrm{gfd}$ at the start and completion of the concentration operation, when the die lube feed was concentrated by $77 \%$. The die lube wastewater feed was then washed with a volume of soft water equal to $274 \%$ of the total concentrated feed volume. During washing, the membrane flux increased from 88 to $92 \mathrm{gfd}$. The COD of the die lube wastewater feed, initially $18,840 \mathrm{mg} / \mathrm{L}$, was reduced to $3,100 \mathrm{mg} / \mathrm{L}$. Upon completion of the experiment, the membranes were flushed with water; the flux was 108 gfd.

\section{Recycling Run \#19}

The flux for the die lube wastewater feed solution was initially 79 gfd and increased to 92 gfd at completion of the concentration operation, when the die lube feed was concentrated by $75 \%$. The die lube wastewater feed was then washed with a volume of soft water equal to $270 \%$ of the total concentrated feed volume. During washing, the membrane flux decreased from 92 to $89 \mathrm{gfd}$. The COD of the die lube wastewater feed, initially $15,750 \mathrm{mg} / \mathrm{L}$, was reduced to $2,100 \mathrm{mg} / \mathrm{L}$. Upon completion of the experiment, the membranes were flushed with water; the flux was $105 \mathrm{gfd}$.

\section{Recycling Run \#20}

The flux for the die lube wastewater feed solution was initially 76 gfd and increased to $91 \mathrm{gfd}$ at completion of the concentration operation, when the die lube feed was concentrated by $76 \%$. The die lube wastewater feed was then washed with a volume of soft water equal to $280 \%$ of the total concentrated feed volume. During washing, the membrane flux decreased from 91 to $87 \mathrm{gfd}$. The COD of the die lube wastewater feed, initially $15,500 \mathrm{mg} / \mathrm{L}$, was reduced to $2,600 \mathrm{mg} / \mathrm{L}$. The system was then cleaned with MC-4 at a $\mathrm{pH}$ of $11,150^{\circ} \mathrm{F}$, dissolved in water. After cleaning, the flux of clean water increased to $238 \mathrm{gfd}$, with the final flush clean water flux of $151 \mathrm{gfd}$.

\section{Recycling Run \#21}

The flux for the die lube wastewater feed solution was initially $118 \mathrm{gfd}$ and decreased to $110 \mathrm{gfd}$ at completion of the concentration operation, when the die lube feed was concentrated by $77 \%$. The die lube wastewater feed was then washed with a volume of soft water equal to $350 \%$ of the total concentrated feed volume. During washing, the membrane flux decreased from 110 to $107 \mathrm{gfd}$. The COD of the die lube wastewater feed, initially $13,500 \mathrm{mg} / \mathrm{L}$, was reduced to $1,230 \mathrm{mg} / \mathrm{L}$. Upon completion of the experiment, the membranes were flushed with water; the flux was $109 \mathrm{gfd}$.

\section{Recycling Run \#22}

The flux for the die lube wastewater feed solution was $104 \mathrm{gfd}$ at the start and completion of the concentration operation, when the die lube feed was concentrated by $78 \%$. The die lube wastewater feed was then washed with a volume of soft water equal to $315 \%$ of the total concentrated feed volume. During washing, the membrane flux decreased from 104 to $100 \mathrm{gfd}$. The COD of the die lube wastewater feed, initially $15,200 \mathrm{mg} / \mathrm{L}$, was reduced to $1,640 \mathrm{mg} / \mathrm{L}$. Upon completion of the experiment, the membranes were flushed with water; the flux was $118 \mathrm{gfd}$.

\section{Recycling Run \#23}

The flux for the die lube wastewater feed solution was initially 98 gfd and increased to $97 \mathrm{gfd}$ at completion of the concentration operation, when the die lube feed was concentrated by $74 \%$. The die lube wastewater feed was then washed with a volume of soft water equal to $295 \%$ of the total concentrated 
feed volume. During washing, the membrane flux increased from 97 to 98 gfd. The COD of the die lube wastewater feed, initially $12,700 \mathrm{mg} / \mathrm{L}$, was reduced to $1,750 \mathrm{mg} / \mathrm{L}$. Upon completion of the experiment, the membranes were flushed with water; the flux was $112 \mathrm{gfd}$.

\section{Recycling Run \#24}

The flux for the die lube wastewater feed solution was initially 99 gfd and decreased to 89 gfd at completion of the concentration operation, when the die lube feed was concentrated by $83 \%$. The die lube wastewater feed was then washed with a volume of soft water equal to $300 \%$ of the total concentrated feed volume. During washing, the membrane flux increased from 89 to $95 \mathrm{gfd}$. The COD of the die lube wastewater feed, initially $13,400 \mathrm{mg} / \mathrm{L}$, was reduced to $1,700 \mathrm{mg} / \mathrm{L}$. The system was then cleaned with $\mathrm{MC}-4$ at a $\mathrm{pH}$ of $11,150^{\circ} \mathrm{F}$ dissolved in water. After cleaning, the flux of clean water increased to 172 gfd.

\section{Recycling Run \#25}

The flux for the die lube wastewater feed solution was initially $104 \mathrm{gfd}$ and decreased to $100 \mathrm{gfd}$ at completion of the concentration operation, when the die lube feed was concentrated by $77 \%$. The die lube wastewater feed was then washed with a volume of soft water equal to $328 \%$ of the total concentrated feed volume. During washing, the membrane flux decreased from 100 to $103 \mathrm{gfd}$. The COD of the die lube wastewater feed, initially $14,600 \mathrm{mg} / \mathrm{L}$, was reduced to $1,530 \mathrm{mg} / \mathrm{L}$. Upon completion of the experiment, the membranes were flushed with water; the flux was 126 gfd.

\section{Recycling Run \#26}

The flux for the die lube wastewater feed solution was initially 91 gfd and increased to 99 gfd at completion of the concentration operation, when the die lube feed was concentrated by $76 \%$. The die lube wastewater feed was then washed with a volume of soft water equal to $330 \%$ of the total concentrated feed volume. During washing, the membrane flux increased from 99 to $100 \mathrm{gfd}$. The COD of the die lube wastewater feed, initially $13,800 \mathrm{mg} / \mathrm{L}$, was reduced to $1,400 \mathrm{mg} / \mathrm{L}$. Upon completion of the experiment, the membranes were flushed with water; the flux was $118 \mathrm{gfd}$.

\section{Recycling Run \#27}

The flux for the die lube wastewater feed solution was initially $99 \mathrm{gfd}$ and increased to $101 \mathrm{gfd}$ at completion of the concentration operation, when the die lube feed was concentrated by $77 \%$. The die lube wastewater feed was then washed with a volume of soft water equal to $250 \%$ of the total concentrated feed volume. During washing, the membrane flux decreased from 101 to $96 \mathrm{gfd}$. The COD of the die lube wastewater feed, initially $21,700 \mathrm{mg} / \mathrm{L}$, was reduced to $2,150 \mathrm{mg} / \mathrm{L}$. The membranes were cleaned after this recycling run because extra time was available, not because of low fluxes. The system was cleaned with MC-4 at a $\mathrm{pH}$ of $11,150^{\circ} \mathrm{F}$, dissolved in water. After cleaning, the flux of clean water increased to 160 gfd.

\section{Recycling Run \#28}

The flux for the die lube wastewater feed solution was initially 108 gfd and decreased to 86 gfd at completion of the concentration operation, when the die lube feed was concentrated by $76 \%$. The die lube wastewater feed was then washed with a volume of soft water equal to $285 \%$ of the total concentrated feed volume. During washing, the membrane flux increased from 84 to $91 \mathrm{gfd}$. The COD of the die lube wastewater feed, initially $14,700 \mathrm{mg} / \mathrm{L}$, was reduced to $2,000 \mathrm{mg} / \mathrm{L}$. Upon completion of the experiment, the membranes were flushed with water; the flux was $116 \mathrm{gfd}$. 


\section{Recycling Run \#29}

The flux for the die lube wastewater feed solution was initially 87 gfd and increased to 89 gfd at completion of the concentration operation, when the die lube feed was concentrated by $73 \%$. The die lube wastewater feed was then washed with a volume of soft water equal to $277 \%$ of the total concentrated feed volume. During washing, the membrane flux increased from 89 to $94 \mathrm{gfd}$. The COD of the die lube wastewater feed, initially $14,800 \mathrm{mg} / \mathrm{L}$, was reduced to $1,970 \mathrm{mg} / \mathrm{L}$. The system was then cleaned with MC-4 at a $\mathrm{pH}$ of $11,150^{\circ} \mathrm{F}$, dissolved in water. After cleaning, the flux of clean water increased to $145 \mathrm{gfd}$.

\subsection{Die Casting with Recycled Die Lube}

A test methodology for reuse of the solids in the casting process was established. A short-term test was performed with good results, so a long-term test was developed. General comments, descriptions, and results of these tests are presented below.

\subsubsection{Plant Operation}

Metaldyne's Twinsburg plant produces aluminum castings for automotive transmissions. It's process is considered best-in-class for cast / trim / ship facilities. Molten ASTM A-380 aluminum is autoladled into the chamber/sleeve at $1,190^{\circ} \mathrm{F}$. Die lubricant, an oil and water emulsion, provides cooling and release. After trim and inspection, automated handling conveyors process parts into a steel grit shot blast machine for final finishing. Final inspection, basket loading, and loading into delivery trucks is sometimes accomplished in one hour.

The die lube is purchased in a concentrate and diluted to suit the process needs. Sixty to seventy ounces of lubricant are sprayed onto the dies per casting cycle (Figure 19). This lubricant is mixed / atomized with 100 psi air and delivered to specified die locations through nozzles located on the manifold (see Figure 20).

The plant's drainage system is designed to accept all liquids from the foundry operations. While the primary waste generated from the casting process is die lubricant, other ingredients enter into the plant piping. Items such as detergents from washing operations, various way oils, greases, and glycol used to maintain the casting machinery are drained into the plant's water treatment system. Also some "process cooling" water and cooling tower bleed are piped into the treatment system.

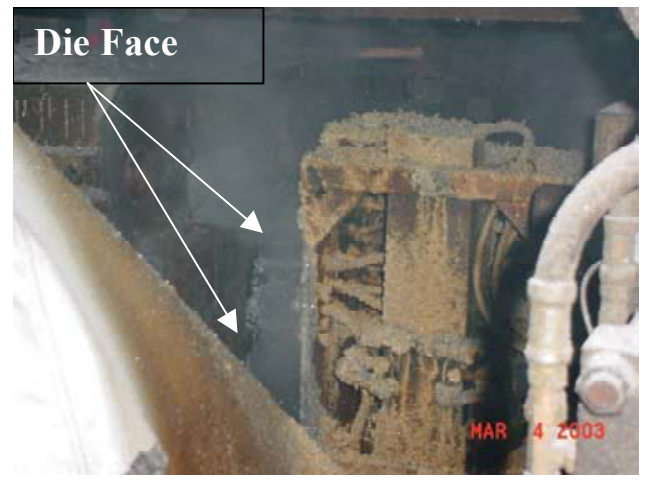

Figure 19. Die face where lube is applied.

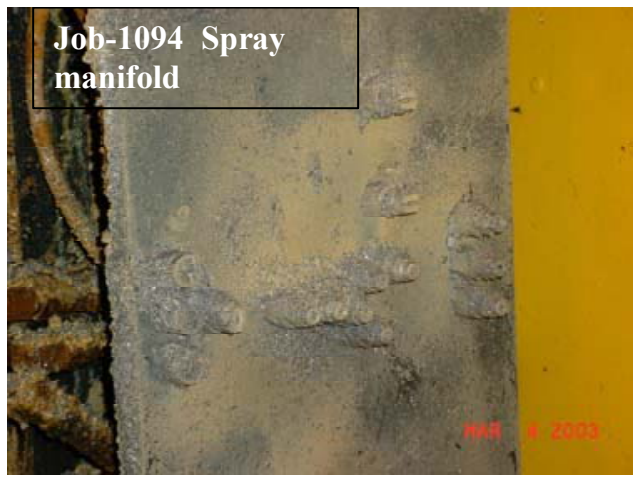

Figure 20. Spray manifold for applying die lube. 


\subsubsection{Test Procedure}

For this test, the water from the casting operation was isolated using several tanks, mechanical interconnections, and control valves. The first treatment step was to remove free oils and greases using rope skimmers and dissolved air floatation. Next, the water was run through the Speedy ${ }^{\mathrm{TM}}$ activemembrane rotary microfilter system, which separated the unwanted pollutants and dilution water from the die lubricant. The concentrated die lubricant was re-diluted using total solids as a test measure. This reestablished the concentration of solids to that of the original die lubricant. Where needed, bacteria control was implemented to maintain product integrity. Batches mixed from $50 \%$ recycled lubricant and $50 \%$ new lubricant were delivered to the casting machine each day. Mixing new and recycled lubricant was a conservative approach designed to provide the casting operation's management with some confidence during testing.

The die casting machine used in this test makes aluminum valve-control body castings known as "Job-1094." This casting process for this product exemplifies the most extreme demands on the die lubricant. In this process, die cooling, mold release characteristics, and resistance to metal adhesion (or soldering) are most critical, in comparison to various other aluminum castings.

The Job-1094 casting, shown in Figure 21 and further described in Table 8, is roughly 10.5 in. square. It is predominantly 1.25 in. thick, with one large feature shown in the lower left of Figure 21a that has a thickness of $2.25 \mathrm{in}$. Because of the features and details of this part, the projected surface area of the casting and related tool steel is great in comparison to the simple square area of this part. The picture on the right is the most extreme example of this. As a result, tool release, metal adhesion, and high temperature soldering are critical challenges.

\subsubsection{Casting Results}

Test data and quality records indicate that the scrap was reduced from $8.4 \%$ to $7.8 \%$. No statistical analysis has been conducted to evaluate the significance of this change.

A slight increase in tooling (measured in cost per unit of production) was observed. This was influenced significantly by tool breakage that occurred during this test. This has been evaluated and cannot be related to the die lubricant. On September 13, two months into the test, a casting was not lifted cleanly by the extractor robot, it was left on/in the die and the die halves re-closed crushing this piece and related die details. The immediate repairs to the die were completed. Some additional die damage around the "bridge area" was not considered detrimental. Several days later, further deterioration to the bridge area required additional die repairs.

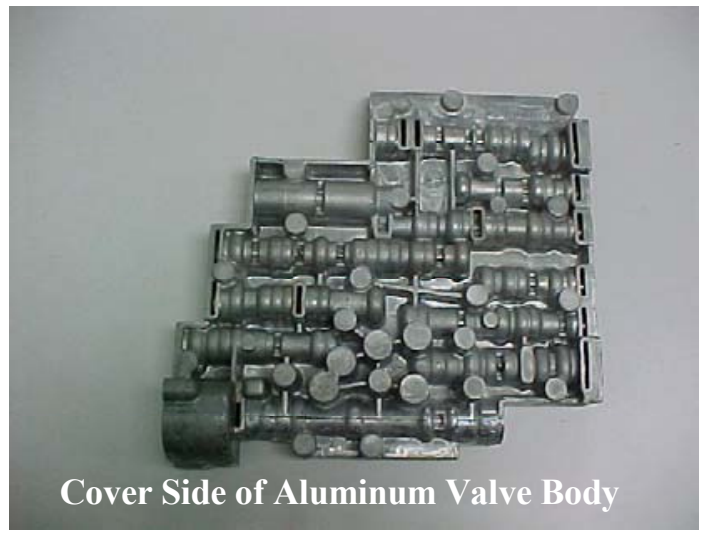

a.

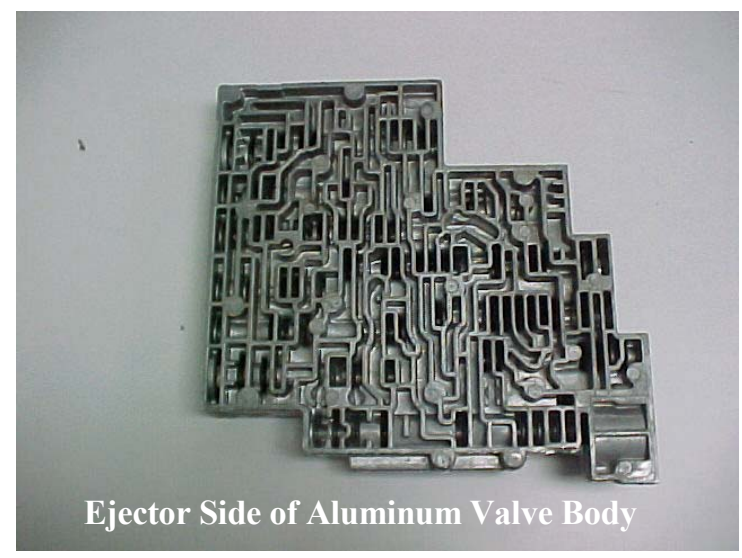

b.

Figure 21. Aluminum valve body cast with recycled die lube. 
Table 8. Test Casting Job 1094.

\begin{tabular}{|c|c|}
\hline Test part: & Aluminum Valve-Control body \\
\hline Material: & ASTM, A380 \\
\hline Customer: & General Motors Power Train \\
\hline $\begin{array}{l}\text { General Motors Power } \\
\text { Train Assembly: }\end{array}$ & Part No. 4L60E \\
\hline Poured Weight: & 9.8Lbs \\
\hline Part Weight: & $6.5 \mathrm{Lbs}$ \\
\hline Injection Temp: & $1180-1205^{\circ} \mathrm{F}$ \\
\hline Testing Period: & July 12,2002 to Sept. 23, 2002. \\
\hline \multicolumn{2}{|l|}{ Die Cast Machine No. 11} \\
\hline \multicolumn{2}{|l|}{ Job number 1094} \\
\hline \multicolumn{2}{|c|}{ Cavity \#17 (i.e., Die \#17, consisting of two halves, "Cover" and "Ejector") } \\
\hline
\end{tabular}

\subsubsection{Casting Results}

Test data and quality records indicate that the scrap was reduced from $8.4 \%$ to $7.8 \%$. No statistical analysis has been conducted to evaluate the significance of this change.

A slight increase in tooling (measured in cost per unit of production) was observed. This was influenced significantly by tool breakage that occurred during this test. This has been evaluated and cannot be related to the die lubricant. On September 13, two months into the test, a casting was not lifted cleanly by the extractor robot, it was left on/in the die and the die halves re-closed crushing this piece and related die details. The immediate repairs to the die were completed. Some additional die damage around the "bridge area" was not considered detrimental. Several days later, further deterioration to the bridge area required additional die repairs.

\subsection{Summary of Phase 3 Recycling Tests}

Phase 3 was a continuous six-week test that demonstrated the SpinTek system's ability to concentrate, wash, and recycle the die lube solution at the Metaldyne plant. Die lube was continually concentrated and the COD reduced by a factor of 8 to 10, which is attributed to successfully washing glycerin from the die lube. The die lube was then recycled in a production die-casting machine. Test data and quality records indicate that scrap from the die casting operation was reduced from $8.4 \%$ to $7.8 \%$.

The two Speedy ${ }^{\mathrm{TM}}$ rotary filters operated continuously for six weeks without any down time due to mechanical or electrical failure. The membranes showed no apparent damage due to abrasion or the effects of the die lube solution. Only seven cleaning cycles were required to maintain filtrate throughput. Several experimental runs were conducted without prior cleaning, which demonstrated that it would not be necessary to clean the membranes between campaigns in full-scale implementation of the system. This is desirable because cleaning generates waste.

There is no doubt that this full-scale production test yielded tremendous results. We established that Metaldyne's die lubricant can be concentrated, washed, and recycled. Further evaluation is needed to determine if this process is cost effective. 


\section{DISCUSSION}

Laboratory testing, using small, flat, sheet membranes and a bench-scale rotary filter, demonstrated that active-surface membrane technology was a good candidate for field testing at Metaldyne's plant. The metals content of the feed solutions was reduced significantly using tight ultrafiltration active-surface membranes. However, significant hydro-gel-like precipitates formed in the permeate solutions upon standing. The gels may be hydrated aluminum and iron oxy-/hydroxy-species. These gels are very $\mathrm{pH}$ sensitive and dissolved immediately with drop-wise additions of acid to 1-L samples. Nanofiltration to polish the effluent concentrated the metal ions slightly. The results of the experiments were encouraging because permeates from the nanofiltration system are clear, colorless, and show only slight discoloration and no significant gel precipitation upon standing

At Metaldyne's plant, we successfully concentrated the die lube solution to the expected 20X concentration, and even as high as 50X, using two rotary membrane systems built by SpinTek, LLC. Although the solution could be concentrated to 50X, the low flux of the membrane between 20X and 50X is impractical for commercial applications. Initially, SpinTek mounted commercial polymer ultrafiltration membranes in the Speedy ${ }^{\mathrm{TM}}$ units. However, the membranes tended to pucker, leading to wear and loss of selectivity. So we changed to stainless steel/ceramic composite membrane materials manufactured by Trumem Membranes. All of the filtrates were very clear, indicating satisfactory die lube removal by the ceramic membranes. Fouling of the membranes was a problem, and cleaning protocols were developed to remove oils, greases, and other foulants from the membranes.

Phase 3 was a continuous six-week test that demonstrated the SpinTek, LLC system's ability to concentrate, wash, and recycle the die lube solution at the Metaldyne plant. Die lube was continually concentrated and the COD reduced by a factor of 8 to 10, which is attributed to successfully washing glycerin from the die lube. The die lube was then recycled in a production die-casting machine. The two Speedy ${ }^{\mathrm{TM}}$ rotary filters operated continuously for six weeks without any down time due to mechanical or electrical failure. The Trumem composite membranes showed no apparent damage due to abrasion or the effects of the die lube solution. Only seven cleaning cycles were required to maintain filtrate throughput. Several experimental runs were conducted without prior cleaning, which demonstrated that it would not be necessary to clean the membranes between every campaign in full-scale implementation of the system. This is desirable because cleaning generates waste. Test data and quality records from the die casting machine, running at full production scale, indicate that production scrap was reduced from $8.4 \%$ to $7.8 \%$.

There is no doubt that this project yielded tremendous results. The full-scale production test proved that it is possible to recycle Metaldyne's die lubricant. Further evaluation is needed to determine if it is cost effective to do so. 


\section{CONCLUSION}

The oil and water mixtures produced by Metaldyne's die casting plant can be cleaned up using active-surface membrane technology. Field testing using the ST-II rotary filter/Speedy ${ }^{\mathrm{TM}}$ system, for concentration of the die lube from waste water generated during die casting operations and for recycling/recovery of die lube, showed very promising results. The feed solution was concentrated to the target of 20X in seven tests, and one test further concentrated the feed to 50X (throughput from 20X to $50 \mathrm{X}$ is too low for commercial use). During all of these tests the filtrate was very clear, indicating nearly complete removal of the die cast material. At the completion of these tests the membranes were cleaned and flux recovered.

When the rotary filter system was used for glycerin removal and die lube solution recycling/reconstitution, the results were also very favorable. This project successfully demonstrated that the rotary microfilter is capable of concentrating the die lube components from the waste stream of a die casting operation, washing out the contaminating glycerin, and producing a die lube suitable for recycling. Manufacturing records indicate that the scrap was reduced from $8.4 \%$ to $7.8 \%$. The recycling system operated continuously for six weeks; only seven membrane cleaning cycles were required and the system experienced no down time due to mechanical or electrical failure.

There is no doubt that the field tests yielded tremendous results. They proved that Metaldyne's die lubricant can be recycled. Although further evaluation is needed to determine if it is cost effective for this die lube to be recycled, this project has shown significant opportunities for further evaluation by Metaldyne, the die casting industry, and other industries with similar waste streams. 


\section{REFERENCES}

1. $\quad$ R. W. Baker et al., Membrane Separations Systems - A Research and Development Needs Assessment, U.S. DOE Contract No. DE-AC01-88ER30133, March 1990.

2. J. L. Humphrey, A. F. Seibert, R. A. Koort, Separation Technologies - Advances and Priorities, U.S. DOE Contract No. AC07-90D12920, February 1991.

3. R. R. McCaffrey, D. G. Cummings, Sep. Sci. And Tech., 23, (12,13), 1627 (1988).

4. C. W. Allen et al., J. Memb. Sci., $\underline{33}, 181$ (1987).

5. R. R. McCaffrey et al., J. Memb. Sci., 28, 47, (1986).

6. D. A. Femec and R. R. McCaffrey, J. Appl. Poly. Sci., 52, 501 (1994).

7. E. S. Peterson, M. L. Stone, W. F. Bauer, and C. J. Orme, Rec. Prog. En Geni des Proc., Membrane Processes, $\underline{6},(22), 381$ (1992).

8. E. S. Peterson, M. L. Stone, R. R. McCaffrey, and D. G. Cummings, Sep. Sci. and Tech., 28, (1-3) (1993).

9. $\quad$ E. S. Peterson and M. L. Stone, J. Memb. Sci., $\underline{86}, 57$ (1994).

10. E. S. Peterson, M. L. Stone, C. J. Orme, and D. A. Reavill III, Sep. Sci. and Tech., 30, (7-9), 1573 (1995).

11. E. S. Peterson, M. L. Stone, and C. J. Orme, U.S. Patent \# 5,385,672, January 1995.

12. R. C. Viadero, R. L. Baughn, and B. E. Reed, J. Memb Sci., 162, 199 (1999).

13. F. A. Cotton and G. Wilkinson, "Advanced Inorganic Chemistry" $5^{\text {th }}$ Edition, 1988, pg. 711. 
Appendix A

Raw and Run Data 
A-2 


\section{Appendix A}

\section{Raw and Run Data}

This appendix contains the following raw data tables:

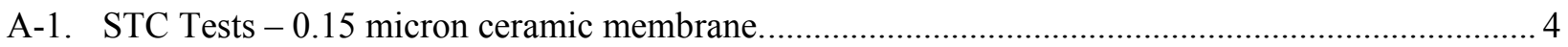

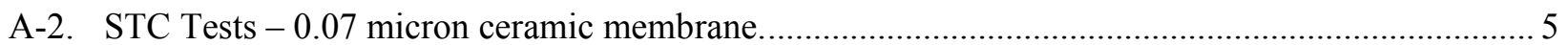

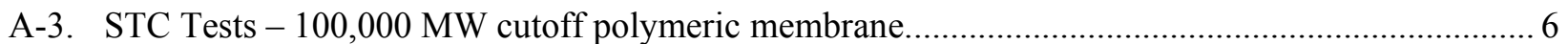

A-4. ST-IIL Rotary Membrane Tests-100,000 Molecular Weight Cut-Off Membrane

(ST-II-L Test 1) Raw Data Run Log

A-5. ST-IIL Rotary Membrane Tests-100,000 Molecular Weight Cut-Off Membrane

(ST-II-L Test 1) Concentration Data Run Log....

A-6. ST-IIL Rotary Membrane Tests_-100,000 Molecular Weight Cut-Off Membrane

(ST-II-L Test 2) Raw Data Run Log

A-7. ST-IIL Rotary Membrane Tests-100,000 Molecular Weight Cut-Off Membrane

(ST-II-L Test 2) Concentration Data Run Log.

A-8. ST-IIL Rotary Membrane Tests-10,000 Molecular Weight Cut-Off Membrane

(ST-II-1 10K Tests 3) Raw Data Run Log.

A-9. ST-IIL Rotary Membrane Tests-10,000 Molecular Weight Cut-Off Membrane (ST-II-1 10K Tests 3) Concentration Data Run Log.

A-10. STC Five-Day Cleaning Test—Static Nano Raw Data Run Log ..............................................25

A-11. Desal 5-Spiral Wound Module 5-Day Cleaning Test, Raw Data Run Log .................................. 26

A-12. Performance Data For Six Week Recycling Of Die Lube............................................................ 27 
Table A-1. STC Tests -0.15 micron ceramic membrane.

Membrane: 0.15 nominal $\mu$

Surface Area: 0.05

Feed Sample: Sample B

Initial Feed Volume: $3500 \mathrm{~mL}$

Final Feed Volume: $3500 \mathrm{~mL}$

Final Concentrate: $1 \mathrm{x}$

Operator: Jason Gilmour

Final Flux: N/A

Date: $12 / 20 / 99$

\begin{tabular}{|c|c|c|c|c|c|c|c|c|}
\hline $\begin{array}{l}\text { Time of } \\
\text { Day } \\
\text { (hh:mm) }\end{array}$ & $\begin{array}{l}\text { Elapsed } \\
\text { Time } \\
\text { (hh:mm) }\end{array}$ & $\begin{array}{c}\text { Feed Flow } \\
\text { (gal/min) }\end{array}$ & $\begin{array}{l}\text { Feed } \\
\text { Press. } \\
\text { (psi) }\end{array}$ & $\begin{array}{l}\text { Conc. } \\
\text { Press. } \\
\text { (psi) }\end{array}$ & $\begin{array}{l}\text { Feed } \\
\text { Temp. } \\
\left({ }^{\circ} \mathrm{F}\right)\end{array}$ & $\begin{array}{c}\text { Permeate } \\
\text { Flow } \\
\text { (mL/min) }\end{array}$ & Comments & $\underset{\text { (gpd/sq ft) }}{\text { Flux }}$ \\
\hline $10: 30$ & 0:00 & 1.00 & 40 & 34 & 60 & 9.90 & Initial Perm. Hazy & 75.2 \\
\hline $10: 45$ & $0: 15$ & 1.00 & 40 & 34 & 60 & 9.50 & & 72.2 \\
\hline $11: 00$ & $0: 30$ & 1.00 & 40 & 35 & 62 & 8.60 & & 65.4 \\
\hline $11: 15$ & $0: 45$ & 1.00 & 40 & 34 & 63 & 7.80 & & 59.3 \\
\hline $11: 30$ & $1: 00$ & 1.00 & 40 & 34 & 64 & 7.30 & & 55.5 \\
\hline $11: 45$ & $1: 15$ & 1.00 & 40 & 34 & 66 & 6.50 & & 49.4 \\
\hline $12: 00$ & $1: 30$ & 1.00 & 40 & 33 & 68 & 6.00 & Clearer Permeate & 45.6 \\
\hline $12: 30$ & $2: 00$ & 1.00 & 40 & 33 & 69 & 5.00 & & 38.0 \\
\hline $1: 00$ & $2: 30$ & 1.00 & 40 & 33 & 69 & 4.00 & & 30.4 \\
\hline $2: 00$ & $3: 30$ & 1.00 & 40 & 33 & 70 & 3.10 & & 23.5 \\
\hline $2: 30$ & $4: 00$ & 1.00 & 40 & 33 & 70 & 2.60 & & 19.8 \\
\hline $3: 30$ & $5: 00$ & 1.00 & 40 & 33 & 70 & 2.30 & & 17.5 \\
\hline \multirow[t]{2}{*}{$4: 30$} & $6: 00$ & 1.00 & 40 & 33 & 70 & 2.10 & & 16.0 \\
\hline & \multicolumn{8}{|c|}{ Test Stopped Due to low flux } \\
\hline
\end{tabular}


Table A-2. STC Tests -0.07 micron ceramic membrane.

Membrane: 0.07 nominal $\mu$

Surface Area: 0.05

Feed Sample: Sample B

Initial Feed Volume: $3500 \mathrm{~mL}$

Final Feed Volume: $3500 \mathrm{~mL}$

Final Concentrate: $1 \mathrm{x}$

Operator: Jason Gilmour

Final Flux: N/A

Date: $12 / 27 / 99$

\begin{tabular}{|c|c|c|c|c|c|c|c|c|}
\hline $\begin{array}{l}\text { Time of } \\
\text { Day } \\
\text { (hh:mm) }\end{array}$ & $\begin{array}{l}\text { Elapsed } \\
\text { Time } \\
\text { (hh:mm) }\end{array}$ & $\begin{array}{c}\text { Feed Flow } \\
\text { (gal/min) }\end{array}$ & $\begin{array}{c}\text { Feed } \\
\text { Press. } \\
(\mathrm{psi})\end{array}$ & $\begin{array}{l}\text { Conc. } \\
\text { Press. } \\
\text { (psi) }\end{array}$ & $\begin{array}{l}\text { Feed } \\
\text { Temp. } \\
\left({ }^{\circ} \mathrm{F}\right)\end{array}$ & $\begin{array}{c}\text { Permeate } \\
\text { Flow } \\
(\mathrm{mL} / \mathrm{min})\end{array}$ & Comments & $\begin{array}{c}\text { Flux } \\
\text { (gpd/sqft) }\end{array}$ \\
\hline 9:00 & $0: 00$ & 1.00 & 40 & 36 & 61 & 6.00 & & 45.6 \\
\hline $9: 15$ & $0: 15$ & 1.00 & 40 & 36 & 61 & 5.80 & $\begin{array}{l}\text { Clear Permeate } \\
\text { Throughout Test }\end{array}$ & 44.1 \\
\hline $9: 30$ & $0: 30$ & 1.00 & 40 & 35 & 61 & 5.00 & & 38.0 \\
\hline $9: 45$ & $0: 45$ & 1.00 & 40 & 35 & 61 & 4.70 & & 35.7 \\
\hline $10: 00$ & $1: 00$ & 1.00 & 40 & 35 & 62 & 4.50 & & 34.2 \\
\hline $10: 15$ & $1: 15$ & 1.00 & 40 & 34 & 62 & 4.30 & & 32.7 \\
\hline $10: 30$ & $1: 30$ & 1.00 & 40 & 34 & 62 & 4.20 & & 31.9 \\
\hline $10: 45$ & $1: 45$ & 1.00 & 40 & 34 & 63 & 4.10 & & 31.2 \\
\hline $11: 15$ & $2: 15$ & 1.00 & 40 & 34 & 63 & 4.00 & & 30.4 \\
\hline $11: 45$ & $2: 45$ & 1.00 & 40 & 34 & 63 & 3.80 & & 28.9 \\
\hline $12: 15$ & $3: 15$ & 1.00 & 40 & 34 & 64 & 3.70 & & 28.1 \\
\hline $12: 45$ & $3: 45$ & 1.00 & 40 & 34 & 64 & 3.60 & & 27.4 \\
\hline $1: 15$ & $4: 15$ & 1.00 & 40 & 34 & 65 & 3.50 & & 26.6 \\
\hline $2: 15$ & $5: 15$ & 1.00 & 40 & 34 & 66 & 3.40 & & 25.8 \\
\hline $3: 15$ & $6: 15$ & 1.00 & 40 & 34 & 67 & 3.30 & & 25.0 \\
\hline $4: 15$ & $7: 15$ & 1.00 & 40 & 34 & 67 & 3.20 & & 24.3 \\
\hline $8: 00$ & $22: 45$ & 1.00 & 40 & 34 & 62 & 1.80 & & 13.7 \\
\hline 9:00 & $23: 45$ & 1.00 & 40 & 34 & 62 & 1.70 & & 12.9 \\
\hline $2: 00$ & $4: 00$ & 1.00 & 40 & 34 & 66 & 1.40 & & 10.6 \\
\hline \multicolumn{9}{|c|}{ Test Stopped Due to Low Flux } \\
\hline
\end{tabular}


Table A-3. STC Tests $-100,000$ MW cutoff polymeric membrane.

Membrane: Polymeric PVFD

Surface Area: 0.05

Feed Sample: Sample B

Initial Feed Volume: $3500 \mathrm{~mL}$

Final Feed Volume: $850 \mathrm{~mL}$

Final Concentrate: $4 \mathrm{x}$

Operator: Jason Gilmour

Final Flux: 41 gpd/sqft

Date: $12 / 29 / 99$

\begin{tabular}{|c|c|c|c|c|c|c|c|c|}
\hline $\begin{array}{l}\text { Time of } \\
\text { Day } \\
\text { (hh:mm) }\end{array}$ & $\begin{array}{l}\text { Elapsed } \\
\text { Time } \\
\text { (hh:mm) }\end{array}$ & $\begin{array}{c}\text { Feed Flow } \\
\text { (gal/min) }\end{array}$ & $\begin{array}{l}\text { Feed } \\
\text { Press. } \\
\text { (psi) }\end{array}$ & $\begin{array}{l}\text { Conc. } \\
\text { Press. } \\
\text { (psi) }\end{array}$ & $\begin{array}{c}\text { Feed Temp } \\
\left({ }^{\circ} \mathrm{F}\right)\end{array}$ & $\begin{array}{c}\text { Permeate } \\
\text { Flow } \\
(\mathrm{mL} / \mathrm{min})\end{array}$ & Comments & $\begin{array}{c}\text { Flux } \\
\text { (gpd/sq ft) }\end{array}$ \\
\hline $2: 15$ & 0:00 & 1.00 & 25 & 18 & 66 & 7.90 & & 60.0 \\
\hline $2: 30$ & $0: 15$ & 1.00 & 25 & 18 & 66 & 7.20 & $\begin{array}{l}\text { Clean Clear } \\
\text { Permeate } \\
\text { Throughout test }\end{array}$ & 54.7 \\
\hline $2: 45$ & $0: 30$ & 1.00 & 25 & 18 & 67 & 7.00 & & 53.2 \\
\hline 3:00 & $0: 45$ & 1.00 & 25 & 18 & 68 & 7.00 & & 53.2 \\
\hline $3: 15$ & $1: 00$ & 1.00 & 25 & 18 & 68 & 7.00 & & 53.2 \\
\hline $3: 30$ & $1: 15$ & 1.00 & 25 & 18 & 68 & 6.90 & & 52.4 \\
\hline $3: 45$ & $1: 30$ & 1.00 & 25 & 18 & 68 & 7.00 & & 53.2 \\
\hline 4:00 & $1: 45$ & 1.00 & 25 & 18 & 68 & 7.00 & & 53.2 \\
\hline $4: 15$ & $2: 00$ & 1.00 & 25 & 18 & 68 & 7.00 & & 53.2 \\
\hline $4: 30$ & $2: 15$ & 1.00 & 25 & 18 & 68 & 6.90 & & 52.4 \\
\hline $4: 45$ & $2: 30$ & 1.00 & 25 & 18 & 69 & 6.90 & & 52.4 \\
\hline $8: 15$ & $18: 00$ & 1.00 & 25 & 18 & 69 & 6.70 & & 50.9 \\
\hline $8: 45$ & $18: 30$ & 1.00 & 25 & 18 & 69 & 6.70 & $\begin{array}{l}\text { Started } \\
\text { Concentrating }\end{array}$ & 50.9 \\
\hline $9: 15$ & $19: 00$ & 1.00 & 25 & 18 & 69 & 6.60 & & 50.2 \\
\hline $9: 45$ & $19: 30$ & 1.00 & 25 & 18 & 69 & 6.50 & & 49.4 \\
\hline $10: 15$ & $20: 00$ & 1.00 & 25 & 18 & 70 & 6.40 & & 48.6 \\
\hline $10: 45$ & $20: 30$ & 1.00 & 25 & 18 & 69 & 6.20 & & 47.0 \\
\hline $11: 15$ & $21: 00$ & 1.00 & 25 & 18 & 68 & 5.90 & & 44.8 \\
\hline $11: 45$ & $21: 30$ & 1.00 & 25 & 18 & 68 & 5.70 & & 43.3 \\
\hline $12: 15$ & $22: 00$ & 1.00 & 25 & 18 & 67 & 5.70 & & 43.3 \\
\hline $12: 45$ & $22: 30$ & 1.00 & 25 & 18 & 67 & 5.60 & & 42.6 \\
\hline $1: 15$ & $23: 00$ & 1.00 & 25 & 18 & 67 & 5.40 & & 41.0 \\
\hline $1: 45$ & $23: 30$ & 1.00 & 25 & 18 & 67 & 5.50 & & 41.8 \\
\hline $2: 15$ & $0: 00$ & 1.00 & 25 & 18 & 68 & 5.40 & & 41.0 \\
\hline $2: 45$ & $0: 30$ & 1.00 & 25 & 18 & 68 & 5.40 & & 41.0 \\
\hline
\end{tabular}


Table A-4. ST-IIL Rotary Membrane Tests-100,000 Molecular Weight Cut-Off Membrane (ST-II-L Test 1) Raw Data Run Log

\begin{tabular}{|c|c|c|c|c|c|c|c|c|}
\hline $\begin{array}{l}\text { Time of } \\
\text { Day }\end{array}$ & $\begin{array}{c}\text { Elapsed } \\
\text { Time } \\
\text { (dd:hh:mm) }\end{array}$ & $\begin{array}{c}\text { Feed } \\
\text { Pressure } \\
\text { (psi) }\end{array}$ & $\begin{array}{c}\text { Feed } \\
\text { Temp. } \\
\left({ }^{\circ} \mathrm{F}\right)\end{array}$ & $\begin{array}{l}\text { Feed } \\
\text { Flow } \\
(\mathrm{gpm})\end{array}$ & $\begin{array}{l}\text { Rotor } \\
\text { Speed } \\
(\mathrm{rpm})\end{array}$ & $\begin{array}{l}\text { Rotor } \\
\text { Power } \\
(\mathrm{kW})\end{array}$ & $\begin{array}{c}\text { Permeate } \\
\text { Flow } \\
\text { (gph) }\end{array}$ & $\begin{array}{c}\text { Permeate Flux } \\
\text { (gal/ } / \mathrm{ft}^{2} \text {-day) }\end{array}$ \\
\hline $15: 00$ & 0:00 & 40 & 62 & 1.00 & 967 & 967 & 4.88 & 117.17 \\
\hline $15: 10$ & $0: 10$ & 39 & 65 & 1.00 & 1195 & 1195 & 4.26 & 102.33 \\
\hline $15: 15$ & $0: 15$ & 39 & 65 & 1.01 & 1190 & 1190 & 4.36 & 104.61 \\
\hline $15: 20$ & $0: 20$ & 40 & 66 & 1.01 & 1183 & 1183 & 4.55 & 109.18 \\
\hline $15: 25$ & $0: 25$ & 40 & 67 & 1.01 & 1191 & 1191 & 4.66 & 111.84 \\
\hline $15: 30$ & $0: 30$ & 40 & 67 & 1.01 & 1184 & 1184 & 4.58 & 109.94 \\
\hline $15: 35$ & $0: 35$ & 40 & 68 & 1.01 & 1187 & 1187 & 4.69 & 112.60 \\
\hline $15: 40$ & $0: 40$ & 40 & 69 & 1.01 & 1188 & 1188 & 4.55 & 109.18 \\
\hline $15: 45$ & $0: 45$ & 40 & 69 & 1.02 & 1181 & 1181 & 4.69 & 112.60 \\
\hline $15: 50$ & $0: 50$ & 40 & 70 & 1.02 & 1188 & 1188 & 4.66 & 111.84 \\
\hline $15: 55$ & $0: 55$ & 40 & 71 & 1.01 & 1180 & 1180 & 4.66 & 111.84 \\
\hline $16: 00$ & $1: 00$ & 39 & 71 & 1.02 & 1188 & 1188 & 4.64 & 111.46 \\
\hline $16: 05$ & $1: 05$ & 40 & 72 & 1.02 & 1182 & 1182 & 4.82 & 115.64 \\
\hline $16: 10$ & $1: 10$ & 40 & 73 & 1.02 & 1185 & 1185 & 4.72 & 113.36 \\
\hline $16: 15$ & $1: 15$ & 39 & 73 & 1.03 & 1190 & 1190 & 4.85 & 116.40 \\
\hline $16: 20$ & $1: 20$ & 39 & 73 & 1.03 & 1186 & 1186 & 4.79 & 114.88 \\
\hline $16: 25$ & $1: 25$ & 40 & 74 & 1.03 & 1170 & 1170 & 4.61 & 110.70 \\
\hline $16: 35$ & $1: 35$ & 40 & 74 & 1.03 & 1188 & 1188 & 4.64 & 111.46 \\
\hline $16: 50$ & $1: 50$ & 40 & 75 & 1.02 & 1189 & 1189 & 4.69 & 112.60 \\
\hline $17: 05$ & $2: 05$ & 40 & 75 & 1.03 & 1187 & 1187 & 4.64 & 111.46 \\
\hline $17: 20$ & $2: 20$ & 39 & 75 & 1.02 & 1186 & 1186 & 4.49 & 107.66 \\
\hline $17: 35$ & $2: 35$ & 40 & 75 & 1.03 & 1186 & 1186 & 4.58 & 109.94 \\
\hline $17: 50$ & $2: 50$ & 40 & 75 & 1.02 & 1184 & 1184 & 4.64 & 111.46 \\
\hline $18: 05$ & $3: 05$ & 40 & 74 & 1.02 & 1183 & 1183 & 4.55 & 109.18 \\
\hline $18: 20$ & $3: 20$ & 39 & 74 & 1.03 & 1184 & 1184 & 4.61 & 110.70 \\
\hline $18: 35$ & $3: 35$ & 40 & 74 & 1.02 & 1185 & 1185 & 4.39 & 105.37 \\
\hline $18: 50$ & $3: 50$ & 39 & 74 & 1.01 & 1183 & 1183 & 4.49 & 107.66 \\
\hline $19: 05$ & $4: 05$ & 39 & 75 & 1.02 & 1178 & 1178 & 4.49 & 107.66 \\
\hline $19: 20$ & $4: 20$ & 40 & 75 & 1.02 & 1186 & 1186 & 4.39 & 105.37 \\
\hline $19: 35$ & $4: 35$ & 39 & 75 & 1.02 & 1186 & 1186 & 4.36 & 104.61 \\
\hline $19: 50$ & $4: 50$ & 40 & 75 & 1.03 & 1186 & 1186 & 4.45 & 106.89 \\
\hline $20: 05$ & $5: 05$ & 40 & 75 & 1.01 & 1188 & 1188 & 4.42 & 106.13 \\
\hline $20: 20$ & $5: 20$ & 40 & 75 & 1.02 & 1175 & 1175 & 4.23 & 101.57 \\
\hline $20: 35$ & $5: 35$ & 40 & 75 & 1.03 & 1177 & 1177 & 4.39 & 105.37 \\
\hline $20: 50$ & $5: 50$ & 40 & 74 & 1.02 & 1182 & 1182 & 4.23 & 101.57 \\
\hline
\end{tabular}


Table A-4. (continued).

\begin{tabular}{|c|c|c|c|c|c|c|c|c|}
\hline $\begin{array}{c}\text { Time of } \\
\text { Day }\end{array}$ & $\begin{array}{c}\text { Elapsed } \\
\text { Time } \\
\text { (dd:hh:mm) }\end{array}$ & $\begin{array}{c}\text { Feed } \\
\text { Pressure } \\
\text { (psi) }\end{array}$ & $\begin{array}{c}\text { Feed } \\
\text { Temp. } \\
\left({ }^{\circ} \mathrm{F}\right)\end{array}$ & $\begin{array}{l}\text { Feed } \\
\text { Flow } \\
(\mathrm{gpm}) \\
\end{array}$ & $\begin{array}{l}\text { Rotor } \\
\text { Speed } \\
(\mathrm{rpm}) \\
\end{array}$ & $\begin{array}{c}\text { Rotor } \\
\text { Power } \\
(\mathrm{kW})\end{array}$ & $\begin{array}{c}\text { Permeate } \\
\text { Flow } \\
\text { (gph) } \\
\end{array}$ & $\begin{array}{c}\text { Permeate Flux } \\
\left(\mathrm{gal} / \mathrm{ft}^{2} \text {-day }\right)\end{array}$ \\
\hline $21: 05$ & $6: 05$ & 39 & 74 & 1.02 & 1181 & 1181 & 4.23 & 101.57 \\
\hline $21: 20$ & $6: 20$ & 40 & 75 & 1.02 & 1179 & 1179 & 4.33 & 103.85 \\
\hline $21: 35$ & $6: 35$ & 39 & 74 & 1.03 & 1195 & 1195 & 4.30 & 103.09 \\
\hline $21: 50$ & $6: 50$ & 39 & 74 & 1.03 & 1181 & 1181 & 4.26 & 102.33 \\
\hline $22: 05$ & $7: 05$ & 40 & 75 & 1.02 & 1179 & 1179 & 4.20 & 100.81 \\
\hline $22: 20$ & $7: 20$ & 40 & 74 & 1.03 & 1186 & 1186 & 4.26 & 102.33 \\
\hline $22: 35$ & $7: 35$ & 39 & 74 & 1.03 & 1185 & 1185 & 4.20 & 100.81 \\
\hline $22: 50$ & $7: 50$ & 40 & 74 & 1.02 & 1180 & 1180 & 4.17 & 100.05 \\
\hline $23: 05$ & $8: 05$ & 40 & 74 & 1.02 & 1180 & 1180 & 4.07 & 97.76 \\
\hline $23: 20$ & $8: 20$ & 40 & 74 & 1.02 & 1179 & 1179 & 4.11 & 98.53 \\
\hline $23: 35$ & $8: 35$ & 39 & 74 & 1.03 & 1181 & 1181 & 4.07 & 97.76 \\
\hline $23: 50$ & $8: 50$ & 40 & 74 & 1.02 & 1185 & 1185 & 4.11 & 98.53 \\
\hline $0: 00$ & $8: 59$ & 39 & 74 & 1.03 & 1194 & 1194 & 4.11 & 98.53 \\
\hline $0: 15$ & $9: 14$ & 40 & 74 & 1.03 & 1178 & 1178 & 4.07 & 97.76 \\
\hline $0: 30$ & $9: 29$ & 40 & 74 & 1.02 & 1188 & 1188 & 4.01 & 96.24 \\
\hline $0: 45$ & $9: 44$ & 39 & 74 & 1.02 & 1188 & 1188 & 4.04 & 97.00 \\
\hline $1: 00$ & $9: 59$ & 39 & 74 & 1.02 & 1186 & 1186 & 3.96 & 95.10 \\
\hline $1: 15$ & $10: 14$ & 39 & 74 & 1.03 & 1181 & 1181 & 4.01 & 96.24 \\
\hline $1: 30$ & $10: 29$ & 40 & 74 & 1.02 & 1191 & 1191 & 3.96 & 95.10 \\
\hline $1: 45$ & $10: 44$ & 39 & 74 & 1.02 & 1173 & 1173 & 4.01 & 96.24 \\
\hline $2: 00$ & $10: 59$ & 39 & 74 & 1.03 & 1181 & 1181 & 3.93 & 94.34 \\
\hline $2: 15$ & $11: 14$ & 39 & 74 & 1.03 & 1185 & 1185 & 3.96 & 95.10 \\
\hline $2: 30$ & $11: 29$ & 40 & 74 & 1.03 & 1181 & 1181 & 3.96 & 95.10 \\
\hline $2: 45$ & $11: 44$ & 40 & 74 & 1.03 & 1186 & 1186 & 3.93 & 94.34 \\
\hline $3: 00$ & $11: 59$ & 39 & 74 & 1.03 & 1181 & 1181 & 3.87 & 92.82 \\
\hline $3: 15$ & $12: 14$ & 39 & 74 & 1.02 & 1174 & 1174 & 3.90 & 93.58 \\
\hline $3: 30$ & $12: 29$ & 40 & 74 & 1.03 & 1180 & 1180 & 3.93 & 94.34 \\
\hline $3: 45$ & $12: 44$ & 39 & 74 & 1.03 & 1184 & 1184 & 3.96 & 95.10 \\
\hline $4: 00$ & $12: 59$ & 40 & 74 & 1.03 & 1185 & 1185 & 3.84 & 92.06 \\
\hline $4: 15$ & $13: 14$ & 40 & 74 & 1.03 & 1182 & 1182 & 3.90 & 93.58 \\
\hline $4: 30$ & $13: 29$ & 39 & 74 & 1.03 & 1182 & 1182 & 3.77 & 90.54 \\
\hline $4: 45$ & $13: 44$ & 40 & 73 & 1.03 & 1181 & 1181 & 3.80 & 91.30 \\
\hline 5:00 & $13: 59$ & 39 & 74 & 1.03 & 1187 & 1187 & 3.87 & 92.82 \\
\hline $5: 15$ & $14: 14$ & 40 & 74 & 1.03 & 1176 & 1176 & 3.77 & 90.54 \\
\hline $5: 30$ & $14: 29$ & 39 & 74 & 1.03 & 1181 & 1181 & 3.80 & 91.30 \\
\hline $5: 45$ & $14: 44$ & 40 & 73 & 1.03 & 1181 & 1181 & 3.80 & 91.30 \\
\hline
\end{tabular}


Table A-4. (continued).

\begin{tabular}{ccccccccc}
\hline $\begin{array}{c}\text { Time of } \\
\text { Day }\end{array}$ & $\begin{array}{c}\text { Elapsed } \\
\text { Time } \\
(\mathrm{dd}: \mathrm{hh}: \mathrm{mm})\end{array}$ & $\begin{array}{c}\text { Feed } \\
\text { Pressure } \\
(\mathrm{psi})\end{array}$ & $\begin{array}{c}\text { Feed } \\
\text { Temp. } \\
\left({ }^{\circ} \mathrm{F}\right)\end{array}$ & $\begin{array}{c}\text { Feed } \\
\text { Flow } \\
(\mathrm{gpm})\end{array}$ & $\begin{array}{c}\text { Rotor } \\
\text { Speed } \\
(\mathrm{rpm})\end{array}$ & $\begin{array}{c}\text { Rotor } \\
\text { Power } \\
(\mathrm{kW})\end{array}$ & $\begin{array}{c}\text { Permeate } \\
\begin{array}{c}\text { Flow } \\
(\mathrm{gph})\end{array}\end{array}$ & $\begin{array}{c}\text { Permeate Flux } \\
\left(\mathrm{gal} / \mathrm{ft}^{2} \text {-day }\right)\end{array}$ \\
\hline $6: 00$ & $14: 59$ & 39 & 74 & 1.03 & 1184 & 1184 & 3.74 & 89.78 \\
$6: 15$ & $15: 14$ & 40 & 73 & 1.03 & 1190 & 1190 & 3.77 & 90.54 \\
$6: 30$ & $15: 29$ & 40 & 73 & 1.03 & 1184 & 1184 & 3.71 & 89.02 \\
$6: 45$ & $15: 44$ & 40 & 74 & 1.03 & 1182 & 1182 & 3.77 & 90.54 \\
$7: 00$ & $15: 59$ & 39 & 74 & 1.03 & 1177 & 1177 & 3.74 & 89.78 \\
$7: 15$ & $16: 14$ & 40 & 74 & 1.03 & 1177 & 1177 & 3.74 & 89.78 \\
$7: 30$ & $16: 29$ & 40 & 73 & 1.04 & 1188 & 1188 & 3.77 & 90.54 \\
$7: 45$ & $16: 44$ & 39 & 73 & 1.03 & 1188 & 1188 & 3.77 & 90.54 \\
$8: 00$ & $16: 59$ & 40 & 73 & 1.03 & 1187 & 1187 & 3.77 & 90.54 \\
$8: 15$ & $17: 14$ & 40 & 73 & 1.03 & 1189 & 1189 & 3.74 & 89.78 \\
$8: 30$ & $17: 29$ & 39 & 73 & 1.03 & 1184 & 1184 & 3.74 & 89.78 \\
$8: 45$ & $17: 44$ & 40 & 73 & 1.03 & 1181 & 1181 & 3.71 & 89.02 \\
$9: 00$ & $17: 59$ & 39 & 73 & 1.03 & 1182 & 1182 & 3.74 & 89.78 \\
$9: 15$ & $18: 14$ & 40 & 73 & 1.02 & 1183 & 1183 & 3.71 & 89.02 \\
\hline
\end{tabular}


Table A-5. ST-IIL Rotary Membrane Tests-100,000 Molecular Weight Cut-Off Membrane (ST-II-L Test 1) Concentration Data Run Log

\begin{tabular}{|c|c|c|c|c|c|c|c|c|}
\hline $\begin{array}{l}\text { Time of } \\
\text { Day }\end{array}$ & $\begin{array}{l}\text { Elapsed } \\
\text { Time } \\
\text { (dd:hh:mm) }\end{array}$ & $\begin{array}{c}\text { Feed } \\
\text { Pressure } \\
\text { (psi) }\end{array}$ & $\begin{array}{l}\text { Feed } \\
\text { Temp. } \\
\left({ }^{\circ} \mathrm{F}\right)\end{array}$ & $\begin{array}{l}\text { Feed Flow } \\
(\mathrm{gpm})\end{array}$ & $\begin{array}{l}\text { Rotor } \\
\text { Speed } \\
(\mathrm{rpm})\end{array}$ & $\begin{array}{c}\text { Rotor } \\
\text { Power } \\
(\mathrm{kW})\end{array}$ & $\begin{array}{c}\text { Permeate } \\
\text { Flow } \\
\text { (gph) }\end{array}$ & $\begin{array}{l}\text { Permeate Flux } \\
\text { (gal//ft'-day) }\end{array}$ \\
\hline $9: 30$ & $18: 29$ & 40 & 73 & 1.02 & 1182 & 1182 & 3.71 & 89.02 \\
\hline $9: 45$ & $18: 44$ & 39 & 73 & 1.03 & 1188 & 1188 & 3.71 & 89.02 \\
\hline $10: 00$ & $18: 59$ & 40 & 73 & 1.03 & 1179 & 1179 & 3.68 & 88.25 \\
\hline $10: 15$ & $19: 14$ & 39 & 73 & 1.03 & 1187 & 1187 & 3.61 & 86.73 \\
\hline $10: 30$ & $19: 29$ & 39 & 73 & 1.03 & 1192 & 1192 & 3.65 & 87.49 \\
\hline $10: 45$ & $19: 44$ & 39 & 73 & 1.03 & 1172 & 1172 & 3.61 & 86.73 \\
\hline 11:00 & $19: 59$ & 39 & 73 & 1.02 & 1180 & 1180 & 3.55 & 85.21 \\
\hline $11: 15$ & $20: 14$ & 39 & 73 & 1.03 & 1183 & 1183 & 3.55 & 85.21 \\
\hline $11: 30$ & $20: 29$ & 39 & 73 & 1.03 & 1185 & 1185 & 3.61 & 86.73 \\
\hline $11: 45$ & $20: 44$ & 39 & 72 & 1.03 & 1180 & 1180 & 3.52 & 84.45 \\
\hline $12: 00$ & $20: 59$ & 40 & 73 & 1.02 & 1181 & 1181 & 3.58 & 85.97 \\
\hline $12: 15$ & $21: 14$ & 40 & 72 & 1.03 & 1174 & 1174 & 3.58 & 85.97 \\
\hline $12: 30$ & $21: 29$ & 39 & 72 & 1.02 & 1181 & 1181 & 3.58 & 85.97 \\
\hline $12: 45$ & $21: 44$ & 39 & 73 & 1.03 & 1177 & 1177 & 3.55 & 85.21 \\
\hline $13: 00$ & $21: 59$ & 39 & 72 & 1.03 & 1181 & 1181 & 3.55 & 85.21 \\
\hline $13: 15$ & $22: 14$ & 40 & 72 & 1.03 & 1168 & 1168 & 3.49 & 83.69 \\
\hline $13: 30$ & $22: 29$ & 40 & 72 & 1.03 & 1190 & 1190 & 3.49 & 83.69 \\
\hline $13: 45$ & $22: 44$ & 40 & 73 & 1.03 & 1189 & 1189 & 3.49 & 83.69 \\
\hline $14: 00$ & $22: 59$ & 40 & 73 & 1.03 & 1183 & 1183 & 3.46 & 82.93 \\
\hline $14: 15$ & $23: 14$ & 40 & 74 & 1.03 & 1181 & 1181 & 3.36 & 80.65 \\
\hline $14: 30$ & $23: 29$ & 39 & 73 & 1.03 & 1186 & 1186 & 3.31 & 79.51 \\
\hline $14: 45$ & $23: 44$ & 40 & 73 & 1.03 & 1182 & 1182 & 3.22 & 77.22 \\
\hline $15: 00$ & $23: 59$ & 40 & 73 & 1.03 & 1187 & 1187 & 3.09 & 74.18 \\
\hline $15: 15$ & $0: 14$ & 40 & 73 & 1.03 & 1177 & 1177 & 3.09 & 74.18 \\
\hline $15: 30$ & $0: 29$ & 39 & 73 & 1.02 & 1182 & 1182 & 3.06 & 73.42 \\
\hline
\end{tabular}


Table A-6. ST-IIL Rotary Membrane Tests-100,000 Molecular Weight Cut-Off Membrane (ST-II-L Test 2) Raw Data Run Log

\begin{tabular}{|c|c|c|c|c|c|c|c|c|}
\hline $\begin{array}{l}\text { Time of } \\
\text { Day }\end{array}$ & $\begin{array}{l}\text { Elapsed } \\
\text { Time } \\
\text { (dd:hh:hm) }\end{array}$ & $\begin{array}{l}\text { Feed } \\
\text { Pressure } \\
\text { (psi) }\end{array}$ & $\begin{array}{l}\text { Feed } \\
\text { Temp. } \\
\left({ }^{\circ} \mathrm{F}\right)\end{array}$ & $\begin{array}{l}\text { Feed } \\
\text { Flow } \\
(\mathrm{gpm})\end{array}$ & $\begin{array}{l}\text { Rotor } \\
\text { Speed } \\
\text { (rpm) }\end{array}$ & $\begin{array}{c}\text { Rotor } \\
\text { Power } \\
(\mathrm{kW})\end{array}$ & $\begin{array}{c}\text { Permeate } \\
\text { Flow } \\
\text { (gph) }\end{array}$ & $\begin{array}{c}\text { Permeate Flux } \\
\text { (gal/ } / \mathrm{ft}^{2} \text {-day) }\end{array}$ \\
\hline $15: 09$ & $0: 00$ & 41 & 69 & 1.03 & 1185 & 1185 & 3.09 & 74.18 \\
\hline $15: 24$ & $0: 15$ & 40 & 71 & 1.01 & 1201 & 1201 & 3.15 & 75.70 \\
\hline $15: 39$ & $0: 30$ & 39 & 73 & 1.01 & 1200 & 1200 & 3.36 & 80.65 \\
\hline $15: 54$ & $0: 45$ & 39 & 74 & 1.01 & 1197 & 1197 & 3.42 & 82.17 \\
\hline $16: 09$ & 1:00 & 40 & 75 & 1.01 & 1206 & 1206 & 3.39 & 81.41 \\
\hline $16: 24$ & $1: 15$ & 40 & 76 & 1.00 & 1198 & 1198 & 3.49 & 83.69 \\
\hline $16: 39$ & $1: 30$ & 39 & 76 & 1.01 & 1196 & 1196 & 3.52 & 84.45 \\
\hline $16: 54$ & $1: 45$ & 40 & 77 & 1.00 & 1199 & 1199 & 3.68 & 88.25 \\
\hline $17: 09$ & $2: 00$ & 40 & 77 & 1.00 & 1198 & 1198 & 3.61 & 86.73 \\
\hline $17: 24$ & $2: 15$ & 40 & 77 & 1.00 & 1198 & 1198 & 3.68 & 88.25 \\
\hline $17: 39$ & $2: 30$ & 39 & 77 & 1.00 & 1195 & 1195 & 3.65 & 87.49 \\
\hline $17: 54$ & $2: 45$ & 39 & 78 & 1.01 & 1200 & 1200 & 3.68 & 88.25 \\
\hline 18:09 & $3: 00$ & 40 & 78 & 1.00 & 1200 & 1200 & 3.74 & 89.78 \\
\hline $18: 24$ & $3: 15$ & 39 & 78 & 1.00 & 1207 & 1207 & 3.71 & 89.02 \\
\hline $18: 39$ & $3: 30$ & 40 & 78 & 1.00 & 1200 & 1200 & 3.68 & 88.25 \\
\hline $18: 54$ & $3: 45$ & 39 & 78 & 1.01 & 1201 & 1201 & 3.71 & 89.02 \\
\hline 19:09 & 4:00 & 40 & 78 & 1.01 & 1205 & 1205 & 3.84 & 92.06 \\
\hline $19: 24$ & $4: 15$ & 39 & 78 & 1.00 & 1198 & 1198 & 3.77 & 90.54 \\
\hline $19: 39$ & $4: 30$ & 40 & 78 & 1.00 & 1195 & 1195 & 3.80 & 91.30 \\
\hline $19: 54$ & $4: 45$ & 40 & 78 & 1.00 & 1195 & 1195 & 3.84 & 92.06 \\
\hline 20:09 & $5: 00$ & 40 & 78 & 1.00 & 1200 & 1200 & 3.84 & 92.06 \\
\hline $20: 24$ & $5: 15$ & 39 & 78 & 0.98 & 1203 & 1203 & 3.77 & 90.54 \\
\hline $20: 39$ & $5: 30$ & 40 & 78 & 0.99 & 1198 & 1198 & 3.80 & 91.30 \\
\hline $20: 54$ & $5: 45$ & 40 & 78 & 1.00 & 1195 & 1195 & 3.87 & 92.82 \\
\hline 21:09 & $6: 00$ & 39 & 78 & 1.00 & 1195 & 1195 & 3.87 & 92.82 \\
\hline $21: 24$ & $6: 15$ & 39 & 78 & 1.00 & 1204 & 1204 & 3.84 & 92.06 \\
\hline $21: 39$ & $6: 30$ & 40 & 78 & 1.00 & 1195 & 1195 & 3.84 & 92.06 \\
\hline $21: 54$ & $6: 45$ & 39 & 78 & 1.00 & 1197 & 1197 & 3.93 & 94.34 \\
\hline 22:09 & 7:00 & 39 & 78 & 0.99 & 1198 & 1198 & 3.84 & 92.06 \\
\hline $22: 24$ & $7: 15$ & 39 & 78 & 1.00 & 1208 & 1208 & 3.87 & 92.82 \\
\hline $22: 39$ & $7: 30$ & 40 & 78 & 1.00 & 1199 & 1199 & 3.87 & 92.82 \\
\hline $22: 54$ & $7: 45$ & 40 & 78 & 1.00 & 1198 & 1198 & 3.87 & 92.82 \\
\hline 23:09 & 8:00 & 39 & 78 & 1.01 & 1197 & 1197 & 3.87 & 92.82 \\
\hline $23: 24$ & $8: 15$ & 40 & 78 & 1.00 & 1199 & 1199 & 3.90 & 93.58 \\
\hline $23: 39$ & $8: 30$ & 39 & 78 & 0.99 & 1198 & 1198 & 3.90 & 93.58 \\
\hline
\end{tabular}


Table A-6. (continued).

\begin{tabular}{|c|c|c|c|c|c|c|c|c|}
\hline $\begin{array}{c}\text { Time of } \\
\text { Day }\end{array}$ & $\begin{array}{c}\text { Elapsed } \\
\text { Time } \\
\text { (dd:hh:hm) }\end{array}$ & $\begin{array}{c}\text { Feed } \\
\text { Pressure } \\
\text { (psi) }\end{array}$ & $\begin{array}{c}\text { Feed } \\
\text { Temp. } \\
\left({ }^{\circ} \mathrm{F}\right)\end{array}$ & $\begin{array}{l}\text { Feed } \\
\text { Flow } \\
(\mathrm{gpm}) \\
\end{array}$ & $\begin{array}{l}\text { Rotor } \\
\text { Speed } \\
(\mathrm{rpm}) \\
\end{array}$ & $\begin{array}{c}\text { Rotor } \\
\text { Power } \\
(\mathrm{kW})\end{array}$ & $\begin{array}{c}\text { Permeate } \\
\text { Flow } \\
\text { (gph) }\end{array}$ & $\begin{array}{c}\text { Permeate Flux } \\
\left(\mathrm{gal} / \mathrm{ft}^{2} \text {-day }\right)\end{array}$ \\
\hline $23: 54$ & $8: 45$ & 40 & 78 & 1.00 & 1202 & 1202 & 3.80 & 91.30 \\
\hline $0: 00$ & $8: 50$ & 39 & 78 & 1.00 & 1201 & 1201 & 3.84 & 92.06 \\
\hline $0: 15$ & $9: 05$ & 40 & 78 & 1.01 & 1201 & 1201 & 3.87 & 92.82 \\
\hline $0: 30$ & $9: 20$ & 40 & 78 & 1.00 & 1195 & 1195 & 3.87 & 92.82 \\
\hline $0: 45$ & $9: 35$ & 40 & 78 & 1.00 & 1199 & 1199 & 3.84 & 92.06 \\
\hline $1: 00$ & $9: 50$ & 40 & 78 & 1.00 & 1199 & 1199 & 3.90 & 93.58 \\
\hline $1: 15$ & $10: 05$ & 39 & 78 & 1.00 & 1202 & 1202 & 3.90 & 93.58 \\
\hline $1: 30$ & $10: 20$ & 40 & 78 & 1.00 & 1198 & 1198 & 3.96 & 95.10 \\
\hline $1: 45$ & $10: 35$ & 40 & 79 & 1.00 & 1209 & 1209 & 3.87 & 92.82 \\
\hline $2: 00$ & $10: 50$ & 39 & 79 & 1.00 & 1197 & 1197 & 3.87 & 92.82 \\
\hline $2: 15$ & $11: 05$ & 40 & 78 & 1.00 & 1197 & 1197 & 3.93 & 94.34 \\
\hline $2: 30$ & $11: 20$ & 40 & 78 & 1.00 & 1202 & 1202 & 3.87 & 92.82 \\
\hline $2: 45$ & $11: 35$ & 39 & 78 & 1.00 & 1195 & 1195 & 3.90 & 93.58 \\
\hline $3: 00$ & $11: 50$ & 40 & 79 & 1.00 & 1202 & 1202 & 3.90 & 93.58 \\
\hline $3: 15$ & $12: 05$ & 39 & 78 & 0.99 & 1195 & 1195 & 3.90 & 93.58 \\
\hline $3: 30$ & $12: 20$ & 40 & 78 & 1.00 & 1196 & 1196 & 3.87 & 92.82 \\
\hline $3: 45$ & $12: 35$ & 40 & 79 & 1.00 & 1205 & 1205 & 3.90 & 93.58 \\
\hline $4: 00$ & $12: 50$ & 40 & 79 & 1.00 & 1195 & 1195 & 3.90 & 93.58 \\
\hline $4: 15$ & $13: 05$ & 40 & 79 & 1.00 & 1202 & 1202 & 3.87 & 92.82 \\
\hline $4: 30$ & $13: 20$ & 40 & 79 & 1.01 & 1199 & 1199 & 3.87 & 92.82 \\
\hline $4: 45$ & $13: 35$ & 40 & 79 & 1.00 & 1195 & 1195 & 3.93 & 94.34 \\
\hline $5: 00$ & $13: 50$ & 40 & 78 & 1.00 & 1197 & 1197 & 3.87 & 92.82 \\
\hline $5: 15$ & $14: 05$ & 39 & 79 & 1.00 & 1201 & 1201 & 3.93 & 94.34 \\
\hline $5: 30$ & $14: 20$ & 39 & 78 & 1.00 & 1200 & 1200 & 3.90 & 93.58 \\
\hline $5: 45$ & $14: 35$ & 39 & 78 & 1.00 & 1204 & 1204 & 3.90 & 93.58 \\
\hline $6: 00$ & $14: 50$ & 40 & 79 & 1.00 & 1200 & 1200 & 3.99 & 95.86 \\
\hline $6: 15$ & $15: 05$ & 39 & 79 & 1.00 & 1206 & 1206 & 3.77 & 90.54 \\
\hline $6: 30$ & $15: 20$ & 39 & 79 & 1.00 & 1201 & 1201 & 3.80 & 91.30 \\
\hline $6: 45$ & $15: 35$ & 39 & 79 & 1.00 & 1206 & 1206 & 3.87 & 92.82 \\
\hline 7:00 & $15: 50$ & 40 & 79 & 1.00 & 1197 & 1197 & 3.87 & 92.82 \\
\hline $7: 15$ & $16: 05$ & 39 & 79 & 1.01 & 1207 & 1207 & 3.90 & 93.58 \\
\hline $7: 30$ & $16: 20$ & 40 & 79 & 1.00 & 1200 & 1200 & 3.87 & 92.82 \\
\hline $7: 45$ & $16: 35$ & 40 & 79 & 1.00 & 1198 & 1198 & 3.93 & 94.34 \\
\hline $8: 00$ & $16: 50$ & 39 & 79 & 1.00 & 1197 & 1197 & 3.84 & 92.06 \\
\hline $8: 15$ & $17: 05$ & 39 & 79 & 1.00 & 1202 & 1202 & 3.99 & 95.86 \\
\hline $8: 30$ & $17: 20$ & 39 & 79 & 1.00 & 1198 & 1198 & 3.80 & 91.30 \\
\hline
\end{tabular}


Table A-6. (continued).

\begin{tabular}{|c|c|c|c|c|c|c|c|c|}
\hline $\begin{array}{l}\text { Time of } \\
\text { Day }\end{array}$ & $\begin{array}{c}\text { Elapsed } \\
\text { Time } \\
\text { (dd:hh:hm) }\end{array}$ & $\begin{array}{c}\text { Feed } \\
\text { Pressure } \\
(\mathrm{psi})\end{array}$ & $\begin{array}{c}\text { Feed } \\
\text { Temp. } \\
\left({ }^{\circ} \mathrm{F}\right)\end{array}$ & $\begin{array}{l}\text { Feed } \\
\text { Flow } \\
(\mathrm{gpm})\end{array}$ & $\begin{array}{l}\text { Rotor } \\
\text { Speed } \\
(\mathrm{rpm})\end{array}$ & $\begin{array}{c}\text { Rotor } \\
\text { Power } \\
(\mathrm{kW})\end{array}$ & $\begin{array}{c}\text { Permeate } \\
\text { Flow } \\
(\mathrm{gph})\end{array}$ & $\begin{array}{c}\text { Permeate Flux } \\
\text { (gal/ } / \mathrm{ft}^{2} \text {-day) }\end{array}$ \\
\hline $8: 45$ & $17: 35$ & 39 & 79 & 1.00 & 1198 & 1198 & 3.84 & 92.06 \\
\hline 9:00 & $17: 50$ & 39 & 79 & 1.00 & 1199 & 1199 & 3.93 & 94.34 \\
\hline $9: 15$ & $18: 05$ & 39 & 78 & 1.00 & 1200 & 1200 & 3.87 & 92.82 \\
\hline $9: 30$ & $18: 20$ & 40 & 78 & 1.00 & 1198 & 1198 & 3.87 & 92.82 \\
\hline $9: 45$ & $18: 35$ & 40 & 77 & 1.00 & 1199 & 1199 & 3.84 & 92.06 \\
\hline $10: 00$ & $18: 50$ & 39 & 77 & 1.00 & 1197 & 1197 & 3.87 & 92.82 \\
\hline $10: 15$ & $19: 05$ & 40 & 77 & 1.00 & 1196 & 1196 & 3.84 & 92.06 \\
\hline $10: 30$ & $19: 20$ & 39 & 77 & 1.01 & 1199 & 1199 & 3.84 & 92.06 \\
\hline $10: 45$ & $19: 35$ & 39 & 77 & 1.00 & 1203 & 1203 & 3.87 & 92.82 \\
\hline $11: 00$ & $19: 50$ & 40 & 77 & 1.00 & 1198 & 1198 & 3.90 & 93.58 \\
\hline $11: 15$ & $20: 05$ & 39 & 77 & 1.00 & 1197 & 1197 & 3.84 & 92.06 \\
\hline $11: 30$ & $20: 20$ & 39 & 77 & 1.00 & 1206 & 1206 & 3.80 & 91.30 \\
\hline $11: 45$ & $20: 35$ & 40 & 77 & 1.01 & 1198 & 1198 & 3.87 & 92.82 \\
\hline $12: 00$ & $20: 50$ & 39 & 77 & 1.00 & 1196 & 1196 & 3.84 & 92.06 \\
\hline $12: 15$ & $21: 05$ & 39 & 77 & 1.00 & 1198 & 1198 & 3.90 & 93.58 \\
\hline $12: 30$ & $21: 20$ & 39 & 77 & 1.00 & 1197 & 1197 & 3.84 & 92.06 \\
\hline $12: 45$ & $21: 35$ & 40 & 77 & 1.00 & 1199 & 1199 & 3.87 & 92.82 \\
\hline $13: 00$ & $21: 50$ & 39 & 77 & 0.99 & 1198 & 1198 & 3.87 & 92.82 \\
\hline $13: 15$ & $22: 05$ & 40 & 78 & 1.00 & 1199 & 1199 & 3.90 & 93.58 \\
\hline $13: 30$ & $22: 20$ & 39 & 78 & 1.00 & 1197 & 1197 & 3.84 & 92.06 \\
\hline $13: 45$ & $22: 35$ & 39 & 78 & 1.00 & 1196 & 1196 & 3.87 & 92.82 \\
\hline $14: 00$ & $22: 50$ & 40 & 78 & 1.00 & 1196 & 1196 & 3.84 & 92.06 \\
\hline $14: 15$ & $23: 05$ & 39 & 79 & 1.00 & 1202 & 1202 & 3.90 & 93.58 \\
\hline $14: 30$ & $23: 20$ & 40 & 78 & 1.00 & 1194 & 1194 & 3.87 & 92.82 \\
\hline $14: 45$ & $23: 35$ & 39 & 78 & 1.00 & 1197 & 1197 & 3.87 & 92.82 \\
\hline $15: 00$ & $23: 50$ & 39 & 79 & 1.00 & 1196 & 1196 & 3.77 & 90.54 \\
\hline $15: 15$ & 0:05 & 39 & 78 & 1.00 & 1194 & 1194 & 3.77 & 90.54 \\
\hline $15: 30$ & $0: 20$ & 40 & 78 & 1.00 & 1195 & 1195 & 3.80 & 91.30 \\
\hline $15: 45$ & $0: 35$ & 39 & 78 & 1.01 & 1195 & 1195 & 3.77 & 90.54 \\
\hline $16: 00$ & $0: 50$ & 40 & 77 & 1.00 & 1195 & 1195 & 3.77 & 90.54 \\
\hline $16: 15$ & $1: 05$ & 39 & 77 & 1.00 & 1196 & 1196 & 3.77 & 90.54 \\
\hline $16: 30$ & $1: 20$ & 40 & 77 & 1.03 & 1199 & 1199 & 3.55 & 85.21 \\
\hline $16: 45$ & $1: 35$ & 40 & 78 & 1.03 & 1201 & 1201 & 3.52 & 84.45 \\
\hline $17: 00$ & $1: 50$ & 40 & 78 & 1.02 & 1192 & 1192 & 3.49 & 83.69 \\
\hline $17: 15$ & $2: 05$ & 40 & 77 & 1.03 & 1197 & 1197 & 3.52 & 84.45 \\
\hline $17: 30$ & $2: 20$ & 40 & 78 & 1.02 & 1198 & 1198 & 3.49 & 83.69 \\
\hline $17: 45$ & $2: 35$ & 40 & 77 & 1.03 & 1195 & 1195 & 3.52 & 84.45 \\
\hline
\end{tabular}


Table A-7. ST-IIL Rotary Membrane Tests-100,000 Molecular Weight Cut-Off Membrane (ST-II-L Test 2) Concentration Data Run Log.

\begin{tabular}{|c|c|c|c|c|c|c|c|c|}
\hline $\begin{array}{c}\text { Time of } \\
\text { Day }\end{array}$ & $\begin{array}{l}\text { Elapsed } \\
\text { Time } \\
\text { (dd:hh:mm) }\end{array}$ & $\begin{array}{c}\text { Feed } \\
\text { Pressure } \\
\text { (psi) }\end{array}$ & $\begin{array}{l}\text { Feed } \\
\text { Temp } \\
\left({ }^{\circ} \mathrm{F}\right)\end{array}$ & $\begin{array}{l}\text { Feed } \\
\text { Flow } \\
(\text { gpm })\end{array}$ & $\begin{array}{l}\text { Rotor } \\
\text { Speed } \\
(\mathrm{rpm})\end{array}$ & $\begin{array}{c}\text { Rotor } \\
\text { Power } \\
(\mathrm{kW})\end{array}$ & $\begin{array}{c}\text { Permeate } \\
\text { Flow } \\
\text { (gph) }\end{array}$ & $\begin{array}{c}\text { Permeate Flux } \\
\text { (gal/ } / \mathrm{ft}^{2} \text {-day) }\end{array}$ \\
\hline $16: 45$ & $1: 35$ & 40 & 78 & 1.03 & 1201 & 1201 & 3.52 & 84.45 \\
\hline $17: 00$ & $1: 50$ & 40 & 78 & 1.02 & 1192 & 1192 & 3.49 & 83.69 \\
\hline $17: 15$ & $2: 05$ & 40 & 77 & 1.03 & 1197 & 1197 & 3.52 & 84.45 \\
\hline $17: 30$ & $2: 20$ & 40 & 78 & 1.02 & 1198 & 1198 & 3.49 & 83.69 \\
\hline $17: 45$ & $2: 35$ & 40 & 77 & 1.03 & 1195 & 1195 & 3.52 & 84.45 \\
\hline $18: 00$ & $2: 50$ & 40 & 77 & 1.02 & 1193 & 1193 & 3.52 & 84.45 \\
\hline $18: 15$ & $3: 05$ & 38 & 77 & 1.03 & 1208 & 1208 & 3.49 & 83.69 \\
\hline $18: 30$ & $3: 20$ & 39 & 78 & 1.02 & 1198 & 1198 & 3.55 & 85.21 \\
\hline $18: 45$ & $3: 35$ & 40 & 77 & 1.03 & 1199 & 1199 & 3.52 & 84.45 \\
\hline $19: 00$ & $3: 50$ & 40 & 77 & 1.01 & 1202 & 1202 & 3.46 & 82.93 \\
\hline $19: 15$ & 4:05 & 40 & 77 & 1.01 & 1197 & 1197 & 3.55 & 85.21 \\
\hline $19: 30$ & $4: 20$ & 39 & 77 & 1.02 & 1196 & 1196 & 3.49 & 83.69 \\
\hline $19: 45$ & $4: 35$ & 40 & 77 & 1.02 & 1198 & 1198 & 3.52 & 84.45 \\
\hline 20:00 & $4: 50$ & 40 & 77 & 1.02 & 1195 & 1195 & 3.52 & 84.45 \\
\hline $20: 15$ & $5: 05$ & 40 & 77 & 1.02 & 1197 & 1197 & 3.49 & 83.69 \\
\hline $20: 30$ & $5: 20$ & 39 & 77 & 1.02 & 1195 & 1195 & 3.49 & 83.69 \\
\hline $20: 45$ & $5: 35$ & 39 & 77 & 1.03 & 1205 & 1205 & 3.46 & 82.93 \\
\hline $21: 00$ & $5: 50$ & 40 & 77 & 1.03 & 1195 & 1195 & 3.49 & 83.69 \\
\hline $21: 15$ & $6: 05$ & 39 & 77 & 1.02 & 1197 & 1197 & 3.49 & 83.69 \\
\hline $21: 30$ & $6: 20$ & 39 & 77 & 1.03 & 1197 & 1197 & 3.52 & 84.45 \\
\hline $21: 45$ & $6: 35$ & 40 & 77 & 1.02 & 1204 & 1204 & 3.55 & 85.21 \\
\hline $22: 00$ & $6: 50$ & 39 & 77 & 1.02 & 1198 & 1198 & 3.49 & 83.69 \\
\hline $22: 15$ & $7: 05$ & 40 & 77 & 1.02 & 1195 & 1195 & 3.49 & 83.69 \\
\hline $22: 30$ & $7: 20$ & 40 & 77 & 1.02 & 1201 & 1201 & 3.49 & 83.69 \\
\hline $22: 45$ & $7: 35$ & 39 & 77 & 1.03 & 1196 & 1196 & 3.49 & 83.69 \\
\hline $23: 00$ & $7: 50$ & 40 & 77 & 1.02 & 1199 & 1199 & 3.49 & 83.69 \\
\hline $23: 15$ & $8: 05$ & 40 & 77 & 1.02 & 1205 & 1205 & 3.52 & 84.45 \\
\hline $23: 30$ & $8: 20$ & 39 & 77 & 1.02 & 1194 & 1194 & 3.52 & 84.45 \\
\hline $23: 45$ & $8: 35$ & 39 & 77 & 1.02 & 1201 & 1201 & 3.49 & 83.69 \\
\hline $0: 00$ & $8: 50$ & 40 & 77 & 1.03 & 1198 & 1198 & 3.52 & 84.45 \\
\hline $0: 15$ & 9:05 & 40 & 77 & 1.03 & 1196 & 1196 & 3.52 & 84.45 \\
\hline $0: 30$ & $9: 20$ & 39 & 77 & 1.03 & 1196 & 1196 & 3.52 & 84.45 \\
\hline $0: 45$ & $9: 35$ & 39 & 77 & 1.03 & 1199 & 1199 & 3.49 & 83.69 \\
\hline $1: 00$ & $9: 50$ & 40 & 77 & 1.02 & 1199 & 1199 & 3.46 & 82.93 \\
\hline $1: 15$ & $10: 05$ & 39 & 77 & 1.02 & 1203 & 1203 & 3.46 & 82.93 \\
\hline
\end{tabular}


Table 7. (continued).

\begin{tabular}{|c|c|c|c|c|c|c|c|c|}
\hline $\begin{array}{l}\text { Time of } \\
\text { Day }\end{array}$ & $\begin{array}{c}\text { Elapsed } \\
\text { Time } \\
\text { (dd:hh:mm) }\end{array}$ & $\begin{array}{l}\text { Feed } \\
\text { Pressure } \\
\text { (psi) }\end{array}$ & $\begin{array}{l}\text { Feed } \\
\text { Temp } \\
\left({ }^{\circ} \mathrm{F}\right)\end{array}$ & $\begin{array}{l}\text { Feed } \\
\text { Flow } \\
(\mathrm{gpm})\end{array}$ & $\begin{array}{l}\text { Rotor } \\
\text { Speed } \\
(\mathrm{rpm})\end{array}$ & $\begin{array}{c}\text { Rotor } \\
\text { Power } \\
(\mathrm{kW})\end{array}$ & $\begin{array}{c}\text { Permeate } \\
\text { Flow } \\
\text { (gph) }\end{array}$ & $\begin{array}{c}\text { Permeate Flux } \\
\text { (gal/ } / \mathrm{ft}^{2} \text {-day) }\end{array}$ \\
\hline $1: 30$ & $10: 20$ & 40 & 78 & 1.03 & 1198 & 1198 & 3.42 & 82.17 \\
\hline $1: 45$ & $10: 35$ & 39 & 77 & 1.03 & 1200 & 1200 & 3.46 & 82.93 \\
\hline $2: 00$ & $10: 50$ & 39 & 77 & 1.03 & 1196 & 1196 & 3.46 & 82.93 \\
\hline $2: 15$ & $11: 05$ & 39 & 77 & 1.03 & 1202 & 1202 & 3.46 & 82.93 \\
\hline $2: 30$ & $11: 20$ & 40 & 77 & 1.03 & 1195 & 1195 & 3.46 & 82.93 \\
\hline $2: 45$ & $11: 35$ & 40 & 77 & 1.03 & 1199 & 1199 & 3.46 & 82.93 \\
\hline 3:00 & $11: 50$ & 39 & 77 & 1.02 & 1199 & 1199 & 3.46 & 82.93 \\
\hline $3: 15$ & $12: 05$ & 39 & 77 & 1.03 & 1198 & 1198 & 3.39 & 81.41 \\
\hline $3: 30$ & $12: 20$ & 39 & 77 & 1.03 & 1197 & 1197 & 3.39 & 81.41 \\
\hline $3: 45$ & $12: 35$ & 39 & 77 & 1.03 & 1201 & 1201 & 3.39 & 81.41 \\
\hline 4:00 & $12: 50$ & 40 & 77 & 1.03 & 1200 & 1200 & 3.42 & 82.17 \\
\hline $4: 15$ & $13: 05$ & 40 & 77 & 1.03 & 1199 & 1199 & 3.39 & 81.41 \\
\hline $4: 30$ & $13: 20$ & 39 & 76 & 1.03 & 1206 & 1206 & 3.39 & 81.41 \\
\hline $4: 45$ & $13: 35$ & 39 & 76 & 1.03 & 1199 & 1199 & 3.36 & 80.65 \\
\hline 5:00 & $13: 50$ & 40 & 77 & 1.03 & 1205 & 1205 & 3.36 & 80.65 \\
\hline $5: 15$ & $14: 05$ & 39 & 77 & 1.03 & 1198 & 1198 & 3.39 & 81.41 \\
\hline $5: 30$ & $14: 20$ & 40 & 77 & 1.03 & 1201 & 1201 & 3.39 & 81.41 \\
\hline $5: 45$ & $14: 35$ & 40 & 77 & 1.03 & 1198 & 1198 & 3.36 & 80.65 \\
\hline $6: 00$ & $14: 50$ & 39 & 76 & 1.03 & 1201 & 1201 & 3.33 & 79.89 \\
\hline $6: 15$ & $15: 05$ & 39 & 76 & 1.03 & 1197 & 1197 & 3.31 & 79.51 \\
\hline $6: 30$ & $15: 20$ & 40 & 76 & 1.03 & 1202 & 1202 & 3.33 & 79.89 \\
\hline $6: 45$ & $15: 35$ & 39 & 76 & 1.02 & 1200 & 1200 & 3.33 & 79.89 \\
\hline $7: 00$ & $15: 50$ & 40 & 76 & 1.03 & 1197 & 1197 & 3.36 & 80.65 \\
\hline $7: 15$ & $16: 05$ & 40 & 76 & 1.03 & 1200 & 1200 & 3.39 & 81.41 \\
\hline $7: 30$ & $16: 20$ & 40 & 76 & 1.03 & 1199 & 1199 & 3.31 & 79.51 \\
\hline $7: 45$ & $16: 35$ & 39 & 76 & 1.03 & 1197 & 1197 & 3.36 & 80.65 \\
\hline 8:00 & $16: 50$ & 39 & 76 & 1.03 & 1199 & 1199 & 3.33 & 79.89 \\
\hline $8: 15$ & $17: 05$ & 40 & 77 & 1.03 & 1201 & 1201 & 3.39 & 81.41 \\
\hline $8: 30$ & $17: 20$ & 40 & 78 & 1.03 & 1203 & 1203 & 3.46 & 82.93 \\
\hline $8: 45$ & $17: 35$ & 40 & 79 & 1.02 & 1207 & 1207 & 3.39 & 81.41 \\
\hline 9:00 & $17: 50$ & 39 & 79 & 1.03 & 1197 & 1197 & 3.39 & 81.41 \\
\hline $9: 15$ & 18:05 & 40 & 79 & 1.03 & 1203 & 1203 & 3.33 & 79.89 \\
\hline 9:30 & $18: 20$ & 39 & 79 & 1.03 & 1199 & 1199 & 3.31 & 79.51 \\
\hline $9: 45$ & $18: 35$ & 40 & 79 & 1.03 & 1199 & 1199 & 3.36 & 80.65 \\
\hline 10:00 & $18: 50$ & 40 & 80 & 1.03 & 1199 & 1199 & 3.19 & 76.46 \\
\hline $10: 15$ & $19: 05$ & 40 & 80 & 1.03 & 1203 & 1203 & 3.25 & 77.98 \\
\hline
\end{tabular}


Table 7. (continued).

\begin{tabular}{ccccccccc}
\hline $\begin{array}{c}\text { Time of } \\
\text { Day }\end{array}$ & $\begin{array}{c}\text { Elapsed } \\
\text { Time } \\
(\mathrm{dd}: \mathrm{hh}: \mathrm{mm})\end{array}$ & $\begin{array}{c}\text { Feed } \\
\text { Pressure } \\
(\mathrm{psi})\end{array}$ & $\begin{array}{c}\text { Feed } \\
\text { Temp } \\
\left({ }^{\circ} \mathrm{F}\right)\end{array}$ & $\begin{array}{c}\text { Feed } \\
\text { Flow } \\
(\mathrm{gpm})\end{array}$ & $\begin{array}{c}\text { Rotor } \\
\text { Speed } \\
(\mathrm{rpm})\end{array}$ & $\begin{array}{c}\text { Rotor } \\
\text { Power } \\
(\mathrm{kW})\end{array}$ & $\begin{array}{c}\text { Permeate } \\
\text { Flow } \\
(\mathrm{gph})\end{array}$ & $\begin{array}{c}\text { Permeate Flux } \\
\left(\mathrm{gal} / \mathrm{ft}^{2} \text {-day }\right)\end{array}$ \\
\hline $10: 30$ & $19: 20$ & 39 & 80 & 1.02 & 1204 & 1204 & 3.25 & 77.98 \\
$10: 45$ & $19: 35$ & 39 & 79 & 1.03 & 1200 & 1200 & 3.25 & 77.98 \\
$11: 00$ & $19: 50$ & 40 & 80 & 1.04 & 1200 & 1200 & 3.15 & 75.70 \\
$11: 15$ & $20: 05$ & 39 & 80 & 1.03 & 1198 & 1198 & 3.15 & 75.70 \\
$11: 30$ & $20: 20$ & 40 & 79 & 1.03 & 1196 & 1196 & 3.09 & 74.18 \\
$11: 45$ & $20: 35$ & 40 & 79 & 1.03 & 1197 & 1197 & 3.06 & 73.42 \\
$12: 00$ & $20: 50$ & 40 & 80 & 1.02 & 1206 & 1206 & 3.06 & 73.42 \\
$12: 15$ & $21: 05$ & 40 & 79 & 1.03 & 1201 & 1201 & 2.93 & 70.38 \\
$12: 30$ & $21: 20$ & 40 & 79 & 1.02 & 1196 & 1196 & 2.90 & 69.61 \\
$12: 45$ & $21: 35$ & 40 & 80 & 1.03 & 1203 & 1203 & 2.84 & 68.09 \\
$13: 00$ & $21: 50$ & 40 & 80 & 1.03 & 1205 & 1205 & 2.77 & 66.57 \\
$13: 15$ & $22: 05$ & 40 & 79 & 1.03 & 1194 & 1194 & 2.66 & 63.91 \\
$13: 30$ & $22: 20$ & 40 & 80 & 1.03 & 1195 & 1195 & 2.60 & 62.39 \\
$13: 45$ & $22: 35$ & 40 & 80 & 1.03 & 1200 & 1200 & 2.50 & 60.10 \\
$14: 00$ & $22: 50$ & 40 & 80 & 1.02 & 1199 & 1199 & 2.38 & 57.06 \\
$14: 15$ & $23: 05$ & 40 & 80 & 1.03 & 1195 & 1195 & 2.22 & 53.26 \\
$14: 30$ & $23: 20$ & 39 & 80 & 1.03 & 1196 & 1196 & 2.09 & 50.21 \\
$14: 45$ & $23: 35$ & 40 & 80 & 1.03 & 1197 & 1197 & 1.98 & 47.55 \\
$15: 00$ & $23: 50$ & 40 & 79 & 1.03 & 1196 & 1196 & 1.76 & 42.23 \\
\hline
\end{tabular}


Table A-8. ST-IIL Rotary Membrane Tests-10,000 Molecular Weight Cut-Off Membrane (ST-II-1 10K Tests 3) Raw Data Run Log.

\begin{tabular}{|c|c|c|c|c|c|c|c|c|}
\hline $\begin{array}{l}\text { Time of } \\
\text { Day }\end{array}$ & $\begin{array}{l}\text { Elapsed } \\
\text { Time } \\
\text { (dd:hh:mm) }\end{array}$ & $\begin{array}{c}\text { Feed } \\
\text { Pressure } \\
\text { (psi) }\end{array}$ & $\begin{array}{c}\text { Feed } \\
\text { Temp. } \\
\left({ }^{\circ} \mathrm{F}\right)\end{array}$ & $\begin{array}{l}\text { Feed } \\
\text { Flow } \\
\text { (gpm) }\end{array}$ & $\begin{array}{l}\text { Rotor } \\
\text { Speed } \\
(\mathrm{rpm})\end{array}$ & $\begin{array}{c}\text { Rotor } \\
\text { Power } \\
(\mathrm{kW})\end{array}$ & $\begin{array}{c}\text { Permeate } \\
\text { Flow } \\
\text { (gph) }\end{array}$ & $\begin{array}{c}\text { Permeate Flux } \\
\text { (gal/ } / \mathrm{ft}^{2} \text {-day) }\end{array}$ \\
\hline $9: 41$ & $0: 00$ & 41 & 71 & 1.03 & 648 & 648 & 3.22 & 77.22 \\
\hline $9: 56$ & $0: 15$ & 39 & 72 & 1.03 & 640 & 640 & 2.57 & 61.63 \\
\hline 10:11 & $0: 30$ & 40 & 72 & 1.03 & 639 & 639 & 2.60 & 62.39 \\
\hline $10: 26$ & $0: 45$ & 40 & 73 & 1.03 & 1203 & 1203 & 2.66 & 63.91 \\
\hline 10:41 & $1: 00$ & 39 & 76 & 1.03 & 1203 & 1203 & 2.81 & 67.33 \\
\hline $10: 56$ & $1: 15$ & 40 & 77 & 1.03 & 1201 & 1201 & 2.96 & 71.14 \\
\hline 11:11 & $1: 30$ & 40 & 78 & 1.03 & 1209 & 1209 & 3.06 & 73.42 \\
\hline $11: 26$ & $1: 45$ & 40 & 79 & 1.03 & 1201 & 1201 & 3.06 & 73.42 \\
\hline $11: 41$ & $2: 00$ & 40 & 80 & 1.03 & 1202 & 1202 & 3.09 & 74.18 \\
\hline $11: 56$ & $2: 15$ & 39 & 81 & 1.03 & 1196 & 1196 & 3.25 & 77.98 \\
\hline $12: 11$ & $2: 30$ & 39 & 82 & 1.03 & 1201 & 1201 & 3.19 & 76.46 \\
\hline $12: 26$ & $2: 45$ & 39 & 82 & 1.03 & 1194 & 1194 & 3.15 & 75.70 \\
\hline $12: 41$ & $3: 00$ & 40 & 83 & 1.03 & 1192 & 1192 & 3.15 & 75.70 \\
\hline $12: 56$ & $3: 15$ & 39 & 83 & 1.02 & 1194 & 1194 & 3.15 & 75.70 \\
\hline $13: 11$ & $3: 30$ & 40 & 84 & 1.02 & 1197 & 1197 & 3.19 & 76.46 \\
\hline $13: 26$ & $3: 45$ & 40 & 84 & 1.03 & 1195 & 1195 & 3.33 & 79.89 \\
\hline $13: 41$ & 4:00 & 39 & 84 & 1.03 & 1179 & 1179 & 3.22 & 77.22 \\
\hline $13: 56$ & $4: 15$ & 39 & 84 & 1.02 & 1197 & 1197 & 3.19 & 76.46 \\
\hline 14:11 & $4: 30$ & 39 & 85 & 1.03 & 1197 & 1197 & 3.28 & 78.74 \\
\hline $14: 26$ & $4: 45$ & 40 & 85 & 1.03 & 1204 & 1204 & 3.28 & 78.74 \\
\hline $14: 41$ & $5: 00$ & 39 & 85 & 1.03 & 1190 & 1190 & 3.22 & 77.22 \\
\hline $14: 56$ & $5: 15$ & 40 & 86 & 1.02 & 1185 & 1185 & 3.31 & 79.51 \\
\hline $15: 11$ & $5: 30$ & 40 & 86 & 1.03 & 1197 & 1197 & 3.31 & 79.51 \\
\hline $15: 26$ & $5: 45$ & 40 & 86 & 1.02 & 1191 & 1191 & 3.42 & 82.17 \\
\hline $15: 41$ & $6: 00$ & 39 & 86 & 1.02 & 1193 & 1193 & 3.49 & 83.69 \\
\hline $15: 56$ & $6: 15$ & 39 & 86 & 1.03 & 1196 & 1196 & 3.22 & 77.22 \\
\hline $16: 11$ & $6: 30$ & 39 & 87 & 1.02 & 1198 & 1198 & 3.36 & 80.65 \\
\hline $16: 26$ & $6: 45$ & 40 & 87 & 1.03 & 1198 & 1198 & 3.42 & 82.17 \\
\hline $16: 41$ & 7:00 & 40 & 86 & 1.03 & 1196 & 1196 & 3.22 & 77.22 \\
\hline $16: 56$ & $7: 15$ & 40 & 86 & 1.02 & 1195 & 1195 & 3.31 & 79.51 \\
\hline $17: 11$ & $7: 30$ & 39 & 86 & 1.02 & 1192 & 1192 & 3.36 & 80.65 \\
\hline $17: 26$ & $7: 45$ & 39 & 87 & 1.02 & 1195 & 1195 & 3.46 & 82.93 \\
\hline $17: 41$ & $8: 00$ & 40 & 86 & 1.02 & 1197 & 1197 & 3.39 & 81.41 \\
\hline $17: 56$ & $8: 15$ & 40 & 87 & 1.02 & 1188 & 1188 & 3.36 & 80.65 \\
\hline $18: 11$ & $8: 30$ & 40 & 87 & 1.03 & 1190 & 1190 & 3.31 & 79.51 \\
\hline
\end{tabular}


Table A-8. (continued).

\begin{tabular}{|c|c|c|c|c|c|c|c|c|}
\hline $\begin{array}{c}\text { Time of } \\
\text { Day }\end{array}$ & $\begin{array}{c}\text { Elapsed } \\
\text { Time } \\
\text { (dd:hh:mm) }\end{array}$ & $\begin{array}{c}\text { Feed } \\
\text { Pressure } \\
(\mathrm{psi}) \\
\end{array}$ & $\begin{array}{l}\text { Feed } \\
\text { Temp. } \\
\left({ }^{\circ} \mathrm{F}\right)\end{array}$ & $\begin{array}{l}\text { Feed } \\
\text { Flow } \\
(\mathrm{gpm}) \\
\end{array}$ & $\begin{array}{l}\text { Rotor } \\
\text { Speed } \\
(\mathrm{rpm}) \\
\end{array}$ & $\begin{array}{c}\text { Rotor } \\
\text { Power } \\
(\mathrm{kW})\end{array}$ & $\begin{array}{c}\text { Permeate } \\
\text { Flow } \\
(\mathrm{gph}) \\
\end{array}$ & $\begin{array}{c}\text { Permeate Flux } \\
\left(\mathrm{gal} / \mathrm{ft}^{2} \text {-day) }\right.\end{array}$ \\
\hline $18: 26$ & $8: 45$ & 39 & 87 & 1.03 & 1197 & 1197 & 3.31 & 79.51 \\
\hline $18: 41$ & $9: 00$ & 40 & 87 & 1.03 & 1194 & 1194 & 3.39 & 81.41 \\
\hline $18: 56$ & $9: 15$ & 40 & 88 & 1.02 & 1201 & 1201 & 3.22 & 77.22 \\
\hline $19: 11$ & $9: 30$ & 40 & 87 & 1.03 & 1197 & 1197 & 3.31 & 79.51 \\
\hline $19: 26$ & $9: 45$ & 40 & 87 & 1.03 & 1202 & 1202 & 3.31 & 79.51 \\
\hline $19: 41$ & $10: 00$ & 40 & 86 & 1.03 & 1199 & 1199 & 3.28 & 78.74 \\
\hline $19: 56$ & $10: 15$ & 40 & 86 & 1.02 & 1194 & 1194 & 3.33 & 79.89 \\
\hline $20: 11$ & $10: 30$ & 39 & 87 & 1.02 & 1206 & 1206 & 3.36 & 80.65 \\
\hline $20: 26$ & $10: 45$ & 40 & 86 & 1.02 & 1197 & 1197 & 3.46 & 82.93 \\
\hline $20: 41$ & $11: 00$ & 40 & 87 & 1.03 & 1195 & 1195 & 3.36 & 80.65 \\
\hline $20: 56$ & $11: 15$ & 39 & 87 & 1.02 & 1202 & 1202 & 3.25 & 77.98 \\
\hline $21: 11$ & $11: 30$ & 39 & 87 & 1.02 & 1191 & 1191 & 3.39 & 81.41 \\
\hline $21: 26$ & $11: 45$ & 39 & 87 & 1.02 & 1198 & 1198 & 3.39 & 81.41 \\
\hline $21: 41$ & $12: 00$ & 39 & 87 & 1.02 & 1189 & 1189 & 3.33 & 79.89 \\
\hline $21: 56$ & $12: 15$ & 40 & 87 & 1.02 & 1188 & 1188 & 3.46 & 82.93 \\
\hline $22: 11$ & $12: 30$ & 39 & 87 & 1.02 & 1192 & 1192 & 3.15 & 75.70 \\
\hline $22: 26$ & $12: 45$ & 40 & 87 & 1.02 & 1199 & 1199 & 3.33 & 79.89 \\
\hline $22: 41$ & $13: 00$ & 40 & 87 & 1.03 & 1196 & 1196 & 3.25 & 77.98 \\
\hline $22: 56$ & $13: 15$ & 39 & 86 & 1.02 & 1194 & 1194 & 3.19 & 76.46 \\
\hline $23: 11$ & $13: 30$ & 39 & 87 & 1.03 & 1195 & 1195 & 3.15 & 75.70 \\
\hline $23: 26$ & $13: 45$ & 40 & 86 & 1.02 & 1196 & 1196 & 3.33 & 79.89 \\
\hline $23: 41$ & $14: 00$ & 39 & 86 & 1.02 & 1195 & 1195 & 3.25 & 77.98 \\
\hline $23: 56$ & $14: 15$ & 40 & 86 & 1.03 & 1198 & 1198 & 3.19 & 76.46 \\
\hline $0: 00$ & $14: 18$ & 39 & 87 & 1.03 & 1196 & 1196 & 3.39 & 81.41 \\
\hline $0: 15$ & $14: 33$ & 39 & 86 & 1.02 & 1195 & 1195 & 3.31 & 79.51 \\
\hline $0: 30$ & $14: 48$ & 39 & 87 & 1.02 & 1198 & 1198 & 3.12 & 74.94 \\
\hline $0: 45$ & $15: 03$ & 40 & 87 & 1.02 & 1190 & 1190 & 3.46 & 82.93 \\
\hline $1: 00$ & $15: 18$ & 40 & 87 & 1.02 & 1203 & 1203 & 3.22 & 77.22 \\
\hline $1: 15$ & $15: 33$ & 40 & 87 & 1.03 & 1191 & 1191 & 3.19 & 76.46 \\
\hline $1: 30$ & $15: 48$ & 40 & 86 & 1.03 & 1196 & 1196 & 3.09 & 74.18 \\
\hline $1: 45$ & $16: 03$ & 40 & 86 & 1.03 & 1193 & 1193 & 3.33 & 79.89 \\
\hline $2: 00$ & $16: 18$ & 40 & 87 & 1.03 & 1196 & 1196 & 3.33 & 79.89 \\
\hline $2: 15$ & $16: 33$ & 40 & 86 & 1.02 & 1192 & 1192 & 3.22 & 77.22 \\
\hline $2: 30$ & $16: 48$ & 40 & 87 & 1.03 & 1189 & 1189 & 3.09 & 74.18 \\
\hline $2: 45$ & $17: 03$ & 40 & 86 & 1.02 & 1194 & 1194 & 3.25 & 77.98 \\
\hline $3: 00$ & $17: 18$ & 40 & 86 & 1.03 & 1195 & 1195 & 3.19 & 76.46 \\
\hline
\end{tabular}


Table A-8. (continued).

\begin{tabular}{ccccccccc}
\hline $\begin{array}{c}\text { Time of } \\
\text { Day }\end{array}$ & $\begin{array}{c}\text { Elapsed } \\
\text { Time } \\
(\mathrm{dd}: \mathrm{hh}: \mathrm{mm})\end{array}$ & $\begin{array}{c}\text { Feed } \\
\text { Pressure } \\
(\mathrm{psi})\end{array}$ & $\begin{array}{c}\text { Feed } \\
\text { Temp. } \\
\left({ }^{\circ} \mathrm{F}\right)\end{array}$ & $\begin{array}{c}\text { Feed } \\
\text { Flow } \\
(\mathrm{gpm})\end{array}$ & $\begin{array}{c}\text { Rotor } \\
\text { Speed } \\
(\mathrm{rpm})\end{array}$ & $\begin{array}{c}\text { Rotor } \\
\text { Power } \\
(\mathrm{kW})\end{array}$ & $\begin{array}{c}\text { Permeate } \\
\text { Flow } \\
(\mathrm{gph})\end{array}$ & $\begin{array}{c}\text { Permeate Flux } \\
\left(\mathrm{gal} / \mathrm{ft}^{2} \text {-day }\right)\end{array}$ \\
\hline $3: 15$ & $17: 33$ & 40 & 86 & 1.02 & 1195 & 1195 & 3.31 & 79.51 \\
$3: 30$ & $17: 48$ & 39 & 87 & 1.02 & 1192 & 1192 & 3.19 & 76.46 \\
$3: 45$ & $18: 03$ & 39 & 87 & 1.02 & 1195 & 1195 & 3.15 & 75.70 \\
$4: 00$ & $18: 18$ & 39 & 86 & 1.02 & 1198 & 1198 & 3.15 & 75.70 \\
$4: 15$ & $18: 33$ & 39 & 86 & 1.02 & 1198 & 1198 & 3.31 & 79.51 \\
$4: 30$ & $18: 48$ & 39 & 86 & 1.03 & 1188 & 1188 & 3.31 & 79.51 \\
$4: 45$ & $19: 03$ & 40 & 86 & 1.02 & 1193 & 1193 & 3.06 & 73.42 \\
$5: 00$ & $19: 18$ & 40 & 86 & 1.02 & 1199 & 1199 & 3.19 & 76.46 \\
$5: 15$ & $19: 33$ & 40 & 86 & 1.02 & 1187 & 1187 & 3.42 & 82.17 \\
$5: 30$ & $19: 48$ & 39 & 86 & 1.02 & 1198 & 1198 & 3.22 & 77.22 \\
$5: 45$ & $20: 03$ & 40 & 86 & 1.02 & 1195 & 1195 & 3.28 & 78.74 \\
$6: 00$ & $20: 18$ & 40 & 85 & 1.03 & 1196 & 1196 & 3.19 & 76.46 \\
$6: 15$ & $20: 33$ & 39 & 86 & 1.01 & 1197 & 1197 & 3.22 & 77.22 \\
$6: 30$ & $20: 48$ & 40 & 86 & 1.01 & 1194 & 1194 & 3.55 & 85.21 \\
$6: 45$ & $21: 03$ & 40 & 86 & 1.01 & 1196 & 1196 & 3.28 & 78.74 \\
$7: 00$ & $21: 18$ & 39 & 86 & 1.00 & 1195 & 1195 & 3.61 & 86.73 \\
$7: 15$ & $21: 33$ & 40 & 85 & 1.00 & 1195 & 1195 & 3.55 & 85.21 \\
$7: 30$ & $21: 48$ & 40 & 85 & 1.00 & 1200 & 1200 & 3.36 & 80.65 \\
$7: 45$ & $22: 03$ & 40 & 85 & 1.00 & 1200 & 1200 & 3.52 & 84.45 \\
$8: 00$ & $22: 18$ & 40 & 84 & 1.00 & 1202 & 1202 & 3.25 & 77.98 \\
$8: 15$ & $22: 33$ & 40 & 80 & 1.01 & 1195 & 1195 & 3.15 & 75.70 \\
\hline & & & & & & & &
\end{tabular}


Table A-9. ST-IIL Rotary Membrane Tests-10,000 Molecular Weight Cut-Off Membrane (ST-II-1 10K Tests 3) Concentration Data Run Log.

\begin{tabular}{|c|c|c|c|c|c|c|c|c|}
\hline $\begin{array}{l}\text { Time of } \\
\text { Day }\end{array}$ & $\begin{array}{l}\text { Elapsed } \\
\text { Time } \\
\text { (dd:hh:mm) }\end{array}$ & $\begin{array}{c}\text { Feed } \\
\text { Pressure } \\
\text { (psi) }\end{array}$ & $\begin{array}{l}\text { Feed } \\
\text { Temp } \\
\left({ }^{\circ} \mathrm{F}\right)\end{array}$ & $\begin{array}{l}\text { Feed } \\
\text { Flow } \\
(\mathrm{gpm})\end{array}$ & $\begin{array}{l}\text { Rotor } \\
\text { Speed } \\
(\mathrm{rpm})\end{array}$ & $\begin{array}{c}\text { Rotor } \\
\text { Power } \\
(\mathrm{kW})\end{array}$ & $\begin{array}{c}\text { Permeate } \\
\text { Flow } \\
\text { (gph) }\end{array}$ & $\begin{array}{l}\text { Permeate Flux } \\
\text { (gal//ft'-day) }\end{array}$ \\
\hline $8: 30$ & $22: 48$ & 39 & 81 & 1.01 & 1202 & 1202 & 2.71 & 65.05 \\
\hline $8: 45$ & $23: 03$ & 39 & 82 & 1.02 & 1196 & 1196 & 2.68 & 64.29 \\
\hline 9:00 & $23: 18$ & 40 & 82 & 1.02 & 1197 & 1197 & 2.68 & 64.29 \\
\hline $9: 15$ & $23: 33$ & 39 & 82 & 1.02 & 1200 & 1200 & 2.63 & 63.15 \\
\hline $9: 30$ & $23: 48$ & 40 & 83 & 1.02 & 1198 & 1198 & 2.71 & 65.05 \\
\hline $9: 45$ & $0: 03$ & 39 & 84 & 1.02 & 1198 & 1198 & 2.74 & 65.81 \\
\hline $10: 00$ & $0: 18$ & 40 & 84 & 1.02 & 1195 & 1195 & 2.68 & 64.29 \\
\hline $10: 15$ & $0: 33$ & 39 & 85 & 1.02 & 1200 & 1200 & 2.68 & 64.29 \\
\hline $10: 30$ & $0: 48$ & 40 & 86 & 1.02 & 1194 & 1194 & 2.71 & 65.05 \\
\hline $10: 45$ & $1: 03$ & 40 & 86 & 1.01 & 1197 & 1197 & 2.90 & 69.61 \\
\hline 11:00 & $1: 18$ & 40 & 87 & 1.02 & 1199 & 1199 & 2.74 & 65.81 \\
\hline 11:15 & $1: 33$ & 39 & 86 & 1.03 & 1190 & 1190 & 2.77 & 66.57 \\
\hline $11: 30$ & $1: 48$ & 39 & 86 & 1.02 & 1194 & 1194 & 2.71 & 65.05 \\
\hline $11: 45$ & $2: 03$ & 39 & 86 & 1.03 & 1197 & 1197 & 2.90 & 69.61 \\
\hline $12: 00$ & $2: 18$ & 40 & 86 & 1.02 & 1198 & 1198 & 2.77 & 66.57 \\
\hline $12: 15$ & $2: 33$ & 39 & 87 & 1.02 & 1197 & 1197 & 2.71 & 65.05 \\
\hline $12: 30$ & $2: 48$ & 40 & 86 & 1.02 & 1195 & 1195 & 2.87 & 68.85 \\
\hline $12: 45$ & $3: 03$ & 39 & 87 & 1.03 & 1190 & 1190 & 3.00 & 71.90 \\
\hline $13: 00$ & $3: 18$ & 39 & 87 & 1.02 & 1201 & 1201 & 2.54 & 60.87 \\
\hline $13: 15$ & $3: 33$ & 40 & 87 & 1.02 & 1198 & 1198 & 2.71 & 65.05 \\
\hline $13: 30$ & $3: 48$ & 39 & 86 & 1.01 & 1203 & 1203 & 2.68 & 64.29 \\
\hline $13: 45$ & 4:03 & 40 & 86 & 1.02 & 1196 & 1196 & 2.71 & 65.05 \\
\hline $14: 00$ & $4: 18$ & 40 & 86 & 1.01 & 1198 & 1198 & 2.71 & 65.05 \\
\hline $14: 15$ & $4: 33$ & 39 & 86 & 1.02 & 1193 & 1193 & 2.74 & 65.81 \\
\hline $14: 30$ & $4: 48$ & 40 & 87 & 1.02 & 1195 & 1195 & 2.50 & 60.10 \\
\hline $14: 45$ & 5:03 & 40 & 86 & 1.03 & 1192 & 1192 & 2.57 & 61.63 \\
\hline $15: 00$ & $5: 18$ & 40 & 86 & 1.02 & 1200 & 1200 & 2.54 & 60.87 \\
\hline $15: 15$ & $5: 33$ & 39 & 87 & 1.02 & 1195 & 1195 & 2.47 & 59.34 \\
\hline $15: 30$ & $5: 48$ & 40 & 86 & 1.03 & 1196 & 1196 & 2.57 & 61.63 \\
\hline $15: 45$ & $6: 03$ & 39 & 86 & 1.03 & 1194 & 1194 & 2.60 & 62.39 \\
\hline $16: 00$ & $6: 18$ & 39 & 86 & 1.03 & 1198 & 1198 & 2.63 & 63.15 \\
\hline $16: 15$ & $6: 33$ & 39 & 86 & 1.01 & 1193 & 1193 & 2.57 & 61.63 \\
\hline $16: 30$ & $6: 48$ & 39 & 86 & 1.02 & 1193 & 1193 & 2.57 & 61.63 \\
\hline $16: 45$ & $7: 03$ & 40 & 87 & 1.03 & 1192 & 1192 & 2.35 & 56.30 \\
\hline $17: 00$ & $7: 18$ & 39 & 86 & 1.02 & 1196 & 1196 & 2.41 & 57.82 \\
\hline
\end{tabular}


Table A-9. (continued).

\begin{tabular}{|c|c|c|c|c|c|c|c|c|}
\hline $\begin{array}{l}\text { Time of } \\
\text { Day }\end{array}$ & $\begin{array}{c}\text { Elapsed } \\
\text { Time } \\
\text { (dd:hh:mm) }\end{array}$ & $\begin{array}{c}\text { Feed } \\
\text { Pressure } \\
(\mathrm{psi})\end{array}$ & $\begin{array}{c}\text { Feed } \\
\text { Temp } \\
\left({ }^{\circ} \mathrm{F}\right) \\
\end{array}$ & $\begin{array}{l}\text { Feed } \\
\text { Flow } \\
(\mathrm{gpm}) \\
\end{array}$ & $\begin{array}{l}\text { Rotor } \\
\text { Speed } \\
(\mathrm{rpm}) \\
\end{array}$ & $\begin{array}{c}\text { Rotor } \\
\text { Power } \\
(\mathrm{kW})\end{array}$ & $\begin{array}{c}\text { Permeate } \\
\text { Flow } \\
(\mathrm{gph}) \\
\end{array}$ & $\begin{array}{c}\text { Permeate Flux } \\
\left(\mathrm{gal} / \mathrm{ft}^{2} \text {-day }\right)\end{array}$ \\
\hline $17: 15$ & $7: 33$ & 40 & 86 & 1.01 & 1195 & 1195 & 2.44 & 58.58 \\
\hline $17: 30$ & $7: 48$ & 39 & 85 & 1.03 & 1189 & 1189 & 2.44 & 58.58 \\
\hline $17: 45$ & $8: 03$ & 39 & 85 & 1.02 & 1196 & 1196 & 2.41 & 57.82 \\
\hline $18: 00$ & $8: 18$ & 40 & 85 & 1.03 & 1196 & 1196 & 2.47 & 59.34 \\
\hline $18: 15$ & $8: 33$ & 39 & 85 & 1.02 & 1194 & 1194 & 2.41 & 57.82 \\
\hline $18: 30$ & $8: 48$ & 39 & 85 & 1.02 & 1197 & 1197 & 2.44 & 58.58 \\
\hline $18: 45$ & $9: 03$ & 40 & 85 & 1.03 & 1192 & 1192 & 2.41 & 57.82 \\
\hline $19: 00$ & $9: 18$ & 40 & 85 & 1.03 & 1195 & 1195 & 2.41 & 57.82 \\
\hline $19: 15$ & $9: 33$ & 40 & 85 & 1.02 & 1188 & 1188 & 2.41 & 57.82 \\
\hline $19: 30$ & $9: 48$ & 40 & 85 & 1.02 & 1188 & 1188 & 2.38 & 57.06 \\
\hline $19: 45$ & $10: 03$ & 40 & 84 & 1.02 & 1199 & 1199 & 2.38 & 57.06 \\
\hline $20: 00$ & $10: 18$ & 39 & 85 & 1.02 & 1192 & 1192 & 2.41 & 57.82 \\
\hline $20: 15$ & $10: 33$ & 40 & 84 & 1.03 & 1195 & 1195 & 2.47 & 59.34 \\
\hline $20: 30$ & $10: 48$ & 39 & 85 & 1.02 & 1202 & 1202 & 2.38 & 57.06 \\
\hline $20: 45$ & $11: 03$ & 40 & 85 & 1.03 & 1198 & 1198 & 2.41 & 57.82 \\
\hline $21: 00$ & $11: 18$ & 40 & 84 & 1.02 & 1203 & 1203 & 2.41 & 57.82 \\
\hline $21: 15$ & $11: 33$ & 40 & 85 & 1.03 & 1202 & 1202 & 2.47 & 59.34 \\
\hline $21: 30$ & $11: 48$ & 39 & 84 & 1.02 & 1197 & 1197 & 2.50 & 60.10 \\
\hline $21: 45$ & $12: 03$ & 39 & 84 & 1.02 & 1197 & 1197 & 2.47 & 59.34 \\
\hline $22: 00$ & $12: 18$ & 39 & 84 & 1.02 & 1195 & 1195 & 2.63 & 63.15 \\
\hline $22: 15$ & $12: 33$ & 40 & 84 & 1.02 & 1192 & 1192 & 2.66 & 63.91 \\
\hline $22: 30$ & $12: 48$ & 40 & 84 & 1.03 & 1196 & 1196 & 2.22 & 53.26 \\
\hline $22: 45$ & $13: 03$ & 39 & 85 & 1.02 & 1197 & 1197 & 2.38 & 57.06 \\
\hline $23: 00$ & $13: 18$ & 39 & 85 & 1.03 & 1194 & 1194 & 2.35 & 56.30 \\
\hline $23: 15$ & $13: 33$ & 39 & 85 & 1.02 & 1202 & 1202 & 2.31 & 55.54 \\
\hline $23: 30$ & $13: 48$ & 40 & 85 & 1.03 & 1201 & 1201 & 2.41 & 57.82 \\
\hline $23: 45$ & $14: 03$ & 40 & 84 & 1.02 & 1198 & 1198 & 2.38 & 57.06 \\
\hline $0: 00$ & $14: 18$ & 39 & 84 & 1.03 & 1198 & 1198 & 2.28 & 54.78 \\
\hline $0: 15$ & $14: 33$ & 39 & 85 & 1.02 & 1197 & 1197 & 2.38 & 57.06 \\
\hline $0: 30$ & $14: 48$ & 39 & 85 & 1.03 & 1189 & 1189 & 2.38 & 57.06 \\
\hline $0: 45$ & $15: 03$ & 39 & 85 & 1.02 & 1198 & 1198 & 2.35 & 56.30 \\
\hline $1: 00$ & $15: 18$ & 39 & 84 & 1.02 & 1195 & 1195 & 2.38 & 57.06 \\
\hline $1: 15$ & $15: 33$ & 39 & 84 & 1.03 & 1195 & 1195 & 2.35 & 56.30 \\
\hline $1: 30$ & $15: 48$ & 40 & 84 & 1.03 & 1188 & 1188 & 2.28 & 54.78 \\
\hline $1: 45$ & $16: 03$ & 39 & 84 & 1.03 & 1204 & 1204 & 2.44 & 58.58 \\
\hline $2: 00$ & $16: 18$ & 41 & 84 & 1.02 & 1195 & 1195 & 2.41 & 57.82 \\
\hline
\end{tabular}


Table A-9. (continued).

\begin{tabular}{|c|c|c|c|c|c|c|c|c|}
\hline $\begin{array}{c}\text { Time of } \\
\text { Day }\end{array}$ & $\begin{array}{c}\text { Elapsed } \\
\text { Time } \\
\text { (dd:hh:mm) }\end{array}$ & $\begin{array}{c}\text { Feed } \\
\text { Pressure } \\
(\mathrm{psi}) \\
\end{array}$ & $\begin{array}{c}\text { Feed } \\
\text { Temp } \\
\left({ }^{\circ} \mathrm{F}\right) \\
\end{array}$ & $\begin{array}{l}\text { Feed } \\
\text { Flow } \\
(\mathrm{gpm}) \\
\end{array}$ & $\begin{array}{l}\text { Rotor } \\
\text { Speed } \\
(\mathrm{rpm}) \\
\end{array}$ & $\begin{array}{c}\text { Rotor } \\
\text { Power } \\
(\mathrm{kW}) \\
\end{array}$ & $\begin{array}{c}\text { Permeate } \\
\text { Flow } \\
(\mathrm{gph}) \\
\end{array}$ & $\begin{array}{c}\text { Permeate Flux } \\
\left(\mathrm{gal} / \mathrm{ft}^{2} \text {-day }\right)\end{array}$ \\
\hline $2: 15$ & $16: 33$ & 40 & 85 & 1.02 & 1196 & 1196 & 2.31 & 55.54 \\
\hline $2: 30$ & $16: 48$ & 40 & 84 & 1.02 & 1199 & 1199 & 2.25 & 54.02 \\
\hline $2: 45$ & $17: 03$ & 40 & 84 & 1.03 & 1195 & 1195 & 2.71 & 65.05 \\
\hline $3: 00$ & $17: 18$ & 40 & 84 & 1.02 & 1193 & 1193 & 2.74 & 65.81 \\
\hline $3: 15$ & $17: 33$ & 40 & 84 & 1.03 & 1193 & 1193 & 2.35 & 56.30 \\
\hline $3: 30$ & $17: 48$ & 39 & 84 & 1.02 & 1204 & 1204 & 2.54 & 60.87 \\
\hline $3: 45$ & $18: 03$ & 40 & 85 & 1.02 & 1196 & 1196 & 2.28 & 54.78 \\
\hline $4: 00$ & $18: 18$ & 40 & 84 & 1.02 & 1196 & 1196 & 2.31 & 55.54 \\
\hline $4: 15$ & $18: 33$ & 40 & 85 & 1.02 & 1196 & 1196 & 2.25 & 54.02 \\
\hline $4: 30$ & $18: 48$ & 39 & 85 & 1.03 & 1194 & 1194 & 2.28 & 54.78 \\
\hline $4: 45$ & $19: 03$ & 40 & 84 & 1.02 & 1196 & 1196 & 2.16 & 51.74 \\
\hline 5:00 & $19: 18$ & 40 & 84 & 1.03 & 1199 & 1199 & 2.50 & 60.10 \\
\hline $5: 15$ & $19: 33$ & 40 & 84 & 1.03 & 1202 & 1202 & 2.09 & 50.21 \\
\hline $5: 30$ & $19: 48$ & 40 & 84 & 1.02 & 1192 & 1192 & 2.35 & 56.30 \\
\hline $5: 45$ & $20: 03$ & 39 & 85 & 1.02 & 1195 & 1195 & 2.63 & 63.15 \\
\hline $6: 00$ & $20: 18$ & 40 & 84 & 1.02 & 1195 & 1195 & 2.41 & 57.82 \\
\hline $6: 15$ & $20: 33$ & 39 & 85 & 1.03 & 1197 & 1197 & 2.03 & 48.69 \\
\hline $6: 30$ & $20: 48$ & 40 & 84 & 1.03 & 1187 & 1187 & 2.35 & 56.30 \\
\hline $6: 45$ & $21: 03$ & 39 & 84 & 1.03 & 1198 & 1198 & 2.35 & 56.30 \\
\hline 7:00 & $21: 18$ & 39 & 84 & 1.03 & 1196 & 1196 & 2.57 & 61.63 \\
\hline $7: 15$ & $21: 33$ & 40 & 84 & 1.02 & 1199 & 1199 & 2.54 & 60.87 \\
\hline $7: 30$ & $21: 48$ & 39 & 85 & 1.02 & 1198 & 1198 & 2.31 & 55.54 \\
\hline $7: 45$ & $22: 03$ & 40 & 84 & 1.02 & 1197 & 1197 & 2.03 & 48.69 \\
\hline $8: 00$ & $22: 18$ & 39 & 84 & 1.03 & 1197 & 1197 & 2.41 & 57.82 \\
\hline $8: 15$ & $22: 33$ & 39 & 85 & 1.02 & 1199 & 1199 & 2.25 & 54.02 \\
\hline $8: 30$ & $22: 48$ & 39 & 84 & 1.02 & 1199 & 1199 & 2.41 & 57.82 \\
\hline $8: 45$ & $23: 03$ & 39 & 85 & 1.02 & 1196 & 1196 & 2.28 & 54.78 \\
\hline $9: 00$ & $23: 18$ & 39 & 84 & 1.02 & 1197 & 1197 & 2.31 & 55.54 \\
\hline $9: 15$ & $23: 33$ & 39 & 85 & 1.02 & 1193 & 1193 & 2.35 & 56.30 \\
\hline $9: 30$ & $23: 48$ & 39 & 85 & 1.02 & 1197 & 1197 & 2.41 & 57.82 \\
\hline $9: 45$ & 0:03 & 39 & 85 & 1.02 & 1197 & 1197 & 2.38 & 57.06 \\
\hline $10: 00$ & $0: 18$ & 39 & 84 & 1.03 & 1191 & 1191 & 2.25 & 54.02 \\
\hline $10: 15$ & $0: 33$ & 40 & 85 & 1.02 & 1196 & 1196 & 2.31 & 55.54 \\
\hline $10: 30$ & $0: 48$ & 39 & 86 & 1.02 & 1196 & 1196 & 2.35 & 56.30 \\
\hline $10: 45$ & $1: 03$ & 39 & 86 & 1.02 & 1196 & 1196 & 2.44 & 58.58 \\
\hline $11: 00$ & $1: 18$ & 40 & 81 & 0.00 & 1196 & 1196 & 2.35 & 56.30 \\
\hline
\end{tabular}


Table A-9. (continued).

\begin{tabular}{|c|c|c|c|c|c|c|c|c|}
\hline $\begin{array}{c}\text { Time of } \\
\text { Day }\end{array}$ & $\begin{array}{c}\text { Elapsed } \\
\text { Time } \\
\text { (dd:hh:mm) }\end{array}$ & $\begin{array}{c}\text { Feed } \\
\text { Pressure } \\
(\mathrm{psi}) \\
\end{array}$ & $\begin{array}{l}\text { Feed } \\
\text { Temp } \\
\left({ }^{\circ} \mathrm{F}\right)\end{array}$ & $\begin{array}{l}\text { Feed } \\
\text { Flow } \\
(\mathrm{gpm})\end{array}$ & $\begin{array}{l}\text { Rotor } \\
\text { Speed } \\
(\mathrm{rpm}) \\
\end{array}$ & $\begin{array}{c}\text { Rotor } \\
\text { Power } \\
(\mathrm{kW})\end{array}$ & $\begin{array}{c}\text { Permeate } \\
\text { Flow } \\
\text { (gph) }\end{array}$ & $\begin{array}{c}\text { Permeate Flux } \\
\left(\mathrm{gal} / \mathrm{ft}^{2} \text {-day) }\right.\end{array}$ \\
\hline $11: 15$ & $1: 33$ & 40 & 80 & 0.00 & 1196 & 1196 & 2.31 & 55.54 \\
\hline $11: 30$ & $1: 48$ & 39 & 86 & 1.03 & 1202 & 1202 & 2.03 & 48.69 \\
\hline $11: 45$ & $2: 03$ & 39 & 86 & 1.03 & 1195 & 1195 & 2.22 & 53.26 \\
\hline $12: 00$ & $2: 18$ & 40 & 86 & 1.03 & 1198 & 1198 & 2.28 & 54.78 \\
\hline $12: 15$ & $2: 33$ & 40 & 86 & 1.02 & 1200 & 1200 & 2.31 & 55.54 \\
\hline $12: 36$ & $2: 54$ & 40 & 86 & 1.01 & 1202 & 1202 & 2.22 & 53.26 \\
\hline $12: 51$ & $3: 09$ & 39 & 87 & 1.02 & 1196 & 1196 & 2.22 & 53.26 \\
\hline $13: 06$ & $3: 24$ & 40 & 86 & 1.02 & 1194 & 1194 & 2.28 & 54.78 \\
\hline $13: 21$ & $3: 39$ & 39 & 86 & 1.03 & 1195 & 1195 & 2.28 & 54.78 \\
\hline $13: 36$ & $3: 54$ & 39 & 87 & 1.03 & 1197 & 1197 & 2.16 & 51.74 \\
\hline $13: 51$ & 4:09 & 40 & 85 & 1.02 & 1190 & 1190 & 2.31 & 55.54 \\
\hline $14: 06$ & $4: 24$ & 39 & 86 & 1.01 & 1191 & 1191 & 2.28 & 54.78 \\
\hline $14: 21$ & $4: 39$ & 39 & 86 & 1.03 & 1188 & 1188 & 2.35 & 56.30 \\
\hline $14: 36$ & $4: 54$ & 40 & 86 & 1.04 & 1189 & 1189 & 2.28 & 54.78 \\
\hline $14: 51$ & 5:09 & 40 & 87 & 1.03 & 1196 & 1196 & 2.22 & 53.26 \\
\hline $15: 06$ & $5: 24$ & 40 & 87 & 1.03 & 1194 & 1194 & 2.19 & 52.50 \\
\hline $15: 21$ & $5: 39$ & 39 & 86 & 1.03 & 1188 & 1188 & 2.25 & 54.02 \\
\hline $15: 36$ & $5: 54$ & 40 & 86 & 1.03 & 1195 & 1195 & 2.31 & 55.54 \\
\hline $15: 51$ & $6: 09$ & 39 & 86 & 1.02 & 1187 & 1187 & 2.16 & 51.74 \\
\hline $16: 06$ & $6: 24$ & 40 & 87 & 1.02 & 1198 & 1198 & 2.28 & 54.78 \\
\hline $16: 21$ & $6: 39$ & 39 & 87 & 1.02 & 1197 & 1197 & 2.19 & 52.50 \\
\hline $16: 36$ & $6: 54$ & 39 & 86 & 1.02 & 1184 & 1184 & 2.19 & 52.50 \\
\hline $16: 51$ & 7:09 & 40 & 87 & 1.02 & 1195 & 1195 & 2.22 & 53.26 \\
\hline $17: 06$ & $7: 24$ & 39 & 87 & 1.02 & 1195 & 1195 & 2.16 & 51.74 \\
\hline $17: 21$ & $7: 39$ & 39 & 86 & 1.02 & 1198 & 1198 & 2.31 & 55.54 \\
\hline $17: 36$ & $7: 54$ & 40 & 86 & 1.02 & 1194 & 1194 & 2.12 & 50.97 \\
\hline $17: 51$ & 8:09 & 39 & 87 & 1.02 & 1202 & 1202 & 2.19 & 52.50 \\
\hline $18: 06$ & $8: 24$ & 39 & 86 & 1.03 & 1195 & 1195 & 2.35 & 56.30 \\
\hline $18: 21$ & $8: 39$ & 39 & 88 & 1.03 & 1195 & 1195 & 2.09 & 50.21 \\
\hline $18: 36$ & $8: 54$ & 40 & 87 & 1.03 & 1192 & 1192 & 2.06 & 49.45 \\
\hline $18: 51$ & $9: 09$ & 40 & 86 & 1.03 & 1194 & 1194 & 2.19 & 52.50 \\
\hline $19: 06$ & $9: 24$ & 40 & 86 & 1.02 & 1194 & 1194 & 2.12 & 50.97 \\
\hline $19: 21$ & $9: 39$ & 39 & 86 & 1.03 & 1189 & 1189 & 2.09 & 50.21 \\
\hline $19: 36$ & $9: 54$ & 40 & 86 & 1.02 & 1196 & 1196 & 2.16 & 51.74 \\
\hline $19: 51$ & $10: 09$ & 40 & 86 & 1.02 & 1195 & 1195 & 2.06 & 49.45 \\
\hline $20: 06$ & $10: 24$ & 39 & 86 & 1.03 & 1186 & 1186 & 2.06 & 49.45 \\
\hline $20: 21$ & $10: 39$ & 39 & 86 & 1.02 & 1195 & 1195 & 1.95 & 46.79 \\
\hline
\end{tabular}


Table A-9. (continued).

\begin{tabular}{ccccccccc}
\hline $\begin{array}{c}\text { Time of } \\
\text { Day }\end{array}$ & $\begin{array}{c}\text { Elapsed } \\
\text { Time } \\
(\mathrm{dd}: \mathrm{hh}: \mathrm{mm})\end{array}$ & $\begin{array}{c}\text { Feed } \\
\text { Pressure } \\
(\mathrm{psi})\end{array}$ & $\begin{array}{c}\text { Feed } \\
\text { Temp } \\
\left({ }^{\circ} \mathrm{F}\right)\end{array}$ & $\begin{array}{c}\text { Feed } \\
\text { Flow } \\
(\mathrm{gpm})\end{array}$ & $\begin{array}{c}\text { Rotor } \\
\text { Speed } \\
(\mathrm{rpm})\end{array}$ & $\begin{array}{c}\text { Rotor } \\
\text { Power } \\
(\mathrm{kW})\end{array}$ & $\begin{array}{c}\text { Permeate } \\
\begin{array}{c}\text { Flow } \\
(\mathrm{gph})\end{array}\end{array}$ & $\begin{array}{c}\text { Permeate Flux } \\
\left(\mathrm{gal} / \mathrm{ft}^{2} \text {-day }\right)\end{array}$ \\
\hline $20: 36$ & $10: 54$ & 39 & 87 & 1.02 & 1199 & 1199 & 2.00 & 47.93 \\
$20: 51$ & $11: 09$ & 40 & 87 & 1.02 & 1195 & 1195 & 2.03 & 48.69 \\
$21: 06$ & $11: 24$ & 40 & 87 & 1.02 & 1195 & 1195 & 2.03 & 48.69 \\
$21: 21$ & $11: 39$ & 39 & 85 & 1.02 & 1196 & 1196 & 2.00 & 47.93 \\
$21: 36$ & $11: 54$ & 40 & 86 & 1.03 & 1201 & 1201 & 1.98 & 47.55 \\
$21: 51$ & $12: 09$ & 39 & 86 & 1.01 & 1196 & 1196 & 1.89 & 45.27 \\
$22: 06$ & $12: 24$ & 39 & 86 & 1.01 & 1199 & 1199 & 1.82 & 43.75 \\
$22: 21$ & $12: 39$ & 39 & 86 & 1.02 & 1200 & 1200 & 1.89 & 45.27 \\
$22: 36$ & $12: 54$ & 39 & 86 & 1.02 & 1196 & 1196 & 1.73 & 41.46 \\
$22: 51$ & $13: 09$ & 39 & 86 & 1.02 & 1197 & 1197 & 1.73 & 41.46 \\
$23: 06$ & $13: 24$ & 40 & 86 & 1.02 & 1196 & 1196 & 1.73 & 41.46 \\
\hline
\end{tabular}


Table A-10. STC Five-Day Cleaning Test-Static Nano Raw Data Run Log

Membrane: 0.015 nominal $\mu$

Surface Area: 0.05

Feed Sample: Metaldyne Wastewater

Initial Feed Volume: $5 \mathrm{~L}$

Final Feed Volume: $5 \mathrm{~L}$

Final Concentrate: $1 \mathrm{x}$

Operator: Jason Gilmour

Final Flux: 25 gfd

Date: $3 / 9 / 00$

\begin{tabular}{|c|c|c|c|c|c|c|c|c|}
\hline $\begin{array}{l}\text { Time of } \\
\text { Day } \\
\text { (hh:mm) }\end{array}$ & $\begin{array}{l}\text { Elapsed } \\
\text { Time } \\
\text { (hh:mm) }\end{array}$ & $\begin{array}{c}\text { Feed Flow } \\
\text { (gal/min) }\end{array}$ & $\begin{array}{r}\text { Feed } \\
\text { Press. } \\
\text { (psi) }\end{array}$ & $\begin{array}{l}\text { Conc. } \\
\text { Press. } \\
\text { (psi) }\end{array}$ & $\begin{array}{l}\text { Feed } \\
\text { Temp. } \\
\left({ }^{\circ} \mathrm{F}\right)\end{array}$ & $\begin{array}{l}\text { Permeate } \\
\text { Flow } \\
\text { (mL/min) }\end{array}$ & Comments & $\begin{array}{c}\text { Flux } \\
(\mathrm{gpd} / \mathrm{sq} \mathrm{ft})\end{array}$ \\
\hline & 0:00 & 1.00 & 60 & 47 & 68 & 25.00 & & 190.0 \\
\hline & $0: 15$ & 1.00 & 60 & 50 & 69 & 20.00 & & 152.0 \\
\hline & $0: 30$ & 1.00 & 60 & 50 & 69 & 17.00 & & 129.2 \\
\hline & $0: 45$ & 1.00 & 60 & 50 & 70 & 16.00 & & 121.6 \\
\hline & $1: 00$ & 1.00 & 60 & 50 & 71 & 14.00 & & 106.4 \\
\hline & $2: 00$ & 1.00 & 60 & 50 & 71 & 13.00 & & 98.8 \\
\hline & $25: 00$ & 1.00 & 60 & 50 & 66 & 3.90 & & 29.6 \\
\hline & 49:00 & 1.00 & 60 & 49 & 69 & 4.00 & & 30.4 \\
\hline & $74: 00$ & 1.00 & 60 & 50 & 68 & 3.80 & $\begin{array}{l}\text { Testing } \\
\text { Procedure }\end{array}$ & 28.9 \\
\hline & $98: 00$ & 1.00 & 60 & 49 & 70 & 3.60 & $\begin{array}{l}\text { Test Stopped, } \\
\text { Started Cleaning } \\
\text { Procedure }\end{array}$ & 27.4 \\
\hline & 121:00 & 1.00 & 60 & 50 & 70 & 3.30 & & 25.1 \\
\hline 9:00 & 0:00 & 1.00 & 60 & 50 & 66 & 6.50 & Resumed Testing & 49.4 \\
\hline $9: 30$ & $0: 30$ & 1.00 & 60 & 50 & 66 & 5.50 & & 41.8 \\
\hline $10: 00$ & $1: 00$ & 1.00 & 60 & 50 & 67 & 4.70 & & 35.7 \\
\hline $10: 30$ & $1: 30$ & 1.00 & 60 & 50 & 68 & 4.20 & & 31.9 \\
\hline $11: 00$ & $2: 00$ & 1.00 & 60 & 50 & 68 & 3.80 & & 28.9 \\
\hline 2:00 & 5:00 & 1.00 & 60 & 50 & 72 & 3.60 & & 27.4 \\
\hline
\end{tabular}


Table A-11. Desal 5-Spiral Wound Module 5-Day Cleaning Test, Raw Data Run Log

Membrane: Desal-5 Spiral Wound NF

Surface Area: 26.9 sq ft

Feed Sample: Metaldyne Wastewater

Initial Feed Volume: 10 gal

Final Feed Volume: 10 gal

Final Concentrate: $1 \mathrm{x}$

Operator: Jason Gilmour

Final Flux: $15.5 \mathrm{gpd} / \mathrm{sq} \mathrm{ft}$

Date: 3/9/00

\begin{tabular}{|c|c|c|c|c|c|c|c|c|}
\hline $\begin{array}{l}\text { Time of } \\
\text { Day } \\
\text { (hh:mm) }\end{array}$ & $\begin{array}{l}\text { Elapsed } \\
\text { Time } \\
\text { (hh:mm) }\end{array}$ & $\begin{array}{c}\text { Feed Flow } \\
\text { (gal/min) }\end{array}$ & $\begin{array}{l}\text { Feed } \\
\text { Press. } \\
\text { (psi) }\end{array}$ & $\begin{array}{l}\text { Conc. } \\
\text { Press. } \\
\text { (psi) }\end{array}$ & $\begin{array}{l}\text { Feed } \\
\text { Temp. } \\
\left({ }^{\circ} \mathrm{F}\right)\end{array}$ & $\begin{array}{l}\text { Permeate } \\
\text { Flow } \\
\text { (mL/min) }\end{array}$ & Comments & $\underset{\text { (gpd/sq ft) }}{\text { Flux }}$ \\
\hline & 0:00 & 4.50 & 180 & 175 & 93 & 1560.00 & & 22.1 \\
\hline & $0: 15$ & 4.50 & 180 & 175 & 92 & 1430.00 & & 20.2 \\
\hline & $0: 30$ & 4.50 & 180 & 175 & 94 & 1300.00 & & 18.4 \\
\hline & $0: 45$ & 4.50 & 180 & 175 & 92 & 1250.00 & & 17.7 \\
\hline & $1: 00$ & 4.50 & 180 & 175 & 90 & 1210.00 & & 17.1 \\
\hline & $2: 00$ & 4.50 & 180 & 175 & 89 & 1200.00 & & 17.0 \\
\hline & $25: 00$ & 4.50 & 180 & 175 & 96 & 1180.00 & & 16.7 \\
\hline & 49:00 & 4.50 & 180 & 175 & 94 & 1130.00 & & 16.0 \\
\hline & $74: 00$ & 4.50 & 180 & 175 & 92 & 1150.00 & & 16.3 \\
\hline & 98:00 & 4.50 & 180 & 175 & 93 & 1100.00 & $\begin{array}{l}\text { Test Stopped, } \\
\text { Began Cleaning } \\
\text { Procedure }\end{array}$ & 15.6 \\
\hline & 121:00 & 4.50 & 180 & 175 & 92 & 1090.00 & & 15.4 \\
\hline $1: 00$ & 0:00 & 4.50 & 180 & 175 & 90 & 1190.00 & Resumed Testing & 16.8 \\
\hline $1: 30$ & $0: 30$ & 4.50 & 180 & 175 & 90 & 1150.00 & & 16.3 \\
\hline $2: 00$ & $1: 00$ & 4.50 & 180 & 175 & 91 & 1130.00 & & 16.0 \\
\hline $2: 30$ & $1: 30$ & 4.50 & 180 & 175 & 92 & 1110.00 & & 15.7 \\
\hline $3: 00$ & $2: 00$ & 4.50 & 180 & 175 & 94 & 1100.00 & & 15.6 \\
\hline $6: 00$ & $5: 00$ & 4.50 & 180 & 175 & 93 & 1080.00 & & 15.3 \\
\hline
\end{tabular}




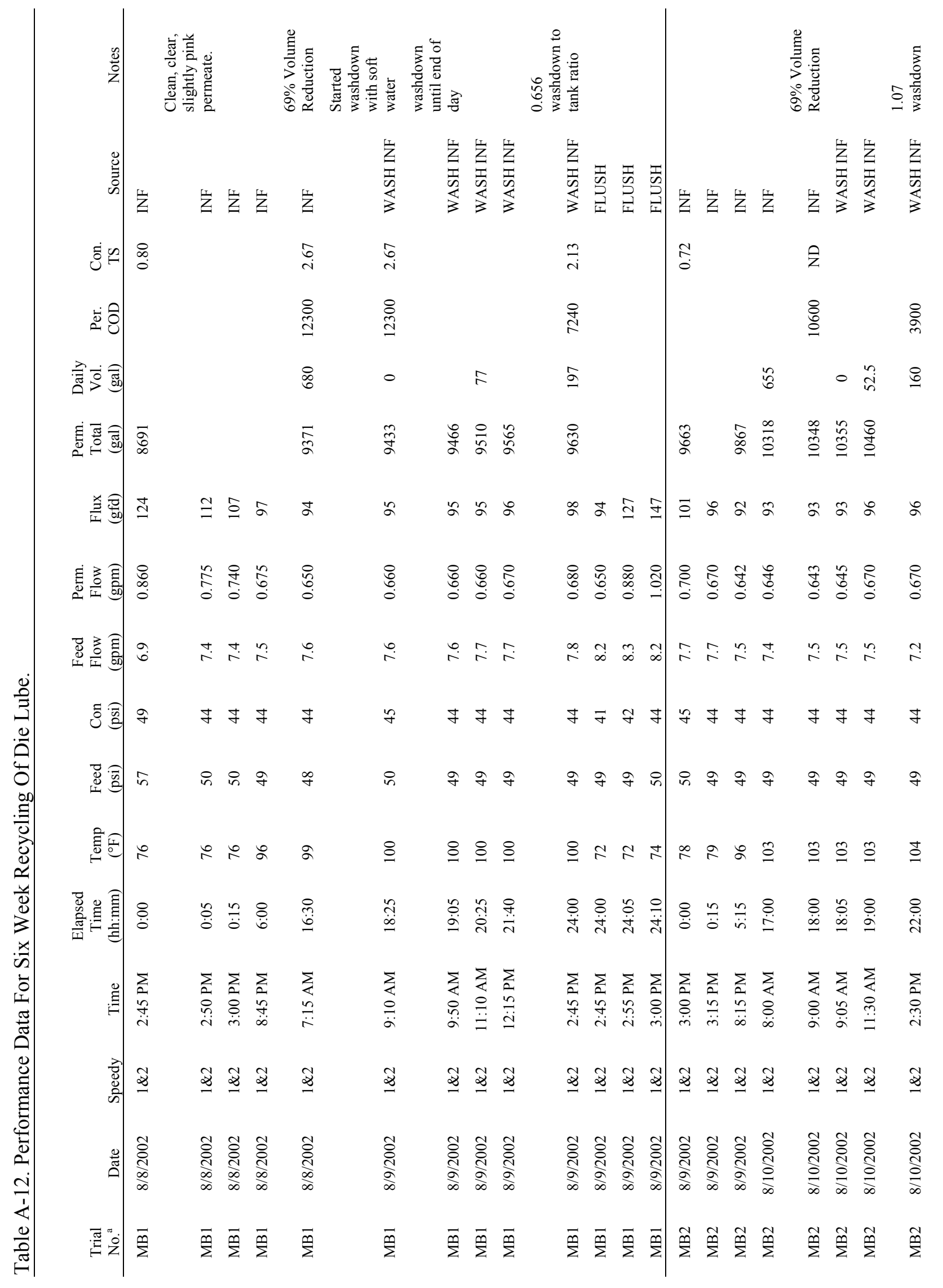




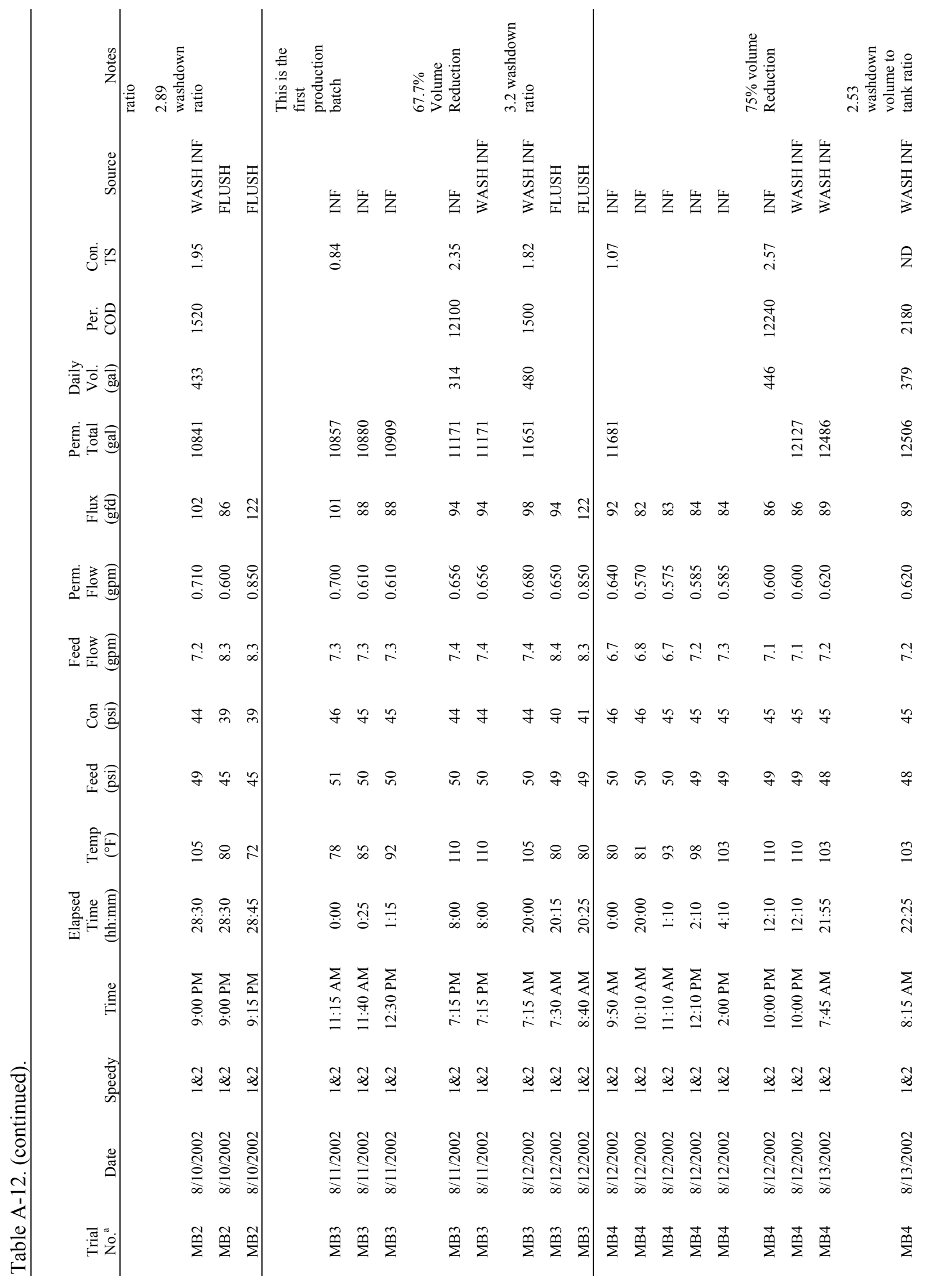




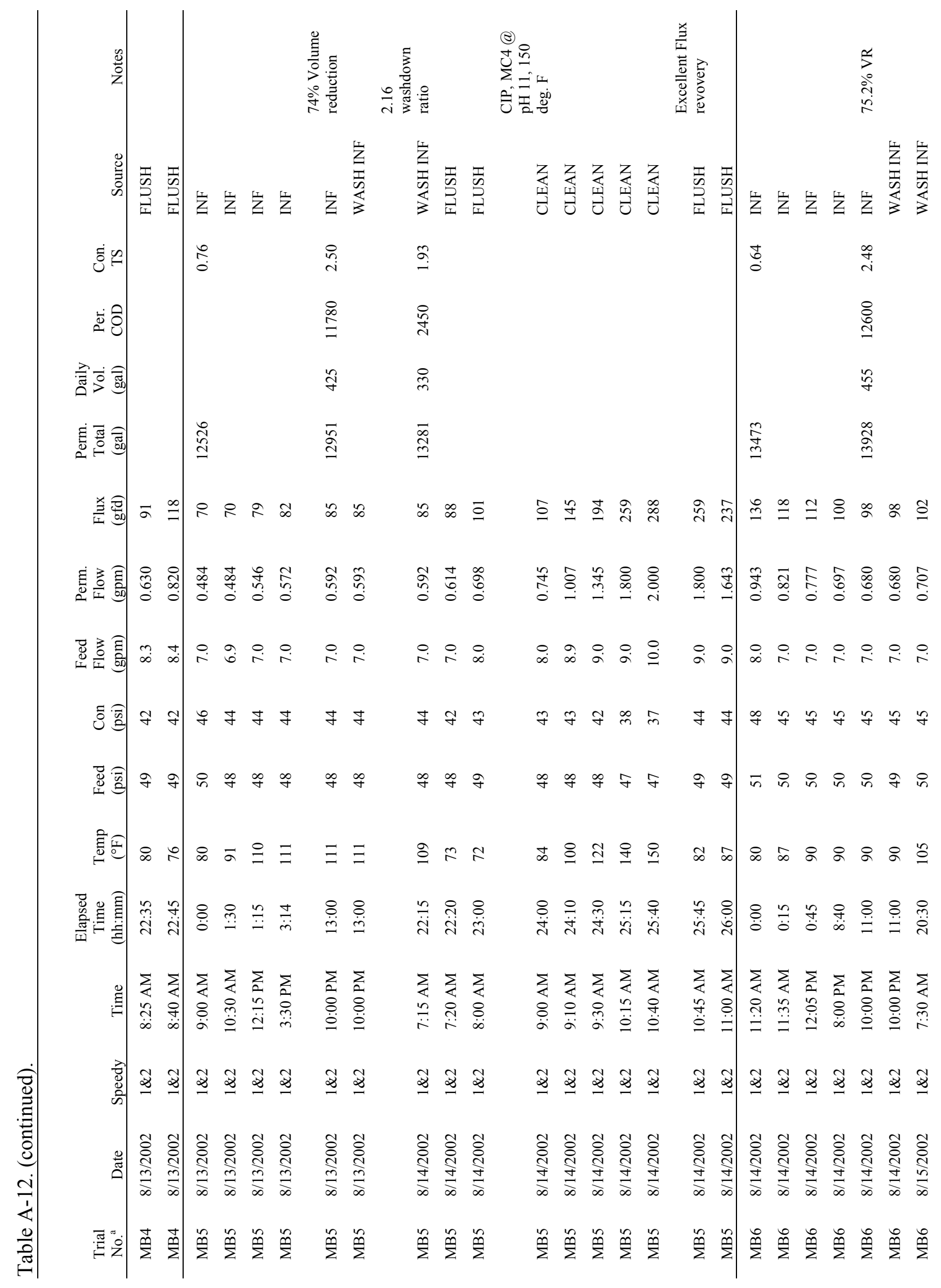




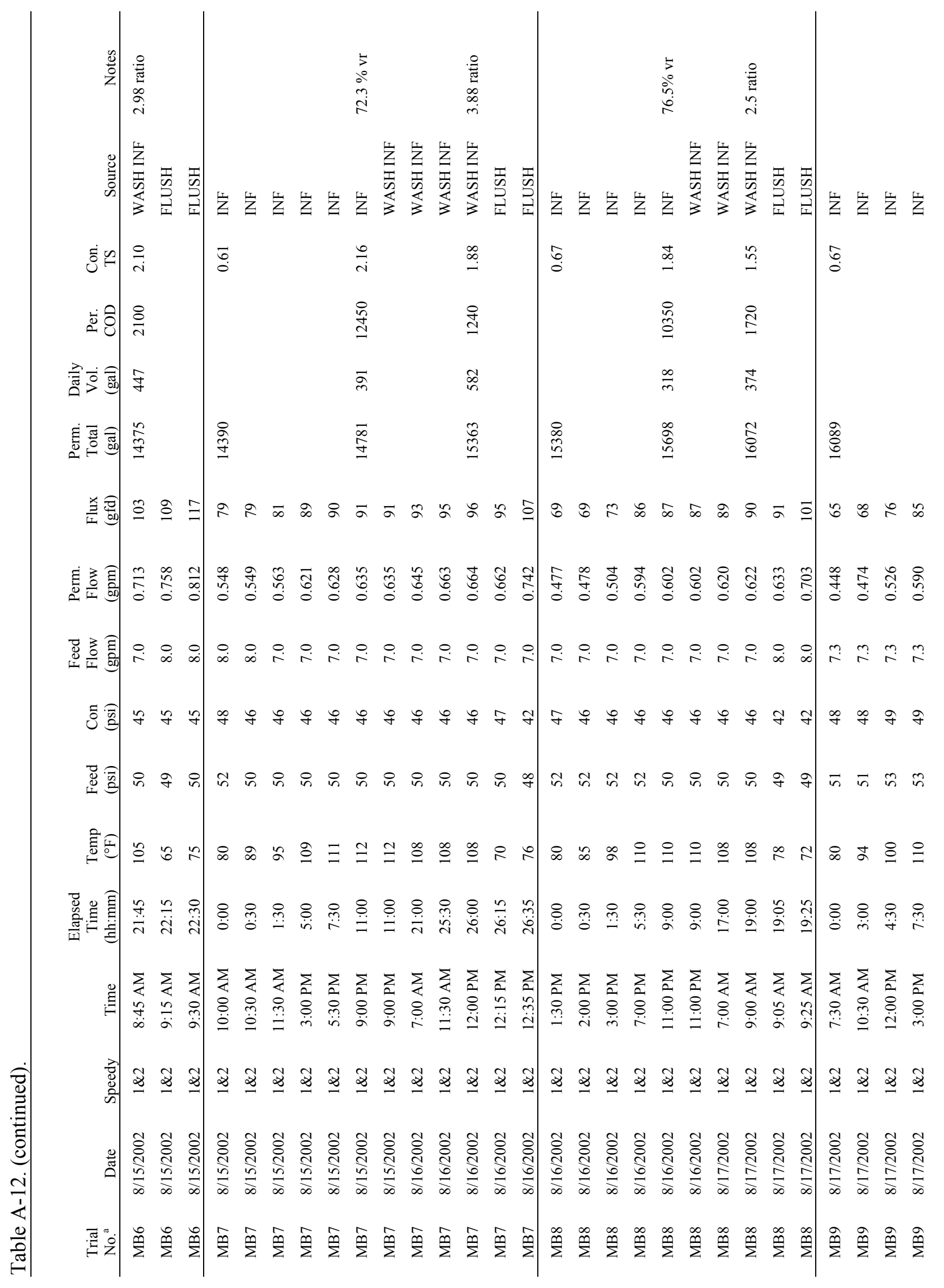




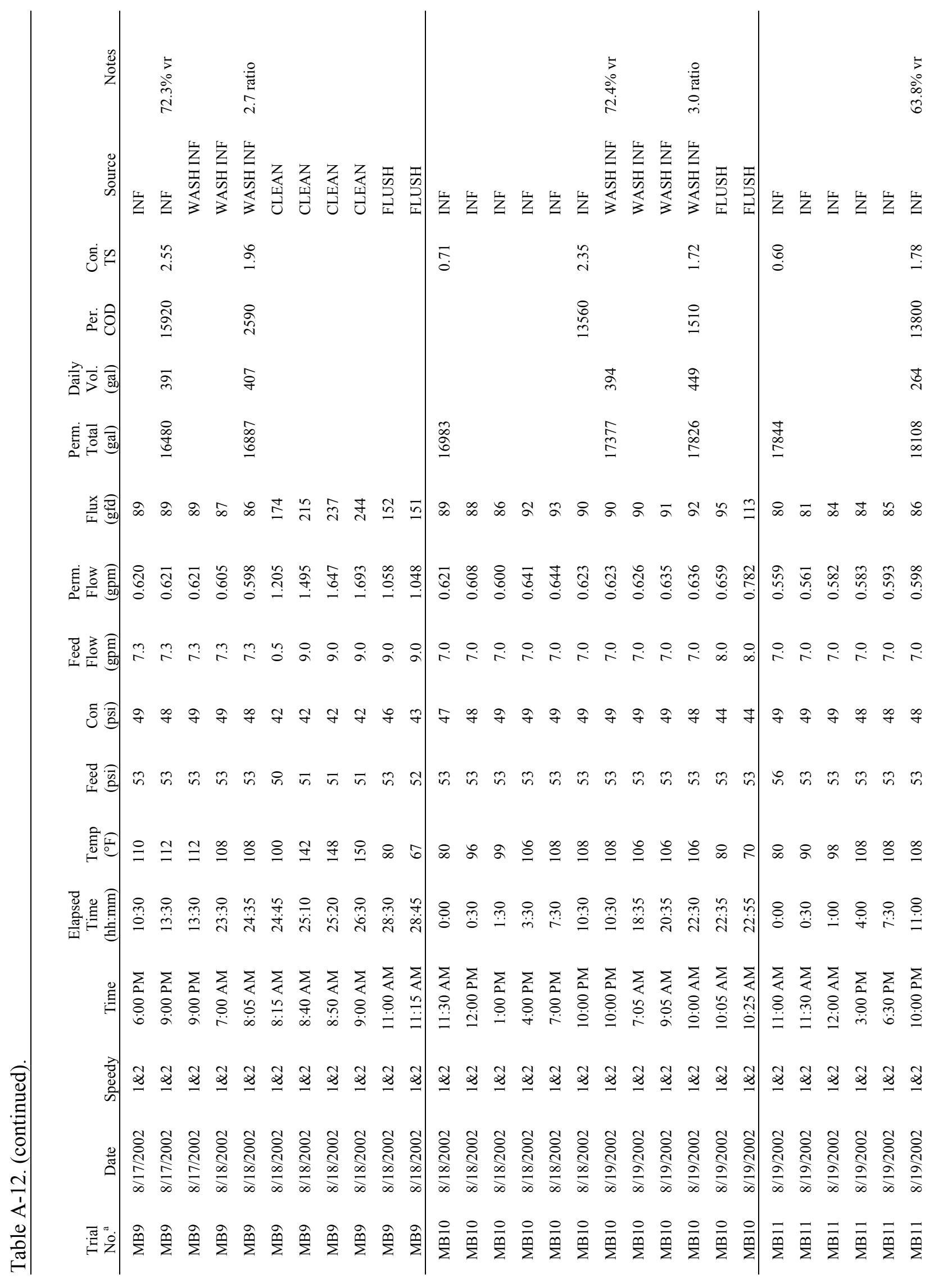




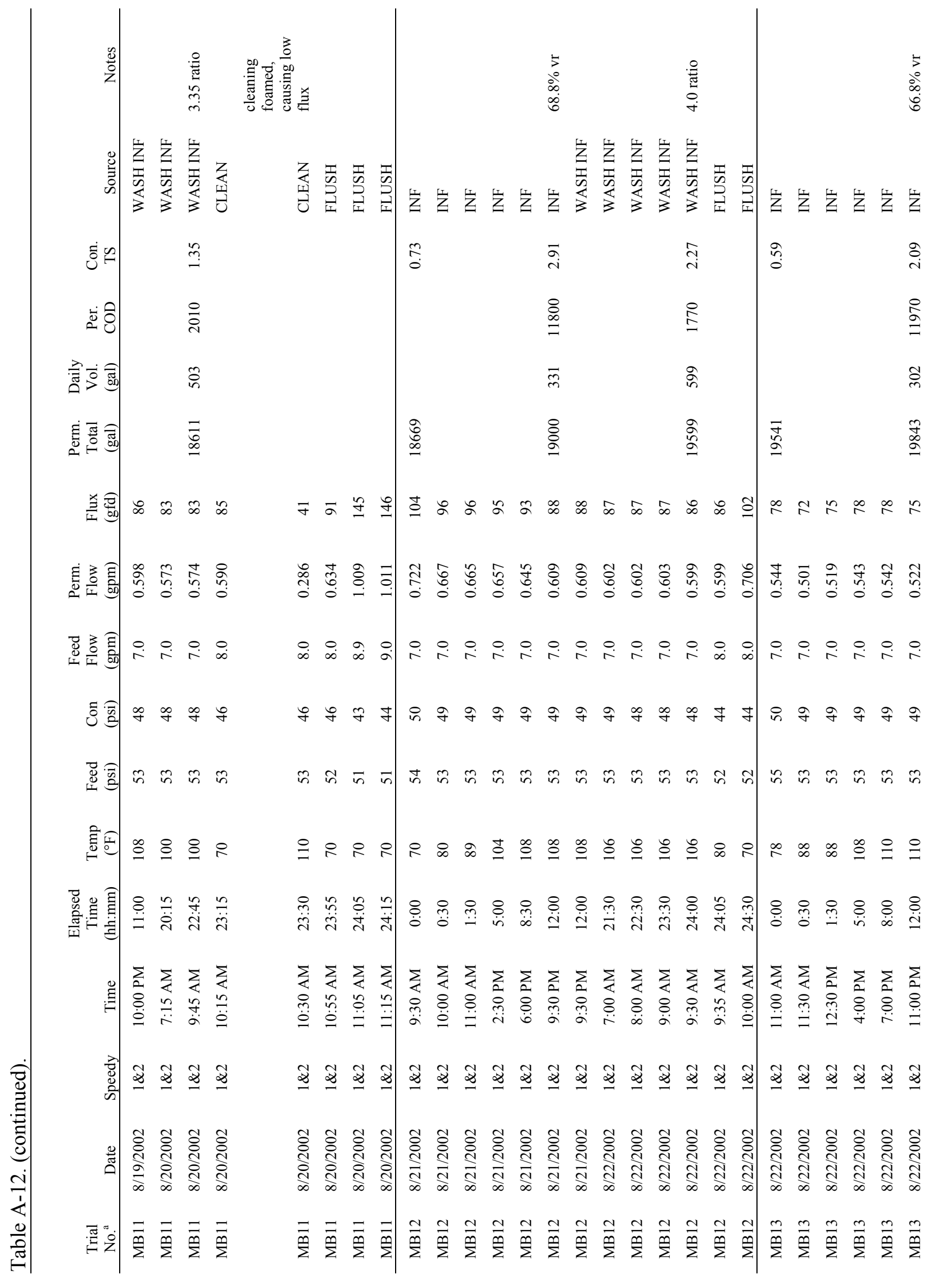




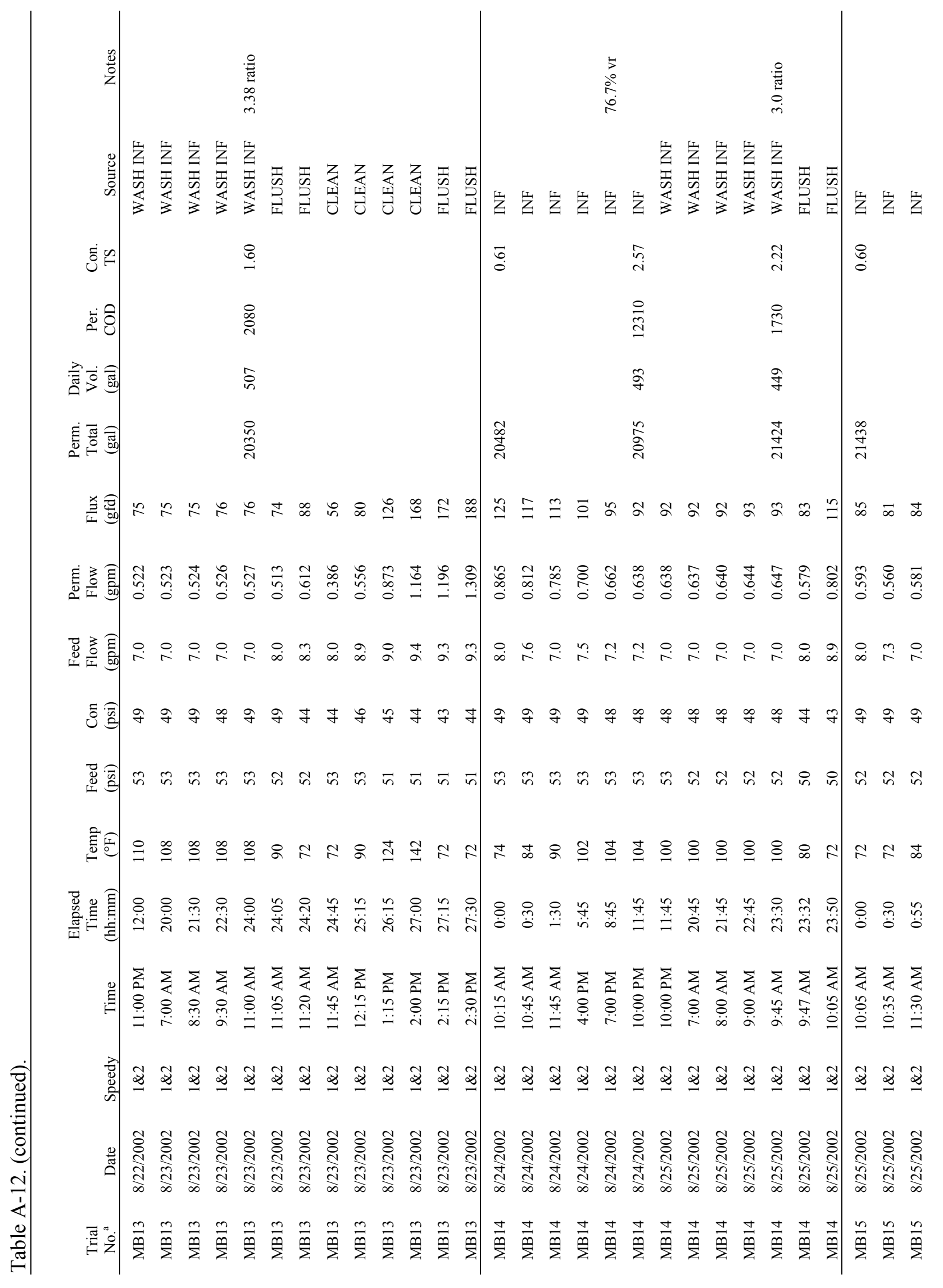




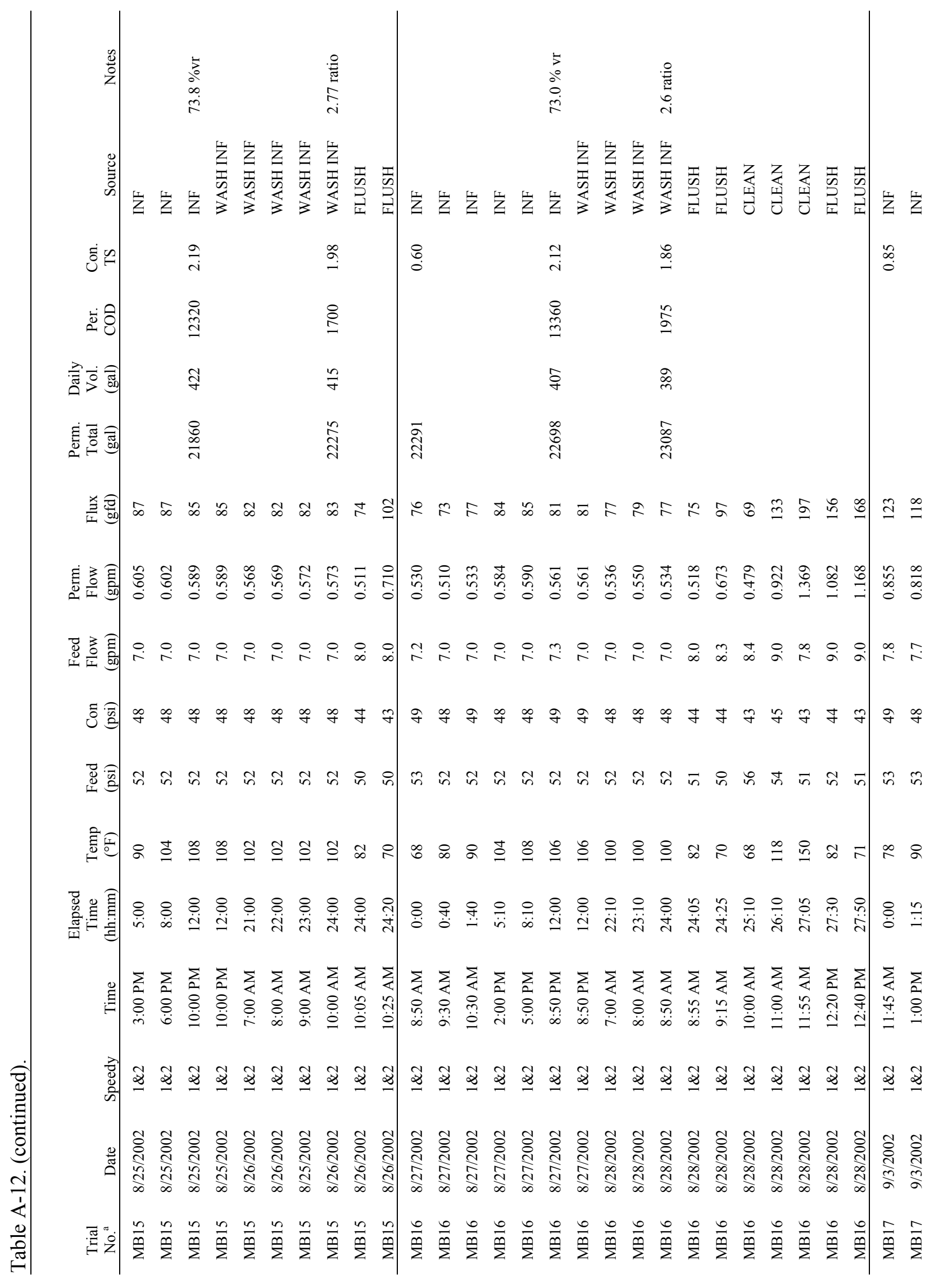




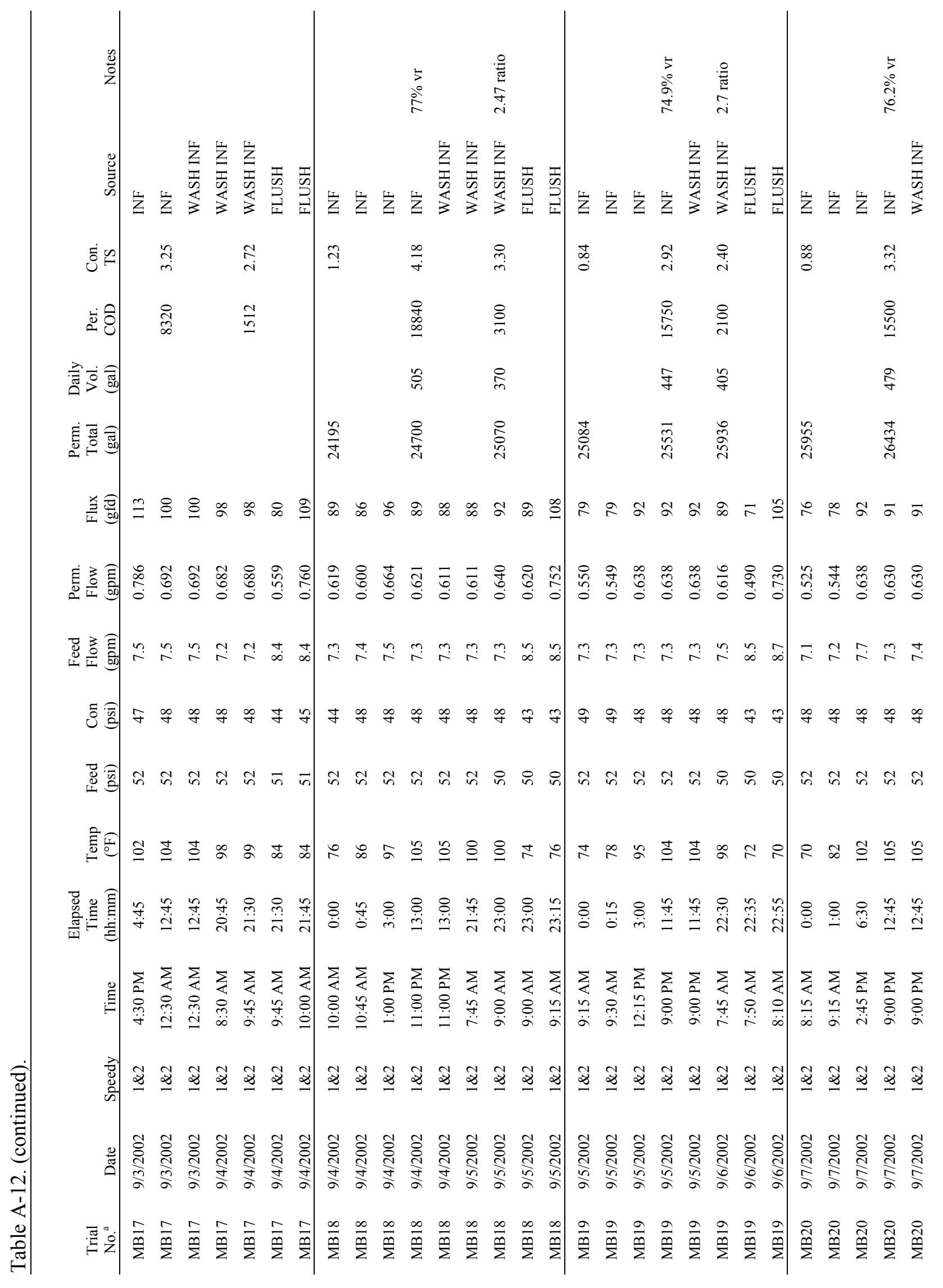




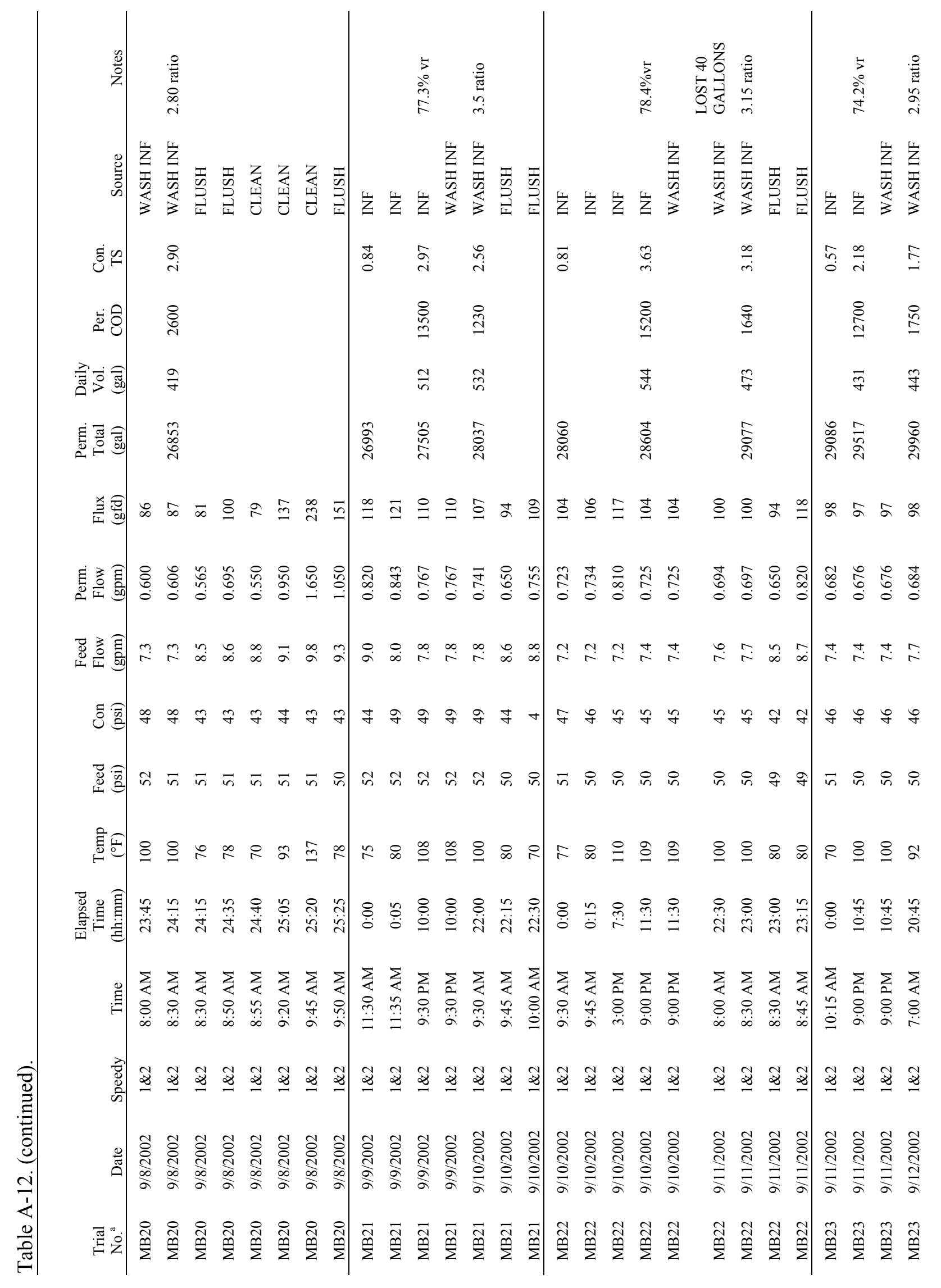




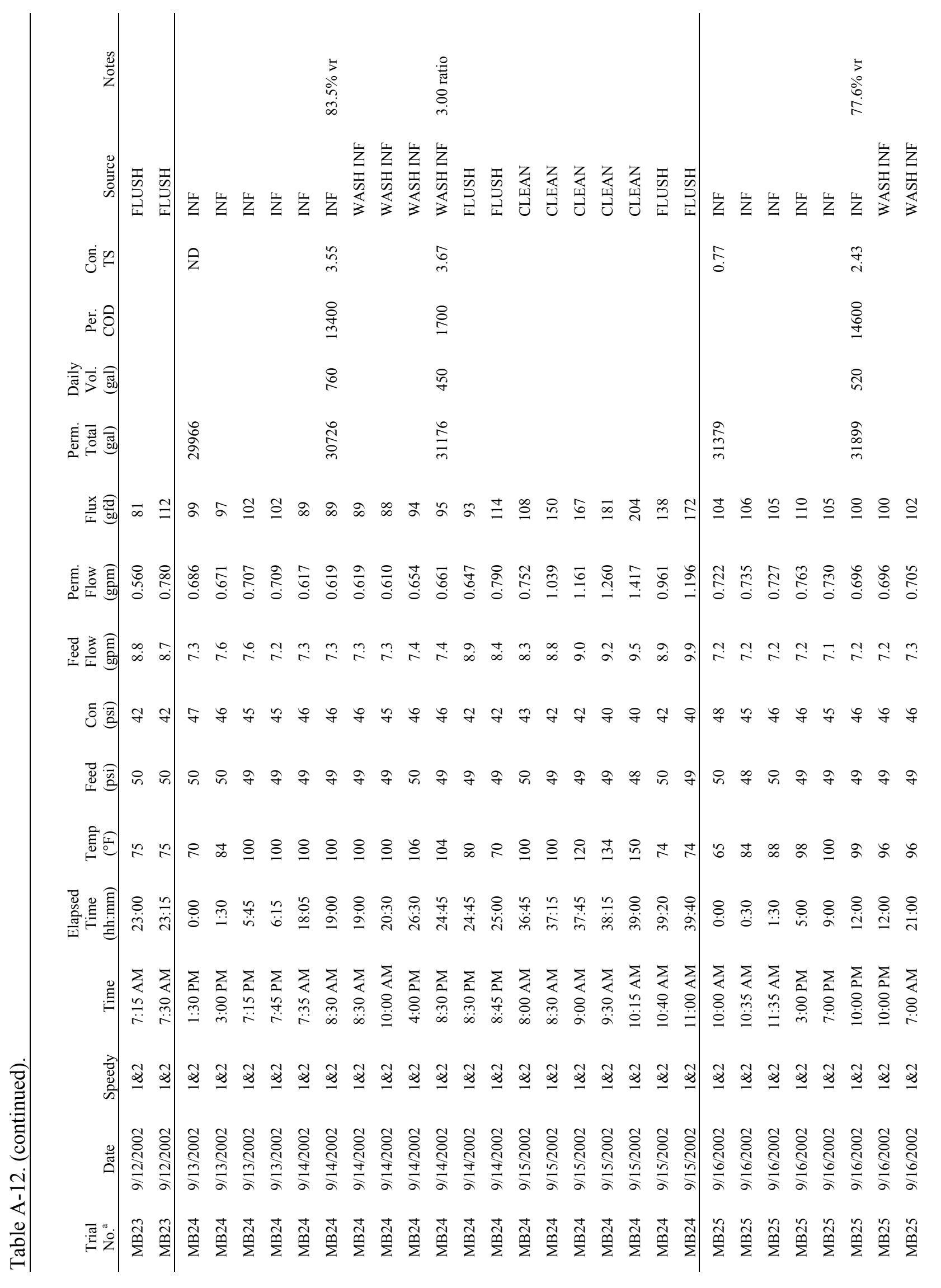




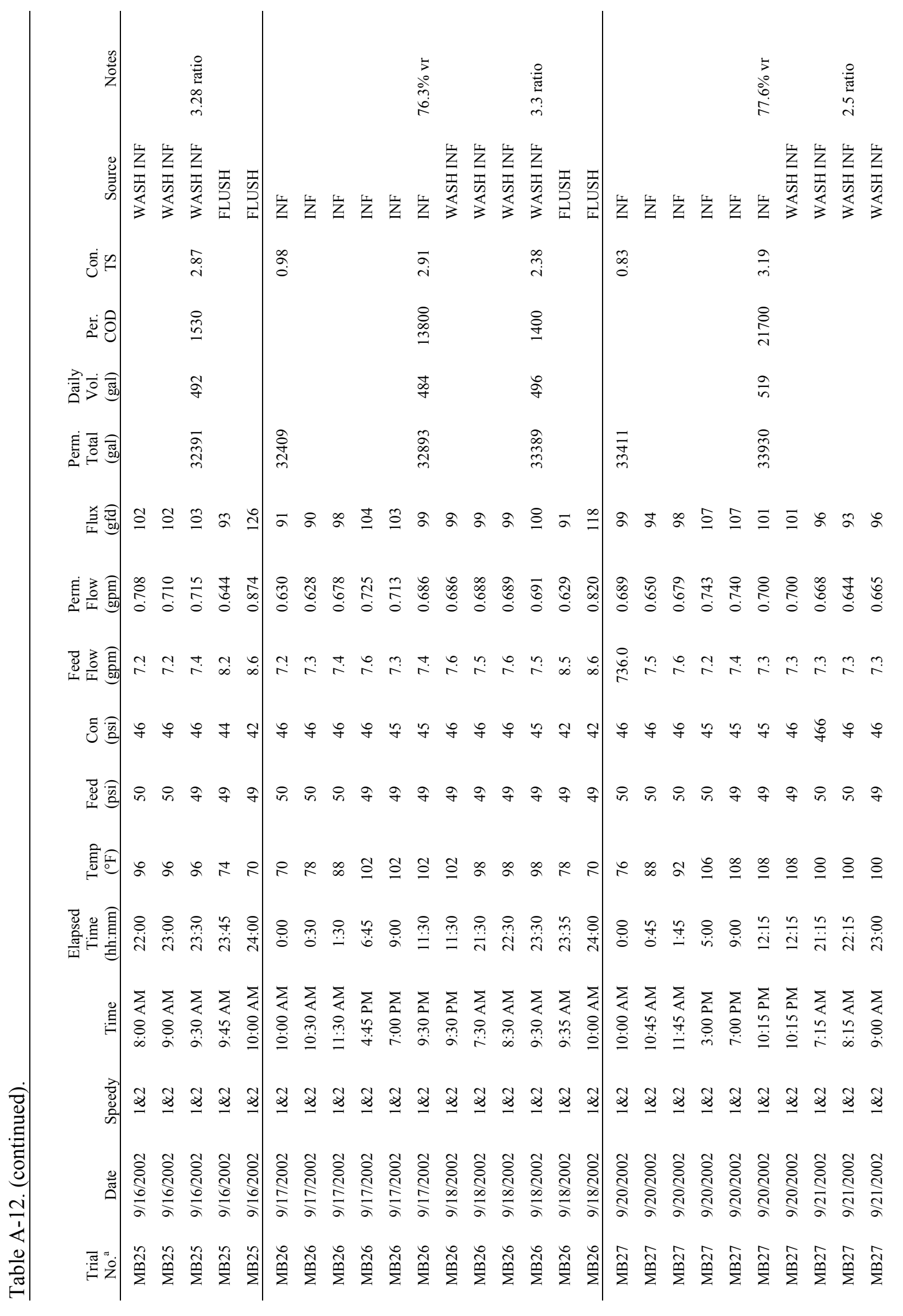




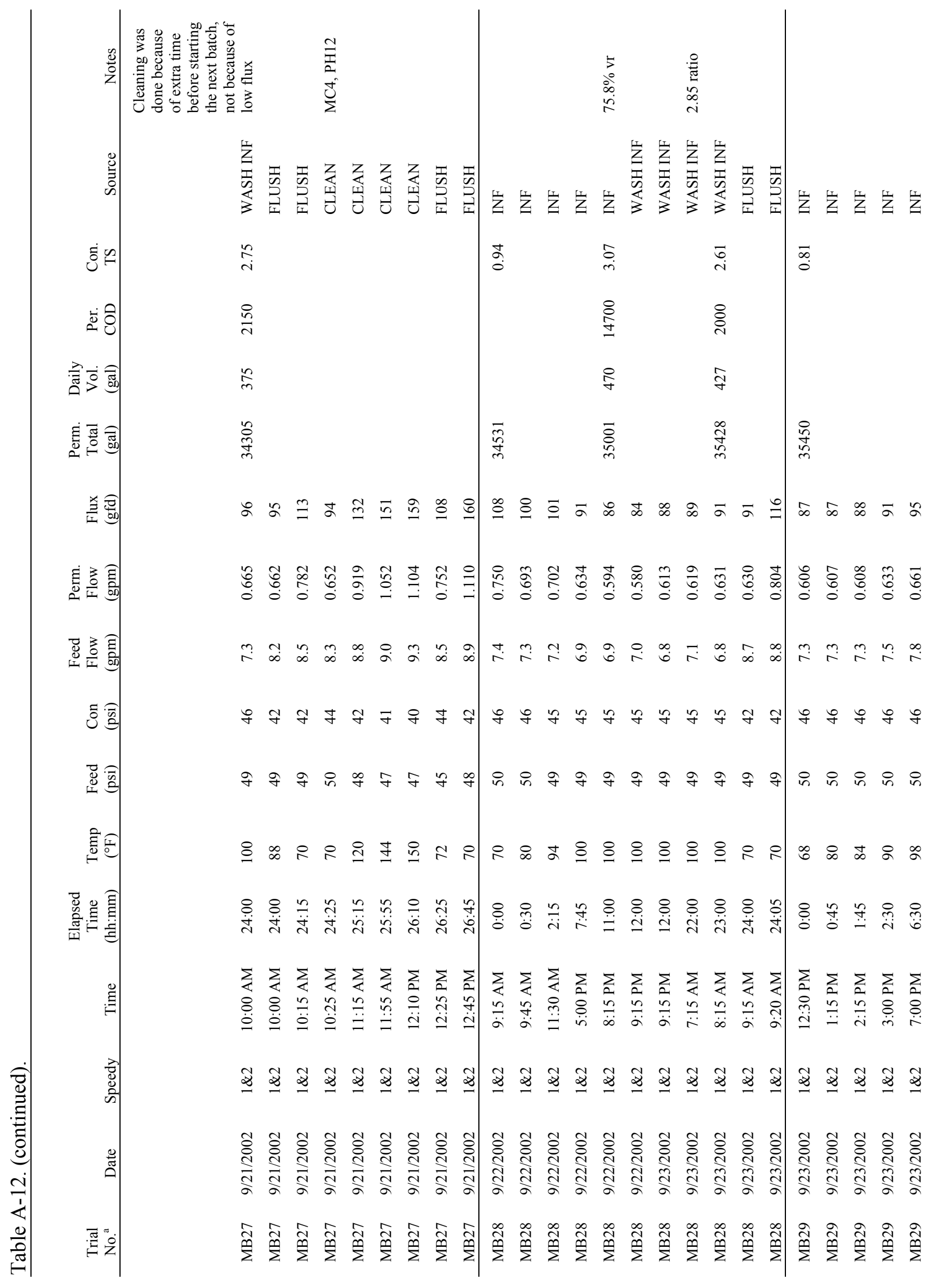




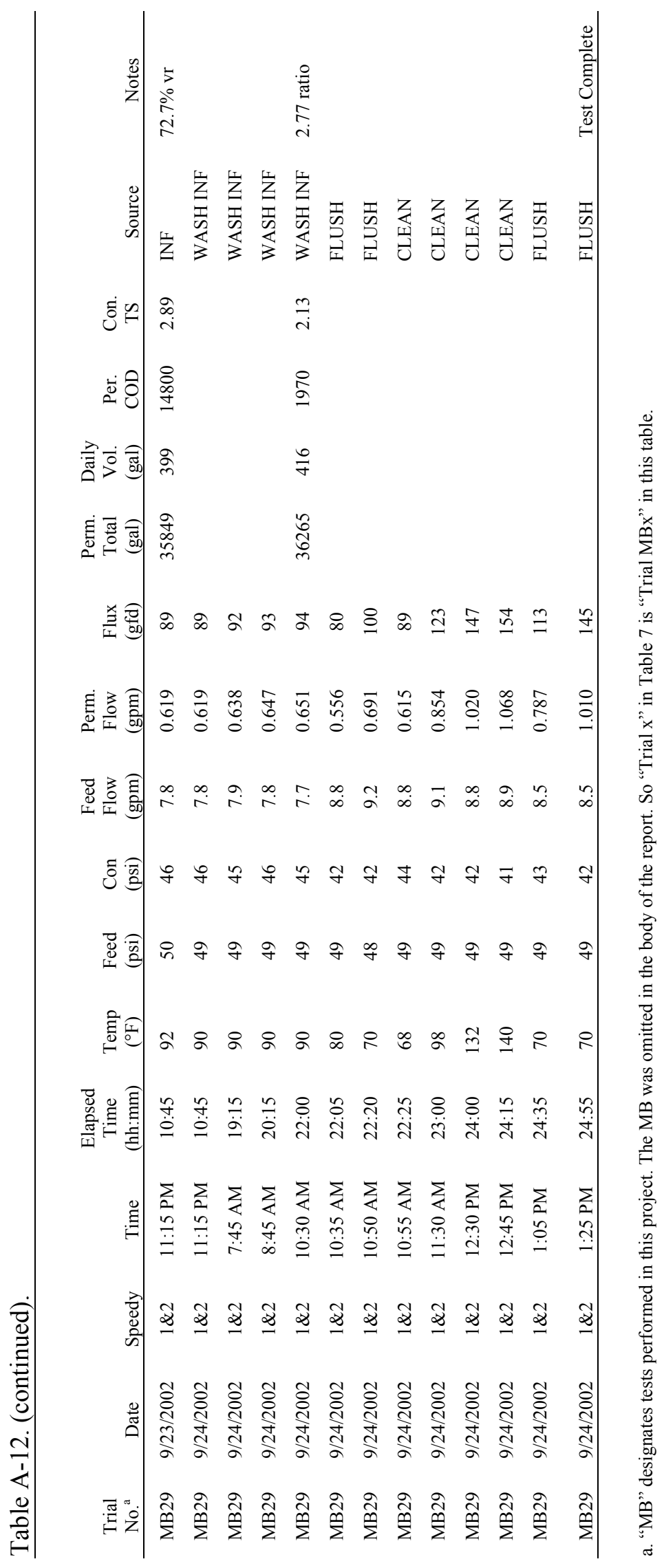

